\title{
Balancing between sepsis, AKI and gentamicin in the emergency department
}

Citation for published version (APA):

Cobussen, M. (2021). Balancing between sepsis, AKI and gentamicin in the emergency department.

[Doctoral Thesis, Maastricht University]. Maastricht University. https://doi.org/10.26481/dis.20210527mc

Document status and date:

Published: 01/01/2021

DOI:

10.26481/dis.20210527mc

Document Version:

Publisher's PDF, also known as Version of record

\section{Please check the document version of this publication:}

- A submitted manuscript is the version of the article upon submission and before peer-review. There can be important differences between the submitted version and the official published version of record.

People interested in the research are advised to contact the author for the final version of the publication, or visit the DOI to the publisher's website.

- The final author version and the galley proof are versions of the publication after peer review.

- The final published version features the final layout of the paper including the volume, issue and page numbers.

Link to publication

\footnotetext{
General rights rights.

- You may freely distribute the URL identifying the publication in the public portal. please follow below link for the End User Agreement:

www.umlib.nl/taverne-license

Take down policy

If you believe that this document breaches copyright please contact us at:

repository@maastrichtuniversity.nl

providing details and we will investigate your claim.
}

Copyright and moral rights for the publications made accessible in the public portal are retained by the authors and/or other copyright owners and it is a condition of accessing publications that users recognise and abide by the legal requirements associated with these

- Users may download and print one copy of any publication from the public portal for the purpose of private study or research.

- You may not further distribute the material or use it for any profit-making activity or commercial gain

If the publication is distributed under the terms of Article $25 \mathrm{fa}$ of the Dutch Copyright Act, indicated by the "Taverne" license above, 


\section{Balancing between sepsis, AKI and gentamicin in the emergency department}


ISBN: 978-94-6423-197-7

Cover design: Maarten Cobussen, Map data (2021 Google Earth Design/lay-out: Guus Gijben | Proefschrift All In One Print: Proefschrift-aio.nl

Online availability: https://doi.org/10.26481/dis.20210527mc

Copyright Maarten Cobussen, 2021

All rights are reserved. No part of this book may be reproduced, distributed, stored in a retrieval system, or transmitted in any form or by any means, without prior written permission of the author. 


\title{
Balancing between sepsis, AKI and gentamicin in the emergency department
}

\author{
PROEFSCHRIFT
}

ter verkrijging van de graad van doctor aan de Universiteit Maastricht, op gezag van de Rector Magnificus prof. dr. Rianne M. Letschert, volgens het besluit van het College van Decanen,

in het openbaar te verdedigen op

donderdag 27 mei 2021 om 12:00 uur

door

Maarten Cobussen 
Promotor

Prof. dr. P.H.M. Savelkoul

Co-promotores

Dr. P.M. Stassen

Dr. M.B. Haeseker (RHMDC)

Manuscriptcommissie

Prof. dr. J.P. Kooman (voorzitter)

Prof. dr. M.J.M. Bonten (UMCU)

Prof. dr. D.J. Touw (UMCG)

Dr. G.J. Oudhuis 


\section{Contents}

Chapter 1 General introduction and outline of the thesis 9

Chapter 2 The incidence and outcome of AKI in patients with sepsis in the emergency department applying different definitions of $A K I$ and sepsis Submitted for publication.

Chapter 3 No increased risk of acute kidney injury after a 49 single dose of gentamicin in patients with sepsis Infect Dis (Lond). 2016 Apr;48(4):274-280.

Chapter 4 Renal safety of a single dose of gentamicin in 69 patients with sepsis in the emergency department Clin Microbiol Infect. 2020 Jul 1:S1198-743X(20)30376-1.

Chapter 5 Gentamicin is frequently underdosed in patients 93 with sepsis in the emergency department Neth J Med. 2015 Nov;73(9):443-4.

Chapter 6 Evaluation of gentamicin peak concentrations in 101 patients with sepsis at the emergency department PLoS One. 2019 Jan 22;14(1):e0210012.

Chapter 7 Summarising discussion

Chapter $8 \quad$ Impact for society 139

Appendices Nederlandse samenvatting 149 List of publications

Dankwoord 165

Curriculum Vitae 173 




\section{Chapter 1}

General introduction and outline of the thesis 


\section{Sepsis}

Sepsis is defined as a syndrome of life-threatening organ dysfunction caused by a dysregulated host response to infection [1]. It is associated with high morbidity and mortality and the primary cause of death from infection [2]. In 2018, more than 5000 patients with sepsis were admitted to an Intensive Care Unit (ICU) in the Netherlands [3]. The number of patients with sepsis visiting the emergency department (ED) is many times higher with a high impact on health care costs and resources [4]. The incidence of sepsis is increasing over the years, possibly due to an ageing population and increased comorbidity [5].

Mortality in sepsis is as high as 20 to $30 \%$ [6]. Early and appropriate sepsis treatment in the early stages of disease is important to decrease morbidity and mortality $[7,8]$. To be able to start treatment early, sepsis first must be recognized. However, since recognizing sepsis can be difficult, definitions for sepsis were developed. In 1991 the American College of Chest Physicians and the Society of Critical Care Medicine held a consensus conference to provide a conceptual and a practical framework to define the systemic inflammatory response to infection, which was defined as a progressive injurious process that falls under the generalized term 'sepsis' and included sepsis-associated organ dysfunction as well. This led to the systemic inflammatory response syndrome (SIRS) criteria [9].

In 2001, a new conference was held by several societies involved in the field of sepsis. They concluded that the diagnostic criteria for SIRS were overly sensitive and non-specific [10]. Due to lack of alternatives, no new definition was introduced. However, the list of diagnostic criteria of the existing criteria was expanded, leading to the renewed SIRS criteria, the Sepsis-2 criteria (Table 1) [10].

The Society of Critical Care Medicine and the European Society of Intensive Care Medicine warranted a review of the 2001 Sepsis-2 definition, which led to the 2016 Third International Consensus Definitions for Sepsis and Septic Shock with a bigger focus on organ dysfunction and less on SIRS [1]. Following from this, the SIRS criteria were replaced by the qSOFA (quick Sequential Organ Failure Assessment) (Table 2) and the SOFA score (Sepsis-3) (Table 3), in an attempt to improve differentiating sepsis from uncomplicated infection and to update definitions of sepsis, to become more consistent with new insights to the pathobiology [1]. 
Table 1. The 2001 systemic inflammatory response syndrome (SIRS) criteria for sepsis.

\begin{tabular}{ll}
\hline Parameter & Points \\
\hline Temperature $>38^{\circ} \mathrm{C}$ or $<36^{\circ} \mathrm{C}$ & 1 \\
Heart rate $>90 /$ min & 1 \\
Respiratory rate $>20 /$ min & 1 \\
White blood cell count $<4,0 \times 10^{\circ} / \mathrm{L},>12 \times 10^{\circ} / \mathrm{L}$, or $>10 \%$ bands & 1 \\
\hline
\end{tabular}

A SIRS score of $\geq 2$ points with the suspicion of an infection defines sepsis.

Table 2. The 2016 quick sequential organ failure assessment (qSOFA) criteria for sepsis.

\begin{tabular}{ll}
\hline Clinical parameter & Points \\
\hline Respiratory rate $\geq 22 / \mathrm{min}$ & 1 \\
Change in mental status & 1 \\
Systolic blood pressure $\leq 100 \mathrm{mmHg}$ & 1 \\
\hline
\end{tabular}

A qSOFA score of $\geq 2$ points indicates sepsis.

Table 3. The 2016 sequential organ failure assessment (SOFA) criteria for sepsis.

\begin{tabular}{|c|c|c|c|c|c|}
\hline \multirow{2}{*}{ Organ system } & \multicolumn{5}{|c|}{ Points } \\
\hline & 0 & 1 & 2 & 3 & 4 \\
\hline \multicolumn{6}{|l|}{ Respiration } \\
\hline $\mathrm{PaO}_{2} / \mathrm{FiO}_{2}, \mathrm{mmHg}$ & $\geq 400$ & $<400$ & $<300$ & $\begin{array}{l}<200 \text { with } \\
\text { respiratory } \\
\text { support }\end{array}$ & $\begin{array}{l}<100 \text { with } \\
\text { respiratory } \\
\text { support }\end{array}$ \\
\hline \multicolumn{6}{|l|}{ Coagulation } \\
\hline Platelets, $\times 10^{9} / \mathrm{L}$ & $\geq 150$ & $<150$ & $<100$ & $<50$ & $<20$ \\
\hline \multicolumn{6}{|l|}{ Liver } \\
\hline Bilirubin, $\mu \mathrm{mol} / \mathrm{l}$ & $<20$ & $20-32$ & 33-101 & $102-204$ & $>204$ \\
\hline \multicolumn{6}{|l|}{ Cardiovascular } \\
\hline & $\begin{array}{l}\text { MAP } \\
\geq 70 \\
\mathrm{mmHg}\end{array}$ & $\begin{array}{l}\text { MAP }<70 \\
m m H g\end{array}$ & $\begin{array}{l}\text { Dopamine } \\
<5 \text { or } \\
\text { dobutamine } \\
\text { (any dose) }\end{array}$ & $\begin{array}{l}\text { Dopamine } \\
5.1-15 \text { or } \\
\text { norepinephrine } \\
\leq 0.1\end{array}$ & $\begin{array}{l}\text { Dopamine } \\
>15 \text { or } \\
\text { norepinephrine } \\
>0.1\end{array}$ \\
\hline \multicolumn{6}{|l|}{$\begin{array}{l}\text { Central nervous } \\
\text { system }\end{array}$} \\
\hline Glasgow coma scale & 15 & $13-14$ & $10-12$ & $6-9$ & $<6$ \\
\hline \multicolumn{6}{|l|}{ Renal } \\
\hline Creatinine, $\mu \mathrm{mol} / \mathrm{l}$ & $<110$ & $100-170$ & $171-299$ & $300-440$ & $>440$ \\
\hline Urine output, ml/day & & & & $<500$ & $<200$ \\
\hline
\end{tabular}

Legend: $\mathrm{PaO}_{2}$, partial pressure of oxygen; $\mathrm{FiO}_{2}$, fraction of inspired oxygen; MAP, mean arterial pressure. Catecholamine doses are given as $\mu \mathrm{g} / \mathrm{kg} / \mathrm{min}$ for at least 1 hour.

A change in baseline of the total SOFA score of $\geq 2$ points represents sepsis. 
Fluid resuscitation, antibiotic therapy and the use of vasopressive agents in the presence of shock are the backbone of sepsis treatment [11]. Early administration of empirical antibiotic therapy within one hour of presentation in patients with sepsis is essential to improve outcome [12,13]. The empirical antibiotic treatment chosen aims at timely administration of the antibiotic and is dependent on the focus of infection. Preferably, it consists of a bactericidal agent with an adequate coverage for all likely pathogens [14].

Empirical therapy of sepsis usually consists of a broad-spectrum beta-lactam antibiotic, frequently combined with an aminoglycoside to broaden the Gram negative spectrum of the beta-lactam antibiotic [15]. When a pathogen has been found, streamlining of antibacterial therapy should take place based on culture results.

\section{Aminoglycosides}

The first aminoglycoside was discovered in 1943 [16]. Streptomycin was isolated from Streptomyces griseus in soil samples by Selman A. Waksman, who later received the 1952 Nobel Prize in Medicine for his discovery of the first antibiotic with anti-tuberculous activity [17]. After the discovery of streptomycin, multiple other aminoglycosides followed, with gentamicin (1964) (Figure 1), tobramycin (1974), and the semisynthetic amikacin (1976) most used today $[18,19]$.

The basic chemical structure of aminoglycosides consists of one or several amino sugars connected by glycosidic linkages, hence the name aminoglycosides [20]. The nomenclature is derived from the bacteria of which they are derived. Those derived from the Streptomyces spp. are named with the suffix '-mycin', whereas those that are derived from Micromonospora spp. are named with the suffix '-micin', however, there are some exceptions to this rule (Table 4) [21].

Since the discovery of aminoglycosides, they have always played an important role in the treatment of a variety of infections, including sepsis. The use of aminoglycosides in hospitals in the Netherlands has remained fairly stable over the last decade, with 4.18 defined daily doses (DDD)/100 patient-days in 2009 and 3.76 DDD/100 patient-days in 2019 [23]. 
Table 4. List of aminoglycosides, their origin and discovery

\begin{tabular}{lll}
\hline Name & Origin & Year of discovery \\
\hline Streptomycin & Streptomyces griseus & 1943 \\
Neomycin & Streptomyces fradiae & 1949 \\
\hline Kanamycin & Streptomyces kanamyceticus & 1957 \\
\hline Paromomycin & Streptomyces fradiae & 1959 \\
\hline Spectinomycin & Streptomyces spectabilis & 1962 \\
\hline Gentamicin & Micromonospora purpurea & 1964 \\
Sisomicin & Micromonospora inyoensis & 1970 \\
\hline Dibekacin & Streptomyces spectabilis & 1971 \\
\hline Tobramycin & Streptomyces tenebrarius & 1974 \\
Netilmicin & Micromonospora inyoensis & 1975 \\
\hline Amikacin & Streptomyces kanamyceticus & 1976 \\
Isepamicin & Micromonospora purpurea & 1978 \\
\hline
\end{tabular}

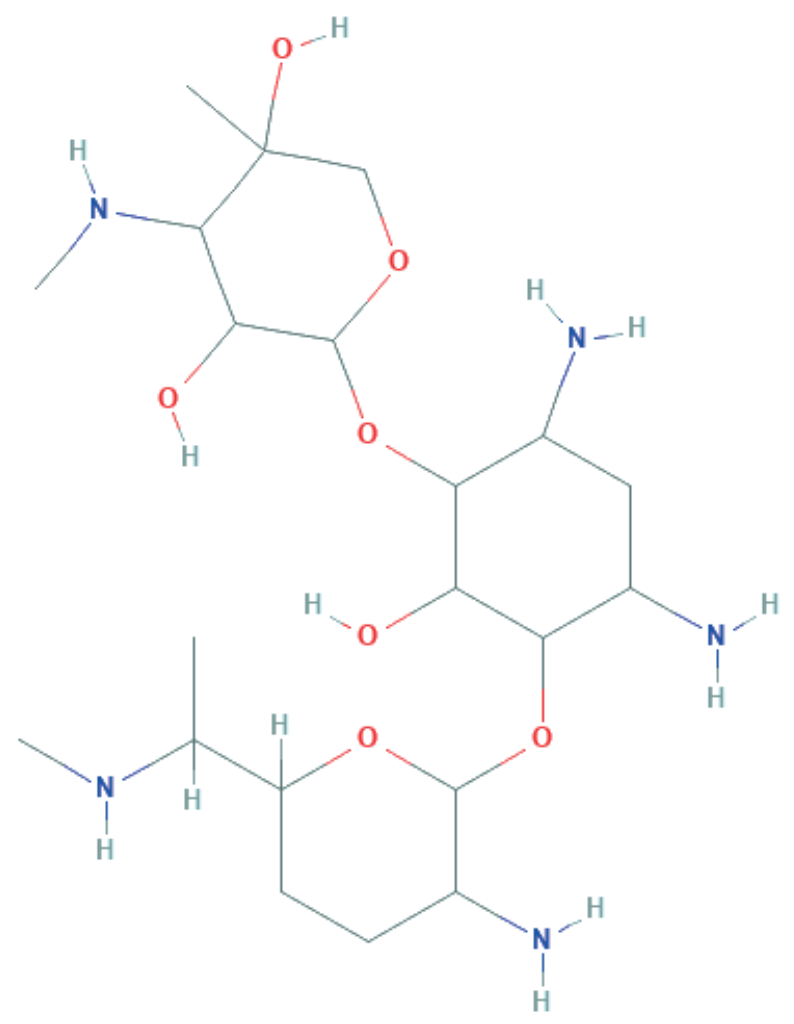

Figure 1. Structural formula of gentamicin [22]. 
The success of aminoglycosides is based on several characteristics. Aminoglycosides have a rapid concentration-dependent bactericidal effect and are potent in clearing bloodstream infections [24]. They produce a prolonged post-antibiotic effect [25] and cover a broad antibiotic spectrum of both Gram positive and Gram negative bacteria, including Staphylococcus spp., Enterobacteriaceae, Acinetobacter spp. and Pseudomonas aeruginosa [26]. Another advantage is that aminoglycosides have low costs due to the expiration of patents. Furthermore, they are synergistic with betalactam antibiotics and have a low rate of true resistance [27]. Interestingly, resistance rates in the Netherlands for the aminoglycosides gentamicin and tobramycin have remained low during the last 5 years at around $5 \%$ or less for Enterobacteriaceae found in non-ICU clinical blood isolates [23].

Across Europe, these numbers average higher at around 10\% for Escherichia coli found in invasive isolates (i.e. blood or cerebrospinal fluid), however, national percentages of resistant isolates ranged from $2.9 \%$ (Iceland) to $24.2 \%$ (Slovakia) in 2015. For Klebsiella pneumoniae the average percentage of aminoglycoside resistance was $22.5 \%$ in 2015 , ranging from $0-68 \%$ [28]. In the USA, aminoglycoside resistance was $14.2 \%$ in E. coli and $7.2 \%$ in $K$. pneumoniae in isolates from lower respiratory tract sites of patients hospitalised (ICU and non-ICU) with pneumonia between 2009 and 2012 [29].

Overall, these numbers are not entirely comparable, however, they show that aminoglycoside resistance in E. coli and K. pneumoniae differs largely in Europe, and also worldwide. In countries with low levels of aminoglycoside resistance, aminoglycosides are very useful to broaden the Gram negative spectrum of empirical sepsis therapy. Furthermore, they can lead to more appropriate antibiotic coverage, as a recent study on patients with Gram negative bloodstream infection showed; patients receiving aminoglycosides had an eight-fold lower risk of inappropriate treatment (1.9\% vs. $14.7 \%$ in patients without aminoglycosides) [30].

\section{Aminoglycosides - mechanism of action and PK/PD}

It has long been thought that aminoglycosides act primarily by impairing bacterial protein synthesis through binding to the $16 \mathrm{~S}$ ribosomal RNA component of the $30 \mathrm{~S}$ subunit of bacterial ribosomes [31, 32]. However, this does not explain the rapid bactericidal characteristics of aminoglycosides, since other antibiotics that inhibit the synthesis of proteins are often not bactericidal. A common theory nowadays is that the primary site of action is 
an energy-independent interaction with the outer bacterial membrane, which accounts for most of the bactericidal effect. The interaction with the outer membrane causes alterations in permeability and leads to self-promoted uptake. After passage through the outer membrane, which is an energydependent process, the aminoglycosides act at the ribosomal level and cause misreading of proteins. When these misread proteins are being built into the outer membrane, further leakage of the outer membrane takes place, resulting in an increase in uptake of aminoglycosides and eventually to death of the bacteria [20, 33, 34].

Aminoglycosides are not absorbed from the gastrointestinal tract and they are generally administered parenterally or topically. After parenteral administration, usually as a 30 minute intravenous infusion, aminoglycosides are not metabolized, but distributed within the extracellular space before they are excreted by the kidneys by glomerular filtration. The plasma half-life is around 2-3 hours in patients with a normal renal function and is prolonged in patients with chronic kidney disease [21, 35, 36].

Gentamicin and tobramycin are usually dosed at $5-7 \mathrm{mg} / \mathrm{kg}$ body weight, whereas amikacin is usually dosed at $20-25 \mathrm{mg} / \mathrm{kg}$ body weight. Since aminoglycosides are hydrophilic, dose adjustment is necessary in patients with overweight; for patients with a BMI $>30 \mathrm{~kg} / \mathrm{m}^{2}$, the adjusted body weight should be used to calculate the dose of aminoglycosides [37]. It is essential that gentamicin is adequately dosed in patients with sepsis in order to achieve a maximal bactericidal effect whereas underdosing will lead to a lower gentamicin peak concentration and consequently to potential treatment failure and increased morbidity and mortality. On the other hand, very high peak concentrations may lead to higher trough concentrations, which are associated with side effects. In addition, pharmacokinetic parameters in the critically ill are much more variable than in the general patient population [38]. Therefore, therapeutic drug monitoring (TDM) should be performed. TDM of gentamicin aims at both peak concentrations and trough concentrations. Peak concentrations are associated with the clinical response rate, whereas trough concentrations are associated with toxicity.

The pharmacodynamical target aims at sufficiently high peak concentrations in order to achieve a maximal bactericidal effect. The peak concentration is associated with the clinical response rate and is usually retrieved 30 minutes after the end of the intravenous infusion. The height of the peak concentration 
corresponds with the clinical response rate and is approximately $85 \%$ with a ratio of $8: 1$, and $90 \%$ with a ratio of $10: 1[39,40]$. Therefore, it is recommended that the ratio between the peak concentration and the minimal inhibitory concentration (MIC) must be $8-10 \times$ MIC [41, 42]. According to the European Committee on Antimicrobial Susceptibility Testing (EUCAST), gentamicin MIC breakpoints for Enterobacteriaceae are $\leq 2 \mathrm{mg} / \mathrm{L}$, which leads to a target peak concentration of $16-20 \mathrm{mg} / \mathrm{L}$ for gentamicin susceptible isolates [43].

Since critically ill patients often are in shock and often receive large quantities of intravenous fluids, leakage of fluid to the extracellular space is common in these patients. This often leads to a higher volume of distribution (Vd), compared to the general population [44, 45]. In addition, critically ill patients often have renal and hepatic failure, which can alter the distribution and elimination of drugs. Since aminoglycosides are hydrophilic, the higher Vd could lead to lower concentrations of aminoglycosides. Therefore, it has been suggested to administer aminoglycosides in higher doses in critically ill patients to achieve optimal concentrations [46]. The altered elimination on the other hand, could lead to impaired clearance of aminoglycosides and a prolonged exposure to the aminoglycosides, which in turn could lead to toxicity (Figure 2) [47].

\section{Nephrotoxicity and acute kidney injury}

Although very potent in controlling bacterial infections, aminoglycosides have some serious side effects, with nephrotoxicity and vestibular-ototoxicity as the most important ones. The nephrotoxic side effects are dose and frequency dependent and can lead to acute kidney injury (AKI) [49]. Aminoglycoside associated $\mathrm{AKI}$ can develop in up to $25 \%$ of patients who are treated with aminoglycosides [50].

Aminoglycoside associated $\mathrm{AKI}$ is the result of accumulation of the aminoglycosides in epithelial cells of the proximal tubular cells of the kidney, where they cause morphological and functional alterations and damage to intracellular processes. This induces the death of epithelial cells leading to tubular necrosis [49, 51-53]. Aminoglycoside associated AKI is characterized by non-oliguric renal failure, a slow rise in serum creatinine, a hypo-osmolar urinary output and the lack of gross morphological changes in glomerular structures [54]. 


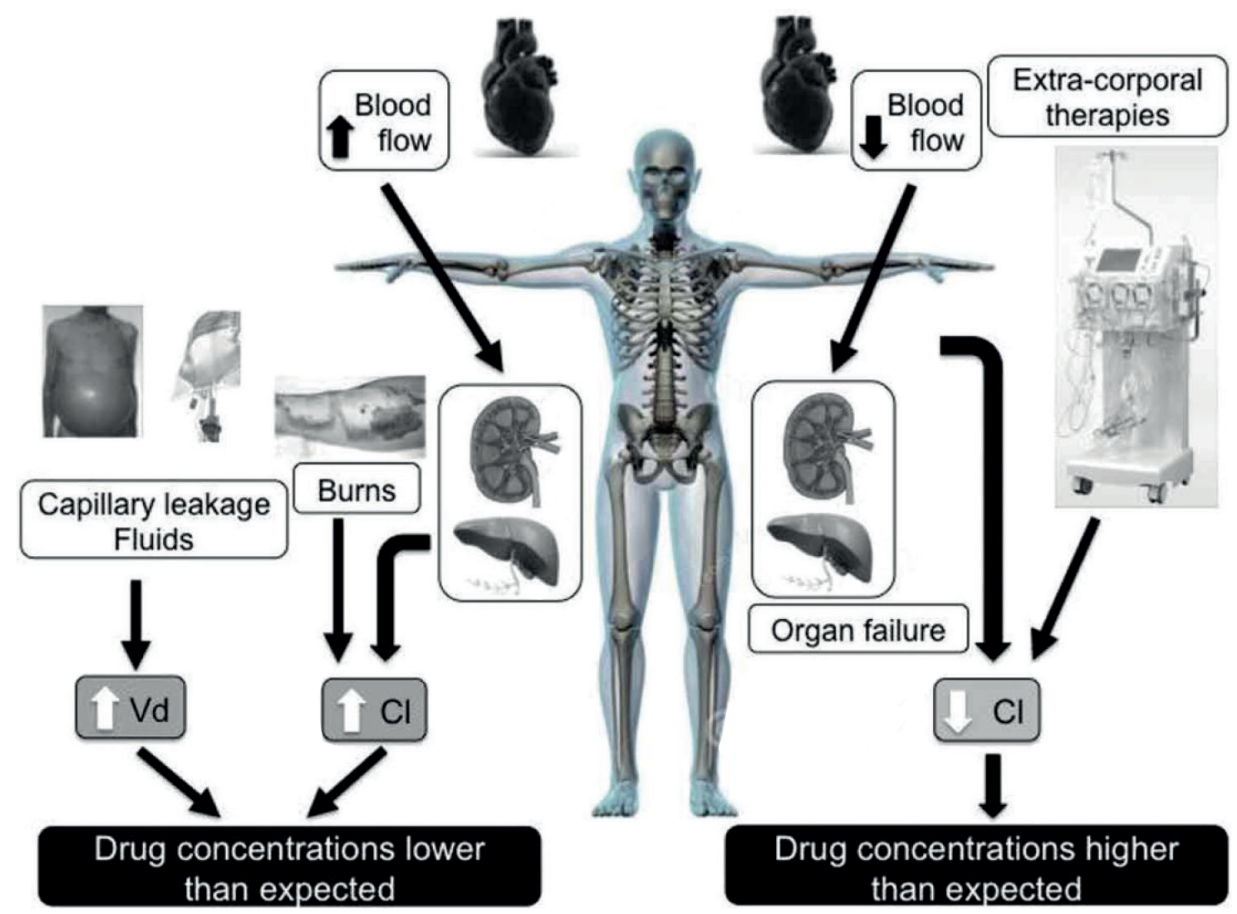

Figure 2. Pharmacokinetic alterations during critical illness [48]. $\mathrm{Cl}=$ clearance; $\mathrm{Vd}=$ volume of distribution .

As stated earlier, aminoglycosides are often used in sepsis. Since sepsis in itself is already associated with $A K I$ and the development of $A K I$ in sepsis is often multifactorial $[55,56]$, determining the additional effect of aminoglycoside on the risk of $\mathrm{AKI}$ in patients with sepsis can be difficult.

Early recognition of AKI in patients with sepsis is important, because it is associated with increased mortality and morbidity and if recognized early, measures can be taken to reverse the renal dysfunction [57]. Since early recognition of $A K I$ can be difficult, definitions with relatively simple criteria for diagnosing AKI were developed. However, in a systematic review of 28 studies, published in 1994, no two studies used the same criteria for AKI [58]. The wide heterogeneity in definitions and lack of consistent criteria for establishing risk factors made the interpretation and comparison of studies difficult and unnecessarily complicated. Therefore, in 2002 the Second International Consensus Conference of the Acute Dialysis Quality Initiative (ADQI) Group was held, to develop a consensus-based definition for AKI. The conference led to the RIFLE criteria, which define three grades of severity 
of AKI (Risk, Injury, Failure) based on a relative increase of serum creatinine or a period of decreased urine output. Patients in whom serum creatinine increased 1.5 times were assigned to RIFLE Class R (Risk), those in whom creatinine doubled to Class I (Injury) and those in whom creatinine tripled to Class F (Failure). In addition, two outcome criteria (Loss and End-stage renal disease) were defined as 4 weeks and 3 months of treatment with renal replacement therapy, respectively [59].

Shortly after the development of the RIFLE criteria, evidence showed that smaller changes in serum creatinine than those considered in the RIFLE criteria might be associated with adverse outcomes. Therefore, the Acute Kidney Injury Network (AKIN), in which the ADQI and several nephrology societies collaborated, held a conference in 2005 where minor changes were made to the existing RIFLE criteria resulting in the AKIN criteria [60].

In 2009 Waikar and Bonventre found a flaw in the RIFLE and AKIN definitions; using serum creatinine kinetics they discovered that the use of increases in percentages underestimated the severity of AKI in patients with chronic kidney disease. Therefore, they proposed their own definition, the so called AKIB definition [61].

In the years after the introduction of the RIFLE and AKIN criteria, it was becoming increasingly clear that also relatively mild acute injury to the kidney is associated with increased morbidity and mortality, both on the short-term as well as the long-term $[62,63]$ This lead to the Kidney Disease Improving Global Outcomes (KDIGO) clinical practice guidelines in which a combination of the previous definitions were combined to the KDIGO criteria (see Chapter 2, Table 1 for an overview of the AKI criteria) [64].

To date, the most commonly used AKI definitions are the RIFLE, AKIN, and KDIGO criteria [59, 60, 64]. It has been shown that the different criteria for AKI show different incidence numbers of AKI, however, the 2019 KDIGO Consensus Conference advised to use the KDIGO definition and classification of AKI rather than alternative definitions [65]. To date, no studies investigated the incidence of AKI in ED patients with sepsis diagnosed based on the new SOFA criteria for sepsis. 
Traditionally, aminoglycosides were administered in multiple daily doses (once every 8 or $12 \mathrm{hrs}$ ). However, in the nineties of the previous century evidence showed that a once daily dosing regimen is at least as effective and less nephrotoxic compared to a multiple daily dosing regimen [66-69]. To reduce toxicity even further, TDM is advised [70]. Since nephrotoxicity caused by aminoglycosides is dose and frequency dependent, it is often recommended to retrieve a trough concentration after 2-3 days of treatment in patients with a normal renal function, since high trough concentrations are associated with an increased risk of nephrotoxicity. In patients with impaired renal function a trough concentration should be obtained earlier, preferably before the second dose. The aimed trough concentration is $<1.0 \mathrm{mg} / \mathrm{L}$. If the trough concentration is higher, the interval of administration should be prolonged instead of lowering the dose, since this could lead to inadequate peak concentrations, followed by treatment failure. Currently, the majority of data does not support a difference in the risk of nephrotoxicity between gentamicin, tobramycin, and amikacin [42, 68, 71-73], however, some evidence shows that gentamicin has a higher risk of nephrotoxicity compared to tobramycin [74].

The use of aminoglycosides in sepsis is debated, mostly because of the nephrotoxic side effects. Previous research showed ambivalent results regarding the development of aminoglycoside associated AKI with a short course of aminoglycosides. Some studies report a high risk of AKI, whereas others found no association [75-77]. To date, most studies on the risk of AKI with gentamicin focussed on ICU patients rather than patients in the ED. However, aminoglycosides are part of the empirical therapy in sepsis in a lot of guidelines, including the Dutch national guidelines [15]. Since ICU patients are the most severely ill and are more often in shock, the results of the ICU studies cannot be extrapolated to ED patients, because the whole spectrum of sepsis as seen in the ED differs. In addition, little is known about the risk of developing AKI after the administration of a single dose of an aminoglycoside. In our experience, aminoglycosides are often administered as a single dose only, and no consecutive doses are administered. This is probably due to the fast clearance of the bloodstream by aminoglycosides [24]. In addition, improved microbiological diagnostics, such as continuous monitoring blood culture systems and MALDI-TOF MS, lead to faster determination of pathogens and consequently faster streamlining of antibiotic therapy [78]. Since accumulation of aminoglycosides after a single dose is unlikely, we hypothesize that a single dose of an aminoglycoside is not nephrotoxic. 


\section{Vestibulo-otoxicity}

Where nephrotoxicity is usually reversible, vestibular-ototoxicity often is not. Aminoglycosides can be toxic to both the vestibular and the cochlear system. Although loss of hearing is probably the most common symptom associated with aminoglycosides, aminoglycosides are primarily vestibulotoxic [79]. They cause damage to the vestibular apparatus, often bilateral, resulting in ataxia, nystagmus, and disequilibrium [36, 80]. Vertigo is typically absent and loss of hearing is rare [81].

The reported incidence of vestibulo-otoxicity varies greatly ranging from 1-25\% [82]. However, establishing the true prevalence is difficult since underreporting is likely $[81,83]$. The occurrence of vestibulo-otoxicity is, like nephrotoxicity, dose and frequency dependent as well. However, even when aminoglycoside blood concentrations are within the recommended therapeutic range, vestibulo-ototoxicity can still develop. In addition, some patients are genetically more susceptible to develop toxicity [53, 83]. Patients who develop vestibulo-toxicity are not more prone to develop nephrotoxicity, or vice versa $[84,85]$. In our thesis, we did not investigate vestibulo-otoxicity.

\section{Aminoglycosides and sepsis}

With a high mortality, the treatment of sepsis remains a challenge for all of us. With the increase of bacterial resistance to commonly used antibiotics worldwide, options for appropriate empirical antibiotic therapy with a beta-lactam antibiotic alone are becoming fewer $[23,86]$. Despite the toxic side effects, aminoglycosides remain very useful in the treatment of (Gram negative) sepsis and will possibly play an even greater role in the treatment of sepsis and other infections in the coming future era with increasing antibiotic resistance. Therefore, in 2018 the WHO stated that aminoglycosides are critically important antimicrobials for human medicine [87]. This is why this thesis aims at establishing the safety and optimising the use of a single dose of gentamicin in patients with sepsis in the emergency department. 


\section{Aim of the thesis}

With the worldwide increase of bacterial resistance to commonly used antibiotics, options for appropriate empirical antibiotic therapy with a betalactam antibiotic alone are becoming fewer. For this reason, aminoglycosides possibly will have an even greater role in the treatment of sepsis in the future era. Since sepsis in itself is already associated with AKI and the development of $A K I$ in sepsis is often multifactorial, determining the additional effect of aminoglycoside on the risk of AKI in patients with sepsis can be difficult. Therefore, it is our aim to evaluate the proportion of patients with sepsis already presenting with $\mathrm{AKI}$ and to establish the balance between sepsis, $\mathrm{AKI}$, and the treatment with gentamicin. In addition, we aim to investigate the safety of a single dose of gentamicin and to optimise the treatment of gentamicin in patients with sepsis in the emergency department.

\section{Outline of the thesis}

In Chapter 2 we studied the epidemiology of sepsis associated AKI by applying different AKI definitions (RIFLE, AKIN, AKIB, delta check, and KDIGO) for the different sepsis classifications (SIRS, qSOFA, and SOFA) and evaluated the association between $\mathrm{AKI}$ and 30-day mortality.

In Chapter 3 we report the results of a retrospective study at the ED investigating the incidence of $A K I$ in patients with sepsis after a single dose of gentamicin $(5 \mathrm{mg} / \mathrm{kg})$. Next to this, possible risk factors for the development of AKI were evaluated. Patients with sepsis of any etiology receiving gentamicin were compared with a control group who received antibiotic treatment without gentamicin. The chosen control group consisted of patients with sepsis with a pulmonary focus since these patients are usually not empirically treated with gentamicin.

Chapter 4 elaborates on the previous chapter and describes a larger retrospective multicentre study in patients with sepsis at the ED's of three hospitals. Local antibiotic policies differed between the three hospitals with respect to the administration of gentamicin. In one hospital, patients with sepsis of unknown origin (or those with suspected urinary tract or hepatobiliary tract infection) received amoxicillin/clavulanic acid plus gentamicin $(5 \mathrm{mg} / \mathrm{kg}$ ) as empirical therapy. In the other two hospitals patients received a 
cephalosporin (plus metronidazole in suspected digestive tract infections). This created a natural experiment for evaluating the influence of gentamicin on the development of AKI in patients with sepsis at the ED. The aim of this study was to determine the effect of a single dose of gentamicin on the incidence of AKI and on the persistence of kidney injury, and to evaluate possible risk factors for $\mathrm{AKI}$ in patients with sepsis in the ED.

Since pharmacokinetic alterations are often present in critically ill patients, dosing of antibiotics can be challenging. Therefore, we examined the actual gentamicin dosing in patients with sepsis in our ED to assess potential underdosing in Chapter 5.

In Chapter 6 we optimised gentamicin dosing in patients with sepsis in the ED. We investigated gentamicin dosing directly by measuring gentamicin peak concentrations in patients with sepsis at the ED after the first dose of gentamicin $(5 \mathrm{mg} / \mathrm{kg})$, to assess whether adequate peak concentrations were achieved. Subsequently, we simulated peak concentrations for different doses $(6-10 \mathrm{mg} / \mathrm{kg}$ ) to investigate which dose was needed to reach adequate peak concentrations. After the implementation of a new gentamicin dosing regimen $(7 \mathrm{mg} / \mathrm{kg}$ ), peak concentrations were measured again to verify whether these corresponded with the simulated doses and to assess whether adequate peak concentrations were achieved with the new dosing regimen. 


\section{References}

1. Singer M, Deutschman CS, Seymour CW, Shankar-Hari M, Annane D, Bauer M, et al. The Third International Consensus Definitions for Sepsis and Septic Shock (Sepsis-3). JAMA. 2016;315(8):801-10.

2. Angus DC, Linde-Zwirble WT, Lidicker J, Clermont G, Carcillo J, Pinsky MR. Epidemiology of severe sepsis in the United States: analysis of incidence, outcome, and associated costs of care. Critical care medicine. 2001;29(7):1303-10.

3. Nationale Intensive Care Evaluatie (NICE). Jaarboek 2018 - Het nut van de NICEregistratie. Nationale Intensive Care Evaluatie (NICE); 2019.

4. Paoli CJ, Reynolds MA, Sinha M, Gitlin M, Crouser E. Epidemiology and Costs of Sepsis in the United States-An Analysis Based on Timing of Diagnosis and Severity Level. Critical care medicine. 2018;46(12):1889-97.

5. Gaieski DF, Edwards JM, Kallan MJ, Carr BG. Benchmarking the incidence and mortality of severe sepsis in the United States. Critical care medicine. 2013;41(5):1167-74.

6. Angus DC, van der Poll T. Severe sepsis and septic shock. The New England journal of medicine. 2013;369(9):840-51.

7. Rivers E, Nguyen B, Havstad S, Ressler J, Muzzin A, Knoblich B, et al. Early goal-directed therapy in the treatment of severe sepsis and septic shock. The New England journal of medicine. 2001;345(19):1368-77.

8. Nguyen HB, Corbett SW, Steele R, Banta J, Clark RT, Hayes SR, et al. Implementation of a bundle of quality indicators for the early management of severe sepsis and septic shock is associated with decreased mortality. Critical care medicine. 2007;35(4):1105-12.

9. Bone RC, Balk RA, Cerra FB, Dellinger RP, Fein AM, Knaus WA, et al. Definitions for sepsis and organ failure and guidelines for the use of innovative therapies in sepsis. The ACCP/ SCCM Consensus Conference Committee. American College of Chest Physicians/Society of Critical Care Medicine. Chest. 1992 Jun;101(6):1644-55.

10. Levy MM, Fink MP, Marshall JC, Abraham E, Angus D, Cook D, et al. 2001 SCCM/ESICM/ ACCP/ATS/SIS International Sepsis Definitions Conference. Critical care medicine. 2003;31(4):1250-6.

11. Rhee C, Chiotos K, Cosgrove SE, Heil EL, Kadri SS, Kalil AC, et al. Infectious Diseases Society of America Position Paper: Recommended Revisions to the National Severe Sepsis and Septic Shock Early Management Bundle (SEP-1) Sepsis Quality Measure. Clinical infectious diseases : an official publication of the Infectious Diseases Society of America. 2020.

12. Seymour CW, Gesten F, Prescott HC, Friedrich ME, Iwashyna TJ, Phillips GS, et al. Time to Treatment and Mortality during Mandated Emergency Care for Sepsis. The New England journal of medicine. 2017;376(23):2235-44.

13. Liu VX, Fielding-Singh V, Greene JD, Baker JM, Iwashyna TJ, Bhattacharya J, et al. The Timing of Early Antibiotics and Hospital Mortality in Sepsis. American journal of respiratory and critical care medicine. 2017;196(7):856-63.

14. Martínez ML, Plata-Menchaca EP, Ruiz-Rodríguez JC, Ferrer R. An approach to antibiotic treatment in patients with sepsis. Journal of thoracic disease. 2020;12(3):1007-21.

15. Dutch Working Party on Antibiotic Policy (SWAB). The Dutch Working Party on Antibiotic Policy (SWAB) guideline for empirical antibacterial therapy of sepsis in adults. Leiden; 2020. 
16. Waksman SA. Streptomycin: background, isolation, properties, and utilization. Science (New York, NY). 1953;118(3062):259-66.

17. Woodruff HB. Selman A. Waksman, winner of the 1952 Nobel Prize for physiology or medicine. Applied and environmental microbiology. 2014;80(1):2-8.

18. Alapi E. M. FJ. Table of Selected Analogue Classes. Analogue-based Drug Discovery: Wiley-VCH Verlag GmbH \& Co. KGaA; 2006. p. 441-552.

19. Begg EJ, Barclay ML. Aminoglycosides-50 years on. British journal of clinical pharmacology. 1995;39(6):597-603.

20. Mingeot-Leclercq MP, Glupczynski Y, Tulkens PM. Aminoglycosides: activity and resistance. Antimicrobial agents and chemotherapy. 1999;43(4):727-37.

21. Appel GB, Neu HC. Gentamicin in 1978. Annals of internal medicine. 1978;89(4):528-38.

22. Information NCfB. Gentamicin, $\mathrm{CID}=3467$ [Available from: https://pubchem.ncbi.nlm.nih. gov/compound/Gentamicin].

23. de Greeff SC, Schoffelen AF, Verduin CM. NethMap 2020 - Consumption of antimicrobial agents and antimicrobial resistance among medically important bacteria in the Netherlands in 2019. 2020.

24. Davis BD. Mechanism of bactericidal action of aminoglycosides. Microbiological reviews. 1987;51(3):341-50.

25. Vogelman B, Craig WA. Kinetics of antimicrobial activity. The Journal of pediatrics. 1986;108(5 Pt 2):835-40.

26. Takahashi Y, Igarashi M. Destination of aminoglycoside antibiotics in the 'post-antibiotic era'. The Journal of antibiotics. 2017.

27. Gonzalez LS, 3rd, Spencer JP. Aminoglycosides: a practical review. American family physician. 1998;58(8):1811-20.

28. European Centre for Disease Prevention and Control. Antimicrobial resistance surveillance in Europe 2015. Annual Report of the European Antimicrobial Resistance Surveillance Network (EARS-Net). Stockholm; 2017.

29. Sader HS, Farrell DJ, Flamm RK, Jones RN. Antimicrobial susceptibility of Gram-negative organisms isolated from patients hospitalised with pneumonia in US and European hospitals: results from the SENTRY Antimicrobial Surveillance Program, 2009-2012. International journal of antimicrobial agents. 2014;43(4):328-34.

30. Deelen JWT, Rottier WC, Buiting AGM, Dorigo-Zetsma JW, Kluytmans J, van der Linden PD, et al. Short-course aminoglycosides as adjunctive empirical therapy in patients with Gram-negative bloodstream infection, a cohort study. Clinical microbiology and infection : the official publication of the European Society of Clinical Microbiology and Infectious Diseases. 2020.

31. Carter AP, Clemons WM, Brodersen DE, Morgan-Warren RJ, Wimberly BT, Ramakrishnan V. Functional insights from the structure of the $30 \mathrm{~S}$ ribosomal subunit and its interactions with antibiotics. Nature. 2000;407(6802):340-8.

32. Vicens $Q$, Westhof $E$. Molecular recognition of aminoglycoside antibiotics by ribosomal RNA and resistance enzymes: an analysis of $x$-ray crystal structures. Biopolymers. 2003;70(1):42-57.

33. Montie T, Patamasucon P. Aminoglycosides: the complex problem of antibiotic mechanisms and clinical applications. European journal of clinical microbiology \& infectious diseases : official publication of the European Society of Clinical Microbiology. 1995;14(2):85-7. 
34. Busse HJ, Wöstmann C, Bakker EP. The bactericidal action of streptomycin: membrane permeabilization caused by the insertion of mistranslated proteins into the cytoplasmic membrane of Escherichia coli and subsequent caging of the antibiotic inside the cells due to degradation of these proteins. Journal of general microbiology. 1992;138(3):551-61.

35. Lortholary O, Tod M, Cohen Y, Petitjean O. Aminoglycosides. The Medical clinics of North America. 1995;79(4):761-87.

36. Hayward RS, Harding J, Molloy R, Land L, Longcroft-Neal K, Moore D, et al. Adverse effects of a single dose of gentamicin in adults: a systematic review. British journal of clinical pharmacology. 2018;84(2):223-38.

37. Traynor AM, Nafziger AN, Bertino JS, Jr. Aminoglycoside dosing weight correction factors for patients of various body sizes. Antimicrobial agents and chemotherapy. 1995;39(2):5458.

38. Roberts DJ, Hall RI. Drug absorption, distribution, metabolism and excretion considerations in critically ill adults. Expert opinion on drug metabolism \& toxicology. 2013;9(9):1067-84.

39. Moore RD, Smith CR, Lipsky JJ, Mellits ED, Lietman PS. Risk factors for nephrotoxicity in patients treated with aminoglycosides. Annals of internal medicine. 1984;100(3):352-7.

40. Kashuba AD, Nafziger AN, Drusano GL, Bertino JS, Jr. Optimizing aminoglycoside therapy for nosocomial pneumonia caused by gram-negative bacteria. Antimicrobial agents and chemotherapy. 1999;43(3):623-9.

41. Lacy MK, Nicolau DP, Nightingale $\mathrm{CH}$, Quintiliani R. The pharmacodynamics of aminoglycosides. Clinical infectious diseases : an official publication of the Infectious Diseases Society of America. 1998;27(1):23-7.

42. Nicolau DP, Freeman CD, Belliveau PP, Nightingale CH, Ross JW, Quintiliani R. Experience with a once-daily aminoglycoside program administered to 2,184 adult patients. Antimicrobial agents and chemotherapy. 1995;39(3):650-5.

43. European Committee on Antimicrobial Susceptibility Testing (EUCAST). Gentamicin rationale for the EUCAST clinical breakpoints, version 1.2.; 2009.

44. Triginer C, Izquierdo I, Fernandez R, Rello J, Torrent J, Benito S, et al. Gentamicin volume of distribution in critically ill septic patients. Intensive care medicine. 1990;16(5):303-6.

45. Marik PE. Aminoglycoside volume of distribution and illness severity in critically ill septic patients. Anaesthesia and intensive care. 1993;21(2):172-3.

46. Rea RS, Capitano B, Bies R, Bigos KL, Smith R, Lee H. Suboptimal aminoglycoside dosing in critically ill patients. Therapeutic drug monitoring. 2008;30(6):674-81.

47. Plajer SM, Chin PK, Vella-Brincat JW, Buffery PJ, Begg EJ. Gentamicin and renal function: lessons from 15 years' experience of a pharmacokinetic service for extended interval dosing of gentamicin. Therapeutic drug monitoring. 2015;37(1):98-103.

48. Jager NG, van Hest RM, Lipman J, Taccone FS, Roberts JA. Therapeutic drug monitoring of anti-infective agents in critically ill patients. Expert review of clinical pharmacology. 2016;9(7):961-79.

49. Martinez-Salgado C, Lopez-Hernandez FJ, Lopez-Novoa JM. Glomerular nephrotoxicity of aminoglycosides. Toxicology and applied pharmacology. 2007;223(1):86-98.

50. Lopes JA, Jorge S, Resina C, Santos C, Pereira A, Neves J, et al. Acute renal failure in patients with sepsis. Critical care (London, England). 2007;11(2):411.

51. Nagai J, Takano M. Molecular aspects of renal handling of aminoglycosides and strategies for preventing the nephrotoxicity. Drug metabolism and pharmacokinetics. 2004;19(3):159-70. 
52. Rodriguez-Barbero A, Lopez-Novoa JM, Arevalo M. Involvement of platelet-activating factor in gentamicin nephrotoxicity in rats. Experimental nephrology. 1997;5(1):47-54.

53. Jospe-Kaufman M, Siomin L, Fridman M. The relationship between the structure and toxicity of aminoglycoside antibiotics. Bioorganic \& medicinal chemistry letters. 2020;30(13):127218.

54. Mingeot-Leclercq MP, Tulkens PM. Aminoglycosides: nephrotoxicity. Antimicrobial agents and chemotherapy. 1999;43(5):1003-12.

55. Bagshaw SM, Uchino S, Bellomo R, Morimatsu H, Morgera S, Schetz M, et al. Septic acute kidney injury in critically ill patients: clinical characteristics and outcomes. Clinical journal of the American Society of Nephrology : CJASN. 2007;2(3):431-9.

56. Alobaidi R, Basu RK, Goldstein SL, Bagshaw SM. Sepsis-associated acute kidney injury. Seminars in nephrology. 2015;35(1):2-11.

57. Poston JT, Koyner JL. Sepsis associated acute kidney injury. BMJ. 2019;364:k4891.

58. Novis BK, Roizen MF, Aronson S, Thisted RA. Association of preoperative risk factors with postoperative acute renal failure. Anesthesia and analgesia. 1994;78(1):143-9.

59. Bellomo R, Ronco C, Kellum JA, Mehta RL, Palevsky P. Acute renal failure - definition, outcome measures, animal models, fluid therapy and information technology needs: the Second International Consensus Conference of the Acute Dialysis Quality Initiative (ADQI) Group. Critical care (London, England). 2004;8(4):R204-12.

60. Mehta RL, Kellum JA, Shah SV, Molitoris BA, Ronco C, Warnock DG, et al. Acute Kidney Injury Network: report of an initiative to improve outcomes in acute kidney injury. Critical care (London, England). 2007;11(2):R31.

61. Waikar SS, Bonventre JV. Creatinine kinetics and the definition of acute kidney injury. Journal of the American Society of Nephrology: JASN. 2009;20(3):672-9.

62. Chertow GM, Burdick E, Honour M, Bonventre JV, Bates DW. Acute kidney injury, mortality, length of stay, and costs in hospitalized patients. Journal of the American Society of Nephrology: JASN. 2005;16(11):3365-70.

63. Hoste EA, Clermont G, Kersten A, Venkataraman R, Angus DC, De Bacquer D, et al. RIFLE criteria for acute kidney injury are associated with hospital mortality in critically ill patients: a cohort analysis. Critical care (London, England). 2006;10(3):R73.

64. Kellum JA, Lameire N, Aspelin P, Barsoum RS, Burdmann EA, Goldstein SL, et al. Kidney disease: improving global outcomes (KDIGO) acute kidney injury work group. KDIGO clinical practice guideline for acute kidney injury. Kidney international supplements. 2012;2(1):1138.

65. Levey AS, Eckardt KU, Dorman NM, Christiansen SL, Hoorn EJ, Ingelfinger JR, et al. Nomenclature for kidney function and disease: report of a Kidney Disease: Improving Global Outcomes (KDIGO) Consensus Conference. Kidney international. 2020;97(6):1117-29.

66. Gilbert DN. Once-daily aminoglycoside therapy. Antimicrobial agents and chemotherapy. 1991;35(3):399-405.

67. Prins JM, Büller HR, Kuijper EJ, Tange RA, Speelman P. Once versus thrice daily gentamicin in patients with serious infections. Lancet. 1993;341(8841):335-9.

68. Barza M, loannidis JP, Cappelleri JC, Lau J. Single or multiple daily doses of aminoglycosides: a meta-analysis. BMJ. 1996;312(7027):338-45.

69. Ali MZ, Goetz MB. A meta-analysis of the relative efficacy and toxicity of single daily dosing versus multiple daily dosing of aminoglycosides. Clinical infectious diseases : an official publication of the Infectious Diseases Society of America. 1997;24(5):796-809. 
70. van Lent-Evers NA, Mathôt RA, Geus WP, van Hout BA, Vinks AA. Impact of goal-oriented and model-based clinical pharmacokinetic dosing of aminoglycosides on clinical outcome: a cost-effectiveness analysis. Therapeutic drug monitoring. 1999;21(1):63-73.

71. Turnidge J. Pharmacodynamics and dosing of aminoglycosides. Infectious disease clinics of North America. 2003;17(3):503-28, v.

72. Sims PJ. Applied Pharmacokinetics \& Pharmacodynamics Principles of Therapeutic Drug Monitoring. Am J Pharm Educ. 2006;70(6):148.

73. Ferriols-Lisart R, Alos-Alminana M. Effectiveness and safety of once-daily aminoglycosides: a meta-analysis. American journal of health-system pharmacy: AJHP : official journal of the American Society of Health-System Pharmacists. 1996;53(10):1141-50.

74. van Maarseveen E, van Buul-Gast MC, Abdoellakhan R, Gelinck L, Neef C, Touw D. Oncedaily dosed gentamicin is more nephrotoxic than once-daily dosed tobramycin in clinically infected patients. The Journal of antimicrobial chemotherapy. 2014;69(9):2581-3.

75. Picard W, Bazin F, Clouzeau B, Bui HN, Soulat M, Guilhon E, et al. Propensity-based study of aminoglycoside nephrotoxicity in patients with severe sepsis or septic shock. Antimicrobial agents and chemotherapy. 2014;58(12):7468-74.

76. Ong L-Z, Tambyah PA, Lum LH, Low Z-J, Cheng I, Murali TM, et al. Aminoglycoside-associated acute kidney injury in elderly patients with and without shock. Journal of Antimicrobial Chemotherapy. 2016;71(11):3250-7.

77. Cobussen M, de Kort JM, Dennert RM, Lowe SH, Stassen PM. No increased risk of acute kidney injury after a single dose of gentamicin in patients with sepsis. Infectious diseases (London, England). 2016;48(4):274-80.

78. Lamy B, Sundqvist M, Idelevich EA. Bloodstream infections - Standard and progress in pathogen diagnostics. Clinical microbiology and infection : the official publication of the European Society of Clinical Microbiology and Infectious Diseases. 2020;26(2):142-50.

79. Forge A, Schacht J. Aminoglycoside antibiotics. Audiology \& neuro-otology. 2000;5(1):3-22.

80. Rutka J. Aminoglycoside Vestibulotoxicity. Advances in oto-rhino-laryngology. 2019;82:10110.

81. Ahmed RM, Hannigan IP, MacDougall HG, Chan RC, Halmagyi GM. Gentamicin ototoxicity: a 23-year selected case series of 103 patients. The Medical journal of Australia. 2012;196(11):701-4.

82. Ariano RE, Zelenitsky SA, Kassum DA. Aminoglycoside-induced vestibular injury: maintaining a sense of balance. The Annals of pharmacotherapy. 2008;42(9):1282-9.

83. O'Sullivan ME, Perez A, Lin R, Sajjadi A, Ricci AJ, Cheng AG. Towards the Prevention of Aminoglycoside-Related Hearing Loss. Frontiers in cellular neuroscience. 2017;11:325.

84. SmithCR,LipskyJJ,LietmanPS. Relationshipbetween aminoglycoside-induced nephrotoxicity and auditory toxicity. Antimicrobial agents and chemotherapy. 1979;15(6):780-2.

85. Dulon D, Aurousseau C, Erre JP, Aran JM. Relationship between the nephrotoxicity and ototoxicity induced by gentamicin in the guinea pig. Acta oto-laryngologica. 1988;106(34):219-25.

86. World Health Organization (WHO). Antimicrobial Resistance: Global Report on Surveillance. Geneva: World Health Organization (WHO); 2014.

87. World Health Organization (WHO). Critically important antimicrobials for human medicine, 6th revision 2018. Geneva: World Health Organization (WHO); 2019. Report No.: 924151552X. 




\section{Chapter 2}

\section{The incidence and outcome of $\mathrm{AKI}$ in patients with sepsis in the emergency department applying different definitions of $\mathrm{AKI}$ and sepsis}

M. Cobussen ${ }^{1,2}$, J. Verhave ${ }^{2}$, J. Buijs ${ }^{3}$, P.M. Stassen ${ }^{1,4}$

1. Department of Internal Medicine, Division of General Medicine, Section Acute Medicine, Maastricht University Medical Center, Maastricht, the Netherlands.

2. Department of Internal Medicine, Rijnstate Hospital, Arnhem, the Netherlands

3. Department of Internal Medicine, Zuyderland Medical Center, Heerlen, the Netherlands

4. CAPHRI School for Public Health and Primary Care, Faculty of Health, Medicine and Life Sciences, Maastricht University, Maastricht, the Netherlands. 


\section{Abstract}

\section{Background}

Sepsis is often accompanied with acute kidney injury (AKI). The incidence of AKI in patients with sepsis according to the new SOFA criteria presenting at the emergency department (ED) is not exactly known, because the definition of sepsis has changed and many definitions of AKI are in use. Given the important clinical consequences of early recognition of AKI in sepsis, our aim was to assess the epidemiology of sepsis associated AKI using different AKI definitions (RIFLE, AKIN, AKIB, delta check, and KDIGO) for the different sepsis classifications (SIRS, qSOFA, and SOFA).

\section{Methods}

We retrospectively enrolled patients with sepsis in the ED in three hospitals and applied different AKI definitions to determine the incidence of sepsis associated AKI. In addition, the association between the different AKI definitions and persistent kidney injury, hospital length of stay and 30-day mortality were evaluated.

\section{Results}

A total of 2065 patients was included. The incidence of AKI was 17.7-51.1\%, with the highest incidence in qSOFA patients, applying the AKIN and KDIGO definition. Patients with positive qSOFA criteria had the highest incidence of AKI (51.1\%), whereas AKI was present in almost $40 \%$ of patients with positive SOFA criteria and in up to a quarter of patients with positive SIRS criteria. Crude 30-day mortality, prolonged length of stay and persistent kidney injury were not differently prevalent using all five AKI definitions.

\section{Conclusion}

The incidence of $A K I$ is highly dependent on the definitions of sepsis and AKI used. When AKI (by any definition) was already present at the ED, 30-day mortality was as high as $22.2 \%$. This reflects the seriousness and importance of early recognition of $A K I$ in patients with sepsis, since AKI may be a sign of more severe disease and adverse outcome in these patients. 


\section{Introduction}

Acute kidney injury (AKI) is a common and serious complication of sepsis. It is caused by several factors, including a dysregulated host response to an infection, which eventually leads to organ failure [1]. The incidence of AKI in sepsis ranges widely from 15 to $87 \%$, depending on which population is studied and how AKI and sepsis are defined [2, 3].

Early recognition of $\mathrm{AKI}$ in patients with sepsis is important, because it is associated with increased mortality and morbidity. In addition, close monitoring of the complications of renal failure are required to preserve and improve renal function [4, 5]. In international literature a variety of definitions for AKI are described. Most commonly used are the RIFLE (Risk, Injury, Failure, Loss of kidney function, and End-stage kidney disease), AKIN (Acute Kidney Injury Network), and KDIGO (Kidney Disease Improving Global Outcomes). Other definitions used are AKIB and the delta check (Table 1) [3, 6]. Moreover, in 2016, a new definition for sepsis was introduced replacing the SIRS criteria (Sepsis-2) with the qSOFA and SOFA criteria (Sepsis-3) [7]. Variations in both classification criteria for sepsis as well as AKI make the interpretation of previous studies on the incidence of $A K I$ in sepsis difficult.

Next to this, previous studies on the incidence of sepsis associated AKI almost exclusively focussed on ICU patients. Only few studies described patients presenting with sepsis in the emergency department (ED). However, these studies used older definitions for both AKI and sepsis [3, 6]. The incidence of $A K I$ in patients with sepsis according to the new SOFA criteria presenting at the ED is therefore uncertain.

Given the important clinical consequences of early recognition of $A K I$ in sepsis, the aim of this multicentre retrospective study was to investigate the incidence of $A K I$ in patients with sepsis at presentation at the ED, according to five AKI classifications (RIFLE, AKIN, AKIB, delta check, and KDIGO) and three sepsis criteria (SIRS, qSOFA, and SOFA). The KDIGO criteria for AKI and the SOFA criteria for sepsis were used as reference, since these are the newest and most widely accepted. 
Table 1. Definitions of AKI

\begin{tabular}{|c|c|c|c|c|c|}
\hline & RIFLE & AKIN & AKIB & delta check & KDIGO \\
\hline Staging & Serum creatinine & Serum creatinine & Serum creatinine & $\begin{array}{l}\text { Serum } \\
\text { creatinine }\end{array}$ & $\begin{array}{l}\text { Serum } \\
\text { creatinine }\end{array}$ \\
\hline $\begin{array}{l}1 \\
\text { (Risk) }\end{array}$ & $>1.5 \times$ baseline & $\begin{array}{l}>1.5 \times \text { baseline } \\
\text { OR } \\
\geq 26.5 \text { increase }\end{array}$ & $\begin{array}{l}>26 \text { increase over } 24 \mathrm{~h} \\
\mathrm{OR}>44 \text { over } 48 \mathrm{~h}\end{array}$ & $>26$ increase & $\begin{array}{l}>1.5 x \\
\text { baseline OR } \\
\geq 26.5 \\
\text { increase }\end{array}$ \\
\hline $\begin{array}{l}2 \\
\text { (Injury) }\end{array}$ & $>2 \times$ baseline & $>2 \times$ baseline & $\begin{array}{l}>44 \text { increase over } 24 \mathrm{~h} \\
\mathrm{OR}>88 \text { over } 48 \mathrm{~h}\end{array}$ & & $>2 \times$ baseline \\
\hline $\begin{array}{l}3 \\
\text { (Failure) }\end{array}$ & $\begin{array}{l}>3 x \text { baseline } \\
O R \geq 44 \text { increase } \\
\text { if } \geq 300\end{array}$ & $\begin{array}{l}>3 x \text { baseline } \\
O R \geq 44 \text { increase } \\
\text { if baseline } \geq 353 \\
O R \text { requiring } R R T\end{array}$ & $\begin{array}{l}>88 \text { increase over } 24 \mathrm{~h} \\
\mathrm{OR}>132 \text { over } 48 \mathrm{~h}\end{array}$ & & $\begin{array}{l}>3 \times \text { baseline } \\
O R \geq 353 O R \\
\text { requiring } \\
\text { RRT }\end{array}$ \\
\hline
\end{tabular}

Serum creatinine is in $\mu \mathrm{mol} / \mathrm{L}$. Acute Dialysis Quality Initiative Group RIFLE: Risk, Injury, Failure, Loss, End Stage Renal Disease [12]; AKIN: Acute Kidney Injury Network [13]; AKIB: Acute Kidney Injury Bonventre [14]; delta check [15]; KDIGO: Kidney Disease Improving Global Outcomes [16]; RRT: renal replacement therapy.

RIFLE categories Loss (requiring $>4$ weeks of RRT) and End Stage Renal Disease (requiring $>12$ weeks of RRT) were not taken into account, because these groups of patients were not included in the study and therefore withdrawn from the table.

\section{Methods}

\section{Study design}

We performed a retrospective study in three large teaching hospitals in the Netherlands (Maastricht University Medical Centre (MUMC), Rijnstate Hospital and Zuyderland Medical Centre). Patients were enrolled between January 2015 and December 2016 (MUMC) and between July and December 2015 (Rijnstate Hospital and Zuyderland Medical Centre).

\section{Study population}

All ED admissions of patients $\geq 18$ years of age for the internal medicine department who fulfilled the sepsis criteria - either SIRS, qSOFA, or SOFA - were included. Patients were excluded when they had a post-renal cause of AKI established within 48 hours of admission, when they received concomitant renal replacement therapy (RRT), or when no creatinine values were available at the time of admission. 


\section{Data collection}

All data were retrieved from the electronic hospital charts. Standardised scoring forms were used to extract age, sex, weight, length, vital parameters, SIRS, qSOFA, and SOFA criteria [7]. According to the SOFA criteria, sepsis was defined when a patient met $\geq 2$ criteria for organ failure. Shock was defined as sepsis accompanied by a lactate $>2 \mathrm{mmol} / \mathrm{l}$ and the need of vasopressors to maintain a MAP $\geq 65 \mathrm{mmHg}$ despite adequate fluid resuscitation [7]. At presentation at the ED, the pre-existing SOFA score was assumed to be zero [8]. Prior medical history, the Charlson Comorbidity Index [9], risk factors for development of $\mathrm{AKI}$, such as diseases potentially influencing renal function, and the use of drugs interfering with renal function were retrieved. Also, 30day all-cause mortality was documented.

\section{Renal function and outcome measures}

The primary outcome for analysis was the incidence of $A K I$ in patients with sepsis, according to the SIRS, qSOFA, and SOFA criteria, using the SOFA criteria as reference. AKI was defined by the RIFLE, AKIN, AKIB, delta check, and KDIGO criteria, using the KDIGO criteria as reference.

To establish baseline renal function (renal function prior to the sepsis episode), creatinine values up to 3 months prior to ED presentation were obtained [10]. When these were not available, we used the lowest creatinine value during three months follow up as baseline creatinine [11]. Baseline eGFR was calculated using the CKD-EPI (Chronic Kidney Disease Epidemiology Collaboration) formula. Chronic kidney disease was defined as a baseline serum creatinine $>178 \mu \mathrm{mol} / \mathrm{l}$ (as part of the Charlson Comorbidity Index).

AKI at the time of presentation at the ED was classified according to the RIFLE, AKIN, AKIB, delta check, and KDIGO criteria for AKI (Table 1) [1216]. Urine production was not documented in a standardised way and was therefore withdrawn from all AKI scores.

In addition, we studied the association between AKI and the secondary outcome measures: persistent kidney injury, hospital length of stay, 30-day mortality, and AKI at admission, as defined by the KDIGO criteria. Persistent kidney injury was defined as at least a stage $1 \mathrm{AKI}$ classification during the second week after admission compared to baseline renal function (renal function prior to the sepsis episode). 


\section{Analysis and statistics}

Statistical analysis was performed using IBM SPSS version 22 (SPSS Inc., USA). Continuous variables were reported as median interquartile range (IQR), and categorical variables as proportions. Comparisons between two groups were made using Mann-Whitney test for continuous data and Pearson's chisquared test for categorical data. Comparisons between multiple groups were made using KruskalWallis test for continuous and Fisher's exact test for categorical data. Hereafter, when a significant difference was found, a posthoc analysis was used to test for differences between the groups. For the post-hoc analysis, the Bonferroni adjustment was used.

Logistic regression analysis was used to assess the association of each AKI severity with 30-day mortality without correction for other confounders. Data are presented as odds ratios (OR) with $95 \%$ confidence intervals $(\mathrm{Cl})$. The overlap between the different AKI definitions were identified and visualized by a Venn diagram, plotted using jvenn (source: http://jvenn.toulouse.inra.fr/ app/index.html) [17]. P-values $<0.05$ were considered statistically significant.

\section{Ethical approval}

The Ethics Committees of all participating hospitals approved this study with a waiver of informed consent (METC 13-4-103.12).

\section{Results}

During the study period, a total of 2065 patients fulfilled at least one sepsis definition. Of these patients, 2011 (97.4\%) met the SIRS criteria, 315 (15.3\%) patients met the qSOFA criteria, and 1246 (60.3\%) fulfilled the SOFA criteria for sepsis (Table 2).

\section{Acute kidney injury by sepsis definition}

Of the patients with sepsis at the ED, $17.7-51.1 \%$ had AKI (Table 3). The highest incidence of AKI was in qSOFA positive patients with up to $51.1 \%$ according to the AKIN and KDIGO definition. Overall, patients in the qSOFA group had the highest incidence of AKI compared to the other two sepsis definitions according to all AKI definitions (qSOFA vs. SIRS and qSOFA vs. SOFA, $\mathrm{p}<0.001$ for all comparisons) (Table 3 ). In addition, patients in the SOFA group more often had AKI compared to patients with SIRS ( $p<0.001)$. 
Table 2. Characteristics of patients stratified by different sepsis definitions.

\begin{tabular}{|c|c|c|c|}
\hline & $\begin{array}{l}\text { SIRS } \\
n=2011\end{array}$ & $\begin{array}{l}\text { qSOFA } \\
\mathrm{n}=315\end{array}$ & $\begin{array}{l}\text { SOFA } \\
n=1246\end{array}$ \\
\hline Age (years) & $69(56-79)$ & $77(65-83)$ & $72(61-81)$ \\
\hline Male sex & 1049 (52.2) & $159(50.5)$ & $708(56.8)$ \\
\hline $\mathrm{BMI}$ & $25.1(22.1-29.1)$ & $25.0(21.8-29.1)$ & $25.2(22.1-29.1)$ \\
\hline Age-adjusted CCl & $6(4-7)$ & $6(5-8)$ & $6(4-7)$ \\
\hline Diabetes mellitus & $155(7.7)$ & $34(10.8)$ & $112(9.0)$ \\
\hline Liver disease & $44(2.2)$ & $11(3.5)$ & $39(3.1)$ \\
\hline Chronic Kidney Disease & $171(8.5)$ & $36(11.4)$ & $145(11.6)$ \\
\hline Baseline creatinine ( $\mu \mathrm{mol} / \mathrm{L})$ & $81(66-107)$ & $84(66-116)$ & $89(69-125)$ \\
\hline $\begin{array}{l}\text { Baseline eGFR (CKD-EPI) } \\
\left(\mathrm{ml} / \mathrm{min} / 1.73 \mathrm{~m}^{2}\right)\end{array}$ & $75(53-93)$ & $66(49-89)$ & $67(44-88)$ \\
\hline Baseline urea (mmol/L) & $6.7(4.8-10.1)$ & $8.6(6.2-14.8)$ & $8.2(5.6-12.8)$ \\
\hline NSAID & $98(4.9)$ & $11(3.5)$ & $53(4.3)$ \\
\hline ACEi/ARB & $616(30.6)$ & $117(37.1)$ & $425(34.1)$ \\
\hline Diuretics & $592(29.4)$ & $128(40.6)$ & 438 (35.1) \\
\hline Shock & $136(6.8)$ & n.a. & $63(5.1)$ \\
\hline ICU admission & $134(6.7)$ & 75 (23.8) & $121(9.7)$ \\
\hline
\end{tabular}

Data are presented in medians (interquartile ranges) or in absolute numbers (percentages). SIRS: systemic inflammatory response syndrome; qSOFA: quick sequential organ failure assessment; SOFA: sequential organ failure assessment; BMI: body mass index; eGFR: estimated glomerular filtration rate; CKD-EPI: Chronic Kidney Disease Epidemiology Collaboration; CCI: Charlson Comorbidity Index; NSAID: non-steroidal anti-inflammatory drug; ACEi: ace inhibitor; ARB: angiotensin receptor blocker.

* The qSOFA criteria only define sepsis and not shock.

\section{Acute kidney injury by AKI definition}

In the SIRS group, the incidence of patients with AKI ranged from 17.7\% (using the RIFLE criteria) to $25.4 \%$ (according to the AKIN and KDIGO criteria) $(p<0.001)$. In the qSOFA group, the incidence of AKI was $51.1 \%$ using the AKIN and KDIGO criteria, with small differences in the severity of AKI between these two definitions.

In patients who fulfilled the SOFA criteria for sepsis, the incidence of AKI varied from $26.8 \%$ (using the RIFLE definition) to $37.3 \%$ (according to the AKIN and KDIGO criteria) $(p<0.001)$. 
Table 3. Incidence of AKI classified by different AKI and sepsis definitions.

\begin{tabular}{|c|c|c|c|c|c|c|c|}
\hline & $\begin{array}{l}\text { AKI } \\
\text { stage }\end{array}$ & RIFLE & AKIN & AKIB & delta check & KDIGO & P-value \\
\hline \multirow{4}{*}{$\begin{array}{c}\text { SIRS } \\
\mathrm{n}=2011 \\
(97.4 \% \\
\text { of total) }\end{array}$} & 1 & $195(9.7)$ & $349(17.4)$ & $188(9.3)$ & $499(24.8)$ & $361(18.0)$ & \\
\hline & 2 & $95(4.7)$ & $95(4.7)$ & $151(7.5)$ & n.a. & $96(4.8)$ & \\
\hline & 3 & $66(3.3)$ & $66(3.3)$ & $160(8.0)$ & n.a. & $53(2.6)$ & \\
\hline & Total & $356(17.7)$ & $510(25.4)$ & 499 (24.8) & $499(24.8)$ & $510(25.4)$ & $<0.001^{*}$ \\
\hline \multirow{4}{*}{$\begin{array}{c}\text { qSOFA } \\
n=315 \\
(15.3 \% \\
\text { of total) }\end{array}$} & 1 & $62(19.7)$ & $93(29.5)$ & $47(14.9)$ & $155(49.2)$ & 99 (31.4) & \\
\hline & 2 & 40 (12.7) & 40 (12.7) & $50(15.9)$ & n.a. & 41 (13.0) & \\
\hline & 3 & $28(8.9)$ & $28(8.9)$ & $58(18.4)$ & n.a. & $21(6.7)$ & \\
\hline & Total & $130(41.3)$ & $161(51.1)$ & $155(49.2)$ & $155(49.2)$ & $161(51.1)$ & $<0.001^{*}$ \\
\hline \multirow{4}{*}{$\begin{array}{c}\text { SOFA } \\
n=1246 \\
(60.3 \% \\
\text { of total) }\end{array}$} & 1 & $166(13.3)$ & $297(23.8)$ & 148 (11.9) & $457(36.7)$ & $309(24.8)$ & \\
\hline & 2 & $97(7.8)$ & $97(7.8)$ & $134(10.8)$ & n.a. & $98(7.9)$ & \\
\hline & 3 & $71(5.7)$ & $71(5.7)$ & $175(14.0)$ & n.a. & $58(4.7)$ & \\
\hline & Total & $334(26.8)$ & 465 (37.3) & $457(36.7)$ & $457(36.7)$ & 465 (37.3) & $<0.001^{*}$ \\
\hline \multicolumn{2}{|c|}{$\begin{array}{c}\text { P-value for total } \\
A K I\end{array}$} & $<0.001^{\dagger}$ & $<0.001^{\dagger}$ & $<0.001^{\dagger}$ & $<0.001^{\dagger}$ & $<0.001^{\dagger}$ & \\
\hline
\end{tabular}

Data are presented in absolute numbers (percentages).

* Significant differences: RIFLE vs. AKIN, RIFLE vs. AKIB, RIFLE vs. delta check, RIFLE vs. KDIGO, $p<0.001$. With Bonferroni adjustment, a $p$-value of $<0.005$ was considered statistically significant.

† Significant differences for all comparisons of total AKI: SIRS vs. qSOFA, SIRS vs. SOFA, qSOFA vs. SOFA, $p<0.001$. With Bonferroni adjustment, a $p$-value of $<0.016$ was considered statistically significant.

Figure 1 shows the overlap of the total incidence of AKI for the different AKI definitions in patients with sepsis according to the SOFA criteria. A total of 326 patients were identified by all five AKI definitions. An additional 131 patients were detected by the AKIN, AKIB, delta check, and KDIGO criteria, whereas another 8 patients were identified by the RIFLE, AKIN, and KDIGO criteria.

\section{Outcomes}

In patients with sepsis according to the SOFA criteria, $5.6-7.8 \%$ of the patients with AKI had persistent kidney injury. All definitions selected the same patients (Table 4). Median length of stay was 8-9 days, irrespective of the AKI definition. Patients with positive SOFA criteria without AKI had a significant shorter length of stay (6 days (4-11), $p<0.001$, (data not shown)) than those with AKI. 
Table 4. Clinical outcomes stratified by different AKI definitions in patients with sepsis according to the SOFA criteria.

\begin{tabular}{|c|c|c|c|c|c|c|c|}
\hline & Clinical outcome & $\begin{array}{l}\text { RIFLE } \\
n=334\end{array}$ & $\begin{array}{l}\text { AKIN } \\
n=465\end{array}$ & $\begin{array}{l}\text { AKIB } \\
n=457\end{array}$ & $\begin{array}{l}\text { delta check } \\
\mathrm{n}=457\end{array}$ & $\begin{array}{l}\text { KDIGO } \\
n=465\end{array}$ & $P$-value \\
\hline \multirow{4}{*}{$\begin{array}{c}\text { SOFA } \\
n= \\
1246\end{array}$} & $\begin{array}{l}\text { Persistent kidney } \\
\text { injury, relative to } \\
\text { baseline }\end{array}$ & $26(7.8)$ & $26(5.6)$ & $26(5.7)$ & $26(5.7)$ & $26(5.6)$ & 0.68 \\
\hline & $\begin{array}{l}\text { Persistent kidney } \\
\text { injury, relative to } \\
\text { admission }\end{array}$ & $3(0.9)$ & $3(0.6)$ & $3(0.7)$ & $3(0.7)$ & $3(0.6)$ & 0.99 \\
\hline & $\begin{array}{l}\text { Hospital length of } \\
\text { stay (days) }\end{array}$ & $9(5-17)$ & $8(5-17)$ & $8(5-17)$ & $8(5-17)$ & $8(5-17)$ & 1.0 \\
\hline & $\begin{array}{l}\text { Crude 30-day } \\
\text { mortality }\end{array}$ & $74(22.2)$ & $100(21.5)$ & $95(20.8)$ & $95(20.8)$ & $100(21.5)$ & 0.99 \\
\hline
\end{tabular}

Data are presented in medians (interquartile ranges) or in absolute numbers (percentages).

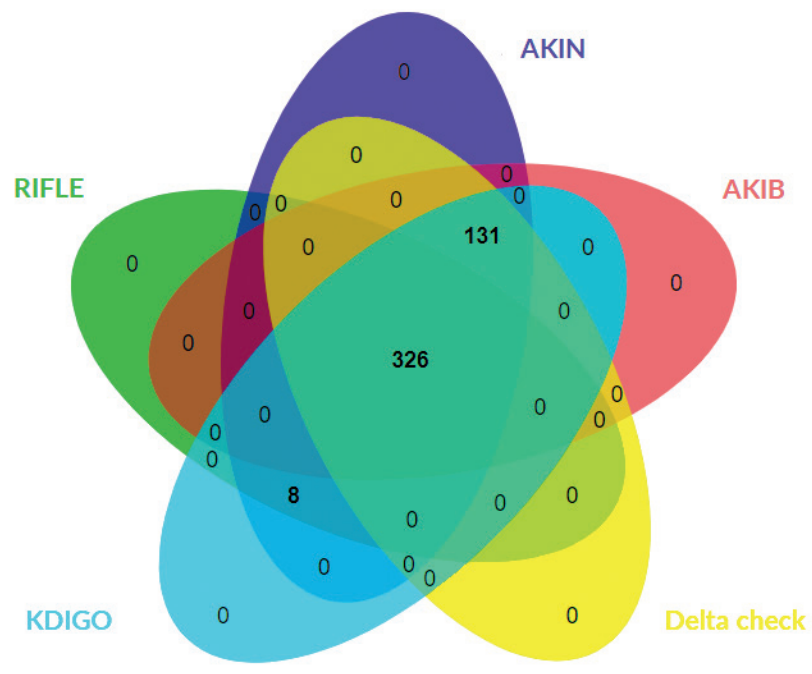

Figure 1. Venn diagram illustrating the overlap between different AKI definitions in patients with sepsis according to the SOFA criteria.

Legend: In patients with sepsis (SOFA), all AKI definitions defined 326 patients as having AKI. All, except for the RIFLE criteria, defined another 131 patients. Another 8 patients were identified by the RIFLE, AKIN, and KDIGO definition. 
In patients with AKI, 20.8 - 22.2\% died within 30 days after admission (vs. $15.0 \%$ in patients without $A K I, p=0.23$ (data not shown)) (Table 4). Using the KDIGO criteria, crude 30 -day mortality was higher in patients with Stage 2 and $3 \mathrm{AKI}$ compared to patients with sepsis without AKI (OR $2.23,95 \% \mathrm{CI}$ $1.37-3.62, p=0.001$, and OR 2.04, 95\% Cl $1.10-3.80, p=0.02$ ), but not Stage $1(p=0.09)$ (Table 5). The same pattern was seen using the RIFLE and AKIN criteria. Using the AKIB criteria, 30-day mortality was higher in Stage $3 \mathrm{AKI}$, compared to patients with sepsis without AKI (OR 1.83, 95\% CI 1.24-2.72, $p=0.003)$, but not in Stage 1 and $2 \mathrm{AKI}(\mathrm{p}=0.33$ and $p=0.29)$.

\section{Discussion}

This multi-centre study shows that the incidence of AKI in patients with sepsis in the ED varies greatly (ranging from $17.7 \%-51.1 \%$ ). This variation seems to be highly dependent on the definition of sepsis, but also on the definition of AKI. When AKI was present, irrespective of the definition applied, patients had a longer length of stay and high 30-day mortality.

Patients with positive qSOFA and SOFA criteria more often had AKI at presentation by any definition compared to patients meeting the SIRS criteria. Patients with positive qSOFA criteria had the highest incidence of AKI (51.5\%), whereas AKI was present in almost $40 \%$ of patients with positive SOFA criteria and in up to a quarter of patients with positive SIRS criteria. The high incidence of AKI in patients with positive qSOFA criteria shows that these criteria probably select the most severely ill patients. Thus far, the qSOFA criteria are used in clinical setting as a screening instrument for sepsis. In line with these findings, we hypothesize that the qSOFA score at the ED may be interpreted as a predictor for the development of AKI.

The higher incidence of $\mathrm{AKI}$ in patients with positive SOFA criteria compared to SIRS may be explained by the fact that the SOFA criteria aim to select patients with more severe stages of sepsis. In addition, the SOFA score was introduced in clinical practice to indicate organ failure, including kidney failure. Serum creatinine is one of six variables of the SOFA score, which explains the association between AKI and sepsis as defined by the SOFA score. 
Table 5. Predictive ability of multivariable logistic regression models of the different AKI definitions in patients with sepsis (SOFA) with respect to crude 30-day mortality

\begin{tabular}{|c|c|c|c|}
\hline & AKI Criteria & Odds ratio $(95 \% \mathrm{Cl})$ & P-value \\
\hline \multirow{17}{*}{$\begin{array}{c}\text { SOFA } \\
n=1246\end{array}$} & RIFLE $^{*}$ & & \\
\hline & Risk & $1.12(0.72-1.74)$ & 0.62 \\
\hline & Injury & $2.02(1.25-3.28)$ & 0.004 \\
\hline & Failure & $2.16(1.25-3.74)$ & 0.006 \\
\hline & AKIN* & & \\
\hline & Stage 1 & $1.30(0.91-1.86)$ & 0.15 \\
\hline & Stage 2 & $2.14(1.31-3.50)$ & 0.002 \\
\hline & Stage 3 & $2.29(1.31-3.99)$ & 0.003 \\
\hline & AKIB $^{*}$ & & \\
\hline & Stage 1 & $1.26(0.79-1.99)$ & 0.33 \\
\hline & Stage 2 & $1.29(0.80-2.08)$ & 0.29 \\
\hline & Stage 3 & $1.83(1.24-2.72)$ & 0.003 \\
\hline & delta check ${ }^{*}$ & $1.48(1.10-1.99)$ & 0.01 \\
\hline & KDIGO* & & \\
\hline & Stage 1 & $1.35(0.96-1.91)$ & 0.09 \\
\hline & Stage 2 & $2.23(1.37-3.62)$ & 0.001 \\
\hline & Stage 3 & $2.04(1.10-3.80)$ & 0.02 \\
\hline
\end{tabular}

"Patients with sepsis without AKI were used as reference

The majority of patients had concordant AKI diagnoses, applying the 5 different AKI criteria, as shown by the Venn diagram. This high concordance between the AKI definitions is not remarkable, as the definitions highly overlap. However, we encountered some differences in the severity of AKI categories between the AKI definitions. In patients with sepsis according to the SOFA criteria, AKI was already present at presentation at the ED in $37.3 \%$ according to the AKIN and the KDIGO criteria, whereas the RIFLE criteria defined AKI in only $26.8 \%$ of cases $(p<0.001)$. In patients with sepsis defined by the SIRS criteria, the AKIN and KDIGO criteria defined AKI in $25.4 \%$, compared to $17.7 \%$ when the RIFLE criteria were applied $(p<0.001)$. In patients with sepsis according to qSOFA, we retrieved similar results. The higher number of AKIN and KDIGO positive patients by any sepsis definition compared to the RIFLE criteria is mainly accounted for by the significantly higher number of stage $1 \mathrm{AKI}$. This is probably explained by the less strict definition of stage $1 \mathrm{AKIN}, \mathrm{AKIB}$ and KDIGO (i.e. $\geq 26.5 \mu \mathrm{mol} / \mathrm{l}$ increase of serum creatinine). Since the mortality numbers are comparable, the question is whether the increase in stage $1 \mathrm{AKI}$, using the AKIN and KDIGO criteria, is of 
clinical relevance. Furthermore, we hypothesise that the relative large proportion of patients with the most severe stage of AKI using the AKIB criteria reflects an overestimation of the most severe stage of AKI, since the ORs for 30-day mortality with this stage were substantially lower than the ORs for the most severe stages of AKI using the RIFLE, AKIN and KDIGO criteria.

When AKI (by any definition) was already present at the ED, 30-day mortality was as high as $22.2 \%$. This reflects the seriousness and importance of early recognition of $A K I$ in patients with sepsis, since AKI may be a sign of more severe disease and adverse outcome in these patients. Moreover, patients with stage 2 and 3 RIFLE, AKIN, and KDIGO AKI showed similar predictions of mortality risk, whereas the AKIB and delta check criteria had lower ORs for 30-day mortality. The predictive ability of AKI (by any definition) with respect to crude 30-day mortality was insufficient in patients with positive SOFA criteria for all five AKI definitions (AUROC curves between $0.55-0.57$, (data not shown)).

Other secondary outcome measures in SOFA patients such as length of stay and persistent kidney injury were not different between all five AKI definitions, whereas patients without AKI had a shorter length of stay. Persistent kidney injury was rare (26/1246, 2.1\%).

Given the important clinical consequences of early recognition of $\mathrm{AKI}$ in sepsis, one can argue which AKI definition should be used, because the incidence of AKI varies greatly depending on the chosen AKI definition. The aim of using criteria for $A K I$ is to recognize $A K I$ in patients with sepsis as early as possible, because sepsis associated AKI is related to increased mortality and morbidity, and to prevent persistent kidney injury. Therefore the criteria should select the patients with true AKI that are at risk for persistent kidney injury and increased morbidity and mortality. In addition, they should be sensitive enough for the initial evaluation and require greater specificity for the final diagnosis. Next to this, over time, the patient's clinical course and response to therapy can be included in the assessment of AKI. Compared to the other definitions of AKI, the KDIGO criteria identified the highest number of patients with AKI and had the highest ORs for 30-day mortality. These findings support the advice of a recent consensus statement of the 2019 KDIGO Consensus Conference, to use the KDIGO criteria to define AKI [18], including patients with sepsis. 
Other studies have described the incidence of AKI in sepsis using different definitions in different settings [19]. Most of these studies were done in patients in the ICU $[2,6,20]$, whereas only few groups studied hospitalized patients in general [21, 22], or specific patient categories [23, 24], with incidences ranging from $4.8 \%$ to $87.5 \%$ depending on setting and population. None of the previous studies described the incidence of AKI in patients presenting with sepsis at the ED, nor did they use the new SOFA criteria for sepsis. In contrast to some other studies, KDIGO stage $1 \mathrm{AKI}$ was not associated with an elevated risk of mortality in our study. Compared to other studies, KDIGO stage 2 and stage 3 AKI had lower ORs for 30-day mortality than previously reported $[20,25]$. This finding may be explained by the fact that we included ED patients, who represent the whole spectrum of sepsis severity, including patients in an early and probably reversible stage of the sepsis syndrome, whereas the abovementioned studies included ICU patients only.

In our multi-center study we studied studied a large population of patients with the whole spectrum of sepsis, which is a good reflection of the daily practice in the ED. However, there are some limitations. Our study focused on the incidence of $A K I$ already present at presentation at the ED. Some patients develop AKI later on during their clinical course. In addition, our study did not include urine production. Urine output may be a sensitive indicator of acute kidney injury [3]. However, standardized documentation of urine production is a difficult parameter to retrieve in retrospective studies, especially in the ED.

In conclusion, this is the first study comparing different AKI definitions and applying different sepsis definitions, including the new SOFA criteria for sepsis. Our multi-centre study in a large population of ED patients with sepsis shows that the incidence of AKI varies greatly and ranges from $17.7 \%-51.1 \%$, dependent on the definition of sepsis and AKI used. In patients with sepsis meeting the SOFA criteria, almost $40 \%$ of patients were classified as having $A K I$ at the ED. When AKI is already present at the ED, this is associated with a longer length of hospital stay and a high 30 -day mortality rate (up to $22.2 \%$, especially when AKI is more severe), irrespective of which AKI definition is used. Early recognition of sepsis associated AKI in patients in the ED is important because of the more severe prognosis. Therefore knowledge of the different AKI definitions is mandatory. This study provides knowledge on the use of the different $\mathrm{AKI}$ and sepsis definitions. 


\section{References}

1. Seymour CW, Liu VX, Iwashyna TJ, Brunkhorst FM, Rea TD, Scherag A, et al. Assessment of Clinical Criteria for Sepsis: For the Third International Consensus Definitions for Sepsis and Septic Shock (Sepsis-3). JAMA. 2016;315(8):762-74.

2. Pereira M, Rodrigues N, Godinho I, Gameiro J, Neves M, Gouveia J, et al. Acute kidney injury in patients with severe sepsis or septic shock: a comparison between the 'Risk, Injury, Failure, Loss of kidney function, End-stage kidney disease' (RIFLE), Acute Kidney Injury Network (AKIN) and Kidney Disease: Improving Global Outcomes (KDIGO) classifications. Clinical kidney journal. 2017;10(3):332-40.

3. Challiner R, Ritchie JP, Fullwood C, Loughnan P, Hutchison AJ. Incidence and consequence of acute kidney injury in unselected emergency admissions to a large acute UK hospital trust. BMC nephrology. 2014;15:84.

4. Bagshaw SM, Uchino S, Bellomo R, Morimatsu H, Morgera S, Schetz M, et al. Septic acute kidney injury in critically ill patients: clinical characteristics and outcomes. Clinical journal of the American Society of Nephrology: CJASN. 2007;2(3):431-9.

5. Poston JT, Koyner JL. Sepsis associated acute kidney injury. BMJ. 2019;364:k4891.

6. Koeze J, Keus F, Dieperink W, van der Horst IC, Zijlstra JG, van Meurs M. Incidence, timing and outcome of $\mathrm{AKI}$ in critically ill patients varies with the definition used and the addition of urine output criteria. BMC nephrology. 2017;18(1):70.

7. Singer M, Deutschman CS, Seymour CW, Shankar-Hari M, Annane D, Bauer M, et al. The Third International Consensus Definitions for Sepsis and Septic Shock (Sepsis-3). JAMA. 2016;315(8):801-10.

8. Raith EP, Udy AA, Bailey M, McGloughlin S, Maclsaac C, Bellomo R, et al. Prognostic Accuracy of the SOFA Score, SIRS Criteria, and qSOFA Score for In-Hospital Mortality Among Adults With Suspected Infection Admitted to the Intensive Care Unit. JAMA. 2017;317(3):290-300.

9. Charlson ME, Pompei P, Ales KL, MacKenzie CR. A new method of classifying prognostic comorbidity in longitudinal studies: development and validation. Journal of chronic diseases. 1987;40(5):373-83.

10. Pickering JW, Endre ZH. Back-calculating baseline creatinine with MDRD misclassifies acute kidney injury in the intensive care unit. Clinical journal of the American Society of Nephrology : CJASN. 2010;5(7):1165-73.

11. Hoste EA, Clermont G, Kersten A, Venkataraman R, Angus DC, De Bacquer D, et al. RIFLE criteria for acute kidney injury are associated with hospital mortality in critically ill patients: a cohort analysis. Critical care (London, England). 2006;10(3):R73.

12. Bellomo R, Ronco C, Kellum JA, Mehta RL, Palevsky P. Acute renal failure - definition, outcome measures, animal models, fluid therapy and information technology needs: the Second International Consensus Conference of the Acute Dialysis Quality Initiative (ADQI) Group. Critical care (London, England). 2004;8(4):R204-12.

13. Mehta RL, Kellum JA, Shah SV, Molitoris BA, Ronco C, Warnock DG, et al. Acute Kidney Injury Network: report of an initiative to improve outcomes in acute kidney injury. Critical care (London, England). 2007;11(2):R31. 
14. Waikar SS, Bonventre JV. Creatinine kinetics and the definition of acute kidney injury. Journal of the American Society of Nephrology : JASN. 2009;20(3):672-9.

15. Garner AE, Lewington AJ, Barth JH. Detection of patients with acute kidney injury by the clinical laboratory using rises in serum creatinine: comparison of proposed definitions and a laboratory delta check. Annals of clinical biochemistry. 2012;49(Pt 1):59-62.

16. Kellum JA, Lameire N, Aspelin P, Barsoum RS, Burdmann EA, Goldstein SL, et al. Kidney disease: improving global outcomes (KDIGO) acute kidney injury work group. KDIGO clinical practice guideline for acute kidney injury. Kidney international supplements. 2012;2(1):1-138.

17. Bardou P, Mariette J, Escudié F, Djemiel C, Klopp C. jvenn: an interactive Venn diagram viewer. BMC Bioinformatics. 2014;15(1):293.

18. Levey AS, Eckardt KU, Dorman NM, Christiansen SL, Hoorn EJ, Ingelfinger JR, et al. Nomenclatureforkidney function and disease: report of a Kidney Disease: Improving Global Outcomes (KDIGO) Consensus Conference. Kidney international. 2020;97(6):1117-29.

19. Gameiro J, Agapito Fonseca J, Jorge S, Lopes JA. Acute Kidney Injury Definition and Diagnosis: A Narrative Review. Journal of clinical medicine. 2018;7(10).

20. Zhou J, Liu Y, Tang Y, Liu F, Zhang L, Zeng X, et al. A comparison of RIFLE, AKIN, KDIGO, and Cys-C criteria for the definition of acute kidney injury in critically ill patients. International urology and nephrology. 2016;48(1):125-32.

21. Zeng X, McMahon GM, Brunelli SM, Bates DW, Waikar SS. Incidence, outcomes, and comparisons across definitions of $\mathrm{AKI}$ in hospitalized individuals. Clinical journal of the American Society of Nephrology : CJASN. 2014;9(1):12-20.

22. Fujii T, Uchino S, Takinami M, Bellomo R. Validation of the Kidney Disease Improving Global Outcomes criteria for AKI and comparison of three criteria in hospitalized patients. Clinical journal of the American Society of Nephrology : CJASN. 2014;9(5):848-54.

23. Rodrigues FB, Bruetto RG, Torres US, Otaviano AP, Zanetta DM, Burdmann EA. Incidence and mortality of acute kidney injury after myocardial infarction: a comparison between KDIGO and RIFLE criteria. PloS one. 2013;8(7):e69998.

24. Roy AK, Mc Gorrian C, Treacy C, Kavanaugh E, Brennan A, Mahon NG, et al. A Comparison of Traditional and Novel Definitions (RIFLE, AKIN, and KDIGO) of Acute Kidney Injury for the Prediction of Outcomes in Acute Decompensated Heart Failure. Cardiorenal medicine. 2013;3(1):26-37.

25. Luo X, Jiang L, Du B, Wen Y, Wang M, Xi X. A comparison of different diagnostic criteria of acute kidney injury in critically ill patients. Critical care (London, England). 2014;18(4):R144. 




\section{Chapter 3}

\section{No increased risk of acute kidney injury after a single dose of gentamicin in patients with sepsis}

M. Cobussen*, J.M.L. de Kort*, R.M. Dennert, S.H. Lowe, P.M. Stassen

Department of Internal Medicine, Maastricht University Medical Center, the Netherlands

${ }^{*}$ Both authors contributed equally to this manuscript.

Infect Dis (Lond). 2016 Apr;48(4):274-280. 


\section{Abstract}

\section{Background}

Aminoglycosides are frequently used in the empirical treatment of sepsis. However, aminoglycosides may induce acute kidney injury (AKI). Data is lacking on the renal safety of a single dose of aminoglycosides in septic patients visiting the emergency department (ED).

\section{Aim of the study}

To investigate the incidence of $A K I$ in septic patients after a single dose of gentamicin $(5 \mathrm{mg} / \mathrm{kg})$ and to evaluate possible risk factors.

\section{Methods}

We retrospectively followed patients, aged $\geq 18$ years, visiting our ED and fulfilling sepsis criteria for one year. Two groups were analysed: septic patients receiving gentamicin in combination with beta-lactam antibiotics, and a control group with pneumosepsis patients only without gentamicin. Renal function was determined prior to admission, at presentation, and during the following 2 weeks. AKI was defined according to the RIFLE criteria.

\section{Results}

In total, 302 patients were included, 179 in the gentamicin and 123 in the control group. Mean gentamicin dose was $4.7 \pm 0.7 \mathrm{mg} / \mathrm{kg}$. At admission, $26.8 \%$ of the gentamicin and $16.3 \%$ of the control group had AKI. After admission, AKI occurred in $6.7 \%$ of the gentamicin and in $3.3 \%$ of the control group $(p=0.30)$. Occurrence of AKI was not associated with gentamicin administration, but with septic shock $(31.2 \%$ in patients with $A K I$ vs. $9.8 \%$ without $\mathrm{AKI}$ after admission, $\mathrm{p}=0.02$ ).

\section{Conclusion}

Our study showed no increased risk of AKI after a single dose of gentamicin to patients with sepsis in the ED, suggesting that a single dose of gentamicin can, with regard to renal function, be safely administered to septic patients. 


\section{Introduction}

Severe sepsis and septic shock are associated with high morbidity and mortality. Aminoglycosides, such as gentamicin, are highly effective for the treatment of a variety of infections including sepsis of unknown origin. Empirical therapy with beta-lactam (B-lactam) antibiotics in combination with an aminoglycoside leads to better survival than B-lactam monotherapy [1-3]. Therefore, aminoglycosides are widely used as a first-choice drug in sepsis in the emergency department (ED). A practical approach is to give a single dose of an aminoglycoside in combination with broad spectrum B-lactam antibiotics to patients presenting with severe sepsis or septic shock in the ED, to re-evaluate after 24 hours, and then to decide whether or not to repeat the aminoglycoside dosing, based on the clinical condition of the patient and the follow up laboratory results. A substantial number of hospitals in the Netherlands, including ours, use this strategy. In our hospital primarily gentamicin is used [3].

Although very effective in controlling bacterial infections, aminoglycosides are nephrotoxic. Acute kidney injury (AKI) occurs in up to $25 \%$ of patients [4-7]. This AKI results from accumulation of the aminoglycosides in the kidney, which leads to tubular necrosis without gross morphological changes in glomerular structures [8-10]. The incidence of AKI depends on the dose and frequency of administration of aminoglycosides, with little differences in the type of aminoglycosides [11-14]. Even when gentamicin is administered only once daily (for more than one day), an increased risk of AKI is observed [15]. One report demonstrated AKI in 12 out of 87 (13.8\%) ICU patients, when gentamicin was administered once daily for multiple days [16]. For a single dose of gentamicin, less is known about the risk of developing AKI. The ICU study showed that 6 out of 54 (11.1\%) ICU patients who received only one dose of gentamicin developed $\mathrm{AKI}$, and when a single dose of gentamicin was given as prophylaxis in orthopaedic patients $(n=7666)$ an increased risk (94\%) of AKI was found [17].

While the administration of multiple doses of gentamicin in a once-daily dosing regimen may induce $\mathrm{AKI}$, there are no studies about the incidence of AKI after the administration of a single dose of gentamicin in patients with sepsis presenting at the ED. Therefore, the purpose of our study was to assess the extent and nature of AKI in patients with sepsis at the ED and specifically in those given a single dose of gentamicin. 


\section{Materials and methods}

\section{Study population}

We performed a retrospective study in the Maastricht University Medical Center, which is a hospital with 715 beds that provides secondary and tertiary healthcare. There are 25,000 ED visits per year and approximately 5000 patients are assessed by an internist. Apart from high emergency cases, most patients are referred to the ED by a general practitioner, and almost all acute admissions originate from the ED (for more information on the organisation of EDs in the Netherlands, we refer to Thijssen et al.) [18].

\section{Patients}

We retrieved the charts of all patients who visited the ED, were admitted to the internal medicine department (general ward, medium care or intensive care unit) from April 2011 until April 2012, and fulfilled the clinical criteria for sepsis, severe sepsis or septic shock (as defined during the International Sepsis Definitions Conference (SCCM) 2001) [19]. We included all patients with sepsis of any origin who received combination treatment with a single dose of gentamicin (aimed dose: $5 \mathrm{mg} / \mathrm{kg}$ ) and a broad-spectrum (B-lactam) antibiotic (usually amoxicillin/clavulanic acid 1000/200 mg q.i.d.) and all patients who were suspected to have pneumosepsis and did not receive gentamicin. This pneumosepsis group served as a control group because the empirical treatment of pneumosepsis in our hospital does not include aminoglycosides, irrespective of the severity of sepsis. By using these pneumosepsis patients as a control group we aimed to avoid confounding by indication. Patients were excluded if they were younger than 18 years of age, received concomitant renal replacement therapy, if no or only one creatinine value was available, if they received more than one dose of gentamicin, and if gentamicin was administered more than 24 hours after admission.

\section{Data collection}

All data was retrieved retrospectively from the ED charts and the electronic hospital database. The diagnosis sepsis and its severity in the ED was established by one and confirmed by a second investigator. Standardized scores were used to extract the data from the ED and hospital charts. We recorded date of visit, date of birth, gender, prior medical history, diseases potentially influencing renal function and risk factors, use of medications influencing or altering renal function (including angiotensin converting enzyme inhibitors (ACEI), angiotensin receptor blockers (ARB), diuretics, and 
non-steroidal anti-inflammatory drugs (NSAID)), exposure to intravenous iodinated contrast within 5 days of hospitalization, vital parameters, suspected focus, type of antibiotics administered at admission and 28-day mortality. Laboratory serum values (creatinine, urea) were determined before the moment of ED presentation, at the moment of ED presentation and followed for up to 14 days when available. To assess baseline renal function, creatinine values up to 3 months prior to ED presentation were retrieved. When these creatinine values were not available, we used the lowest creatinine value during admission as baseline creatinine [20,21]. The eGFR was calculated using the abbreviated modification of diet in renal disease (MDRD) formula. The suspected focus of sepsis on admission diagnosis was based on the conclusion in the ED chart and/or radiological findings. The shock index (SI) was defined as heart rate divided by systolic blood pressure, with a normal range of 0.5 to 0.7 in healthy adults [22]. Comorbidities, such as chronic kidney disease (CKD), chronic vascular disease (CVD), diabetes mellitus, and liver cirrhosis, as well as clinical symptoms, such as severity of sepsis, and dehydration, were considered potential risk factors for the development of AKI and were retrieved from the patients' charts. The diagnosis dehydration was based on clinical findings by the treating physician. The dose of gentamicin $(5 \mathrm{mg} / \mathrm{kg}$ ) was based on body weight. For obese patients $\left(\mathrm{BMI}>30 \mathrm{~kg} / \mathrm{m}^{2}\right)$, adjusted body weight was used to calculate the dose of gentamicin [13]. Twenty-eight-day mortality was defined as all-cause mortality within 28 days of admission.

\section{Outcome measures}

The primary endpoint of our study was occurrence of AKI, which was classified according to the risk, injury, failure, loss of function, and end stage renal disease (RIFLE) criteria using serum creatinine values [23]. The RIFLE criteria define three grades of severity of AKI (Risk, Injury, Failure) based on a relative increase of serum creatinine or a period of decreased urine output. Patients in whom serum creatinine increased 1.5 times were assigned to RIFLE Class $R$ (Risk), those in whom creatinine doubled to Class I (Injury), and those in whom creatinine tripled to Class F (Failure). In addition, two outcome criteria (Loss and End-stage renal disease) were defined as 4 weeks and 3 months of treatment with renal replacement therapy, respectively [24]. 
For patients without $\mathrm{AKI}$ on admission, $\mathrm{AKI}$ was defined as the development of $\mathrm{AKI}$ at any moment during follow up. For those who already had $\mathrm{AKI}$ on admission, worsening of AKI during follow up (i.e. a higher RIFLE classification relative to TO) was considered as AKI after admission.

To evaluate and describe renal function after admission, we used three categories: improved, worsened, and stable renal function during three different time periods (T1: 1-2 days, T2: 3-7 days, T3: 8-14 days after admission). When more than one creatinine value was available during a time period, the highest value was used for the analysis. We used the RIFLE criteria to define worsened renal function. To define improved renal function, we used the opposite of the RIFLE criteria: a creatinine decrease of $>33.3 \%$ compared to the creatinine on admission. Stable renal function was defined as $-33.3 \% \leq$ creatinine $\leq 50 \%$ compared to the creatinine on admission.

We tested for differences between the gentamicin group and the control group at baseline. For the analysis of renal function after admission, the patients were divided into four groups. First, two groups (AKI or no AKI on admission) were formed on the basis of their renal function on admission, to assess whether AKI on admission was a risk factor for the development or persistence of $\mathrm{AKI}$ after administration of a single dose of gentamicin. Each of these two groups was then further divided into two groups based on the administration of gentamicin, to evaluate the incidence of $A K I$ in each of the groups.

In addition to the above mentioned analyses in which the administration of gentamicin was placed central, we placed the occurrence of AKI (after admission) centrally and tested which possible risk factors (including the administration of gentamicin) played a role in the occurrence of AKI.

\section{Statistical analysis}

Statistical analysis was done using IBM SPSS version 22 (SPSS Inc., Chicago, IL, USA) software. Continuous variables were reported as mean \pm standard deviation or median (interquartile range), and categorical variables as proportions. Comparisons between two groups were made using unpaired$t$-test for continuous variables with Gaussian distribution, Mann-Whitney test for continuous non-Gaussian data and Pearson's chi-squared test for categorical data. Friedman's test was used to compare the course of median creatinine values in the four groups. Post hoc analysis was performed using 
a separate Wilcoxon signed-rank test and adjusted using the Bonferroni method. The log-rank test was used to test for differences in survival. A univariate regression model was used to test for clinical risk factors for the development of AKI after admission. Afterwards, a multivariate analysis of the clinical risk factors found in the univariate analysis was planned. Relative risks (RR) were calculated for a comparison between the groups with and without AKI after admission for categorical variables. Valid percentages were reported, since some creatinine values were missing during follow up. P-values $<0.05$ were considered statistically significant. For the analyses with Bonferroni adjustment, $\mathrm{p}$-values $<0.005$ were considered statistically significant.

\section{Ethical approval}

The protocol for this study was reviewed and approved by the Ethics Committee of the Maastricht University Medical Center.

\section{Results}

During the 12-month study period, a total of 341 consecutive patients with sepsis presented at the ED. Thirty-nine patients were excluded, due to concomitant use of renal replacement therapy (24), missing creatinine values (8), receiving more than one dose of gentamicin (6), and start of treatment with gentamicin later than 24 hours after admission (1). Of the remaining 302 patients, 179 patients were treated with a broad spectrum B-lactam antibiotic in combination with a single dose of gentamicin, and 123 patients with B-lactams or other antibiotics, but without gentamicin. These patients served as the control group.

The suspected focus of infection in the gentamicin group was in most cases the urinary tract $(n=49,27.4 \%)$, followed by the lower respiratory $(n=42$, $23.5 \%)$, the digestive $(n=19,10.6 \%)$ and the hepato-biliary tract $(n=19$, 10.6\%) (Table 1). These patients were treated with a single dose of $4.7 \mathrm{mg} /$ $\mathrm{kg} \pm 0.7$ (SD) gentamicin, in combination with a broad spectrum B-lactam antibiotic $(n=174,97.2 \%)$. The control group, that consisted of patients with pneumosepsis only, received mainly broad spectrum B-lactam antibiotics $(n=91,74.0 \%)$ and fluoroquinolones $(n=27,22.0 \%)$. 
Table 1. Baseline characteristics.

\begin{tabular}{|c|c|c|c|}
\hline & $\begin{array}{l}\text { Gentamicin group } \\
\mathrm{n}=179\end{array}$ & $\begin{array}{l}\text { Control group } \\
n=123\end{array}$ & P-value \\
\hline Male sex & $97(54.2)$ & $58(47.2)$ & 0.24 \\
\hline Age (years), mean \pm SD & $67 \pm 17$ & $69 \pm 16$ & 0.33 \\
\hline \multicolumn{4}{|l|}{ Focus of infection on admission } \\
\hline Urinary tract & $49(27.4)$ & & \\
\hline Lower respiratory tract & $42(23.5)$ & $123(100)$ & \\
\hline Digestive tract & $19(10.6)$ & & \\
\hline Hepato-biliary tract & $19(10.6)$ & & \\
\hline Skin and soft tissue & $15(8.4)$ & & \\
\hline Other & $7(3.9)$ & & \\
\hline Unknown & $28(15.7)$ & & \\
\hline \multicolumn{4}{|l|}{ Gentamicin } \\
\hline Dose of gentamicin (mg/kg), mean \pm SD & $4.7 \pm 0.7$ & n.a. & \\
\hline \multicolumn{4}{|l|}{ Disease severity } \\
\hline Sepsis & $73(40.8)$ & $58(47.2)$ & 0.29 \\
\hline Severe sepsis & $79(44.1)$ & $59(48.0)$ & 0.48 \\
\hline Septic shock & $27(15.1)$ & $6(4.9)$ & 0.005 \\
\hline Shock index (HR/SBP) & $1.05 \pm 0.32$ & $0.96 \pm 0.33$ & 0.44 \\
\hline ICU admission & $18(10.1)$ & $6(4.9)$ & 0.13 \\
\hline \multicolumn{4}{|l|}{ Comorbidities } \\
\hline CKD & $26(14.5)$ & $22(17.9)$ & 0.43 \\
\hline CVD & $82(45.8)$ & $70(56.9)$ & 0.06 \\
\hline Diabetes mellitus & $40(22.3)$ & $22(17.9)$ & 0.39 \\
\hline Liver cirrhosis & $9(5.0)$ & $4(3.3)$ & 0.57 \\
\hline Dehydration & $69(38.5)$ & $37(30.1)$ & 0.14 \\
\hline \multicolumn{4}{|l|}{ Renal function influencing medication } \\
\hline ACEI/ARB & $47(26.3)$ & $37(30.1)$ & 0.51 \\
\hline NSAID & $17(9.6)$ & $6(4.9)$ & 0.19 \\
\hline Diuretics & $54(30.2)$ & $36(29.3)$ & 1.0 \\
\hline Intravenous contrast & $17(9.5)$ & $3(2.5)$ & 0.02 \\
\hline \multicolumn{4}{|l|}{ Kidney function } \\
\hline Baseline creatinine ( $\mu m o l / I)$, median (IQR) & $82(67-103)$ & $82(63-107)$ & 0.67 \\
\hline Baseline eGFR (MDRD) $\left(\mathrm{ml} / \mathrm{min} / 1.73 \mathrm{~m}^{2}\right)$, mean $\pm \mathrm{SD}$ & $81 \pm 57$ & $75 \pm 35$ & 0.40 \\
\hline Creatinine on admission ( $\mu \mathrm{mol} / \mathrm{I})$, median (IQR) & $108(77-167)$ & $96(70-132)$ & 0.02 \\
\hline AKI on admission, by RIFLE class & $48(26.8)$ & $20(16.3)$ & 0.04 \\
\hline Risk & $18(10.1)$ & $15(12.2)$ & 0.58 \\
\hline Injury & $16(8.9)$ & $3(2.4)$ & 0.03 \\
\hline Failure & $14(7.8)$ & $2(1.6)$ & 0.02 \\
\hline Urea on admission (mmol/l), mean $\pm \mathrm{SD}$ & $11.6 \pm 12.4$ & $8.7 \pm 6.4$ & 0.03 \\
\hline \multicolumn{4}{|l|}{ Mortality } \\
\hline 28-day mortality & $24(13.4)$ & $17(13.8)$ & 0.93 \\
\hline
\end{tabular}

Data are presented in absolute numbers (percentage) unless otherwise indicated. HR, heart rate; SB, systolic blood pressure; ICU, intensive care unit; CKD, chronic kidney disease; CVD, chronic vascular disease; ACEI, ACE inhibitor; ARB, angiotensin receptor blocker; NSAID, nonsteroidal anti-inflammatory drug; IQR, interquartile range; eGFR, estimated glomerular filtration rate; MDRD, modification of diet in renal disease; AKI, acute kidney injury; RIFLE classification, $\mathrm{R}=$ Risk, $\mathrm{I}=$ Injury, $\mathrm{F}=$ Failure, $\mathrm{L}=$ Loss, $\mathrm{E}=$ End stage renal disease . 
The gentamicin group more often had septic shock compared to the control group ( 15.1 vs. $4.9 \%, p=0.005$ ), and in this group, intravenous iodinated contrast was administered more frequently compared to the control group ( 9.5 vs. $2.5 \%, p=0.02$ ).

\section{Renal function}

Creatinine levels were higher on admission compared to baseline (TO) in all four groups (gentamicin group with or without AKI on admission, control group with or without $\mathrm{AKI}$ on admission, $\mathrm{p}<0.001$ for all comparisons) (Figure 1). After 8-14 days of admission (T3), these values normalised towards baseline in all groups, including the two groups that received gentamicin (T0 vs. T3, $p<0.003$ ), except for the control group without AKI on admission $(p=0.03)$. AKI on admission was present in 68 patients $(22.5 \%)$ and more often in the gentamicin (26.8\%) than in the control group (16.3\%, $p=0.04$ ) (Table 1 ).

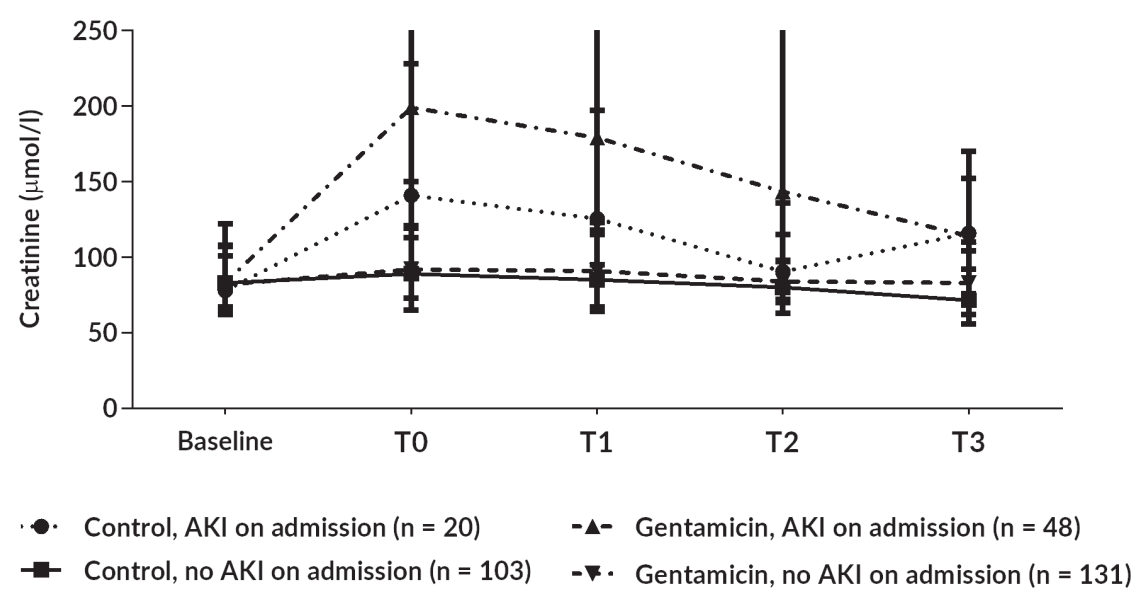

Figure 1. Median serum creatinine levels over a 14 day period

Baseline, most recent serum creatinine value before admission, or, if not available, lowest creatinine value during hospitalisation. T0, on admission; T1, 1-2 days; T2, 3-7 days; T3, 8-14 days after admission. Gentamicin, gentamicin treatment group, Control; control group; AKI, acute kidney injury.

After admission, AKI occurred in 12 patients (6.7\%) in the gentamicin and in 4 patients (3.3\%) in the control group ( $p=0.30$ ) (Table 2). The severity of AKI was comparable in both groups. When AKI occurred after admission, it occurred within 48 hours in the majority of patients (75.0\%). 
Table 2. Renal function over time

\begin{tabular}{llll}
\hline & $\begin{array}{l}\text { Gentamicin group } \\
\mathbf{n}=\mathbf{1 7 9}\end{array}$ & $\begin{array}{l}\text { Control group } \\
\mathbf{n}=123\end{array}$ & P-value \\
\hline $\begin{array}{l}\text { AKI on admission (T0), RIFLE class } \\
(\mathbf{n}=\mathbf{6 8 )}\end{array}$ & $48(26.8)$ & $20(16.3)$ & 0.04 \\
Risk & $18(10.1)$ & $15(12.2)$ & 0.58 \\
Injury & $16(8.9)$ & $3(2.4)$ & 0.03 \\
Failure & $14(7.8)$ & $2(1.6)$ & 0.02
\end{tabular}

AKI after admission (T1 - T3), RIFLE class

$(n=16)$

Risk

Failure
$12(6.7)$

$4(2.2)$

$5(2.8)$

$3(1.7)$

Renal function over time (compared to T0) $n=48$

AKI on admission $(n=68)$

$\mathrm{T} 1$ ( $\mathrm{n}=66$ )

Improved
Stable
Worsened

$\mathrm{T} 2$ ( $\mathrm{n}=53$ )

Improved

Stable

Worsened

T3 ( $\mathrm{n}=32$ )

Improved

Stable

Worsened

No AKI on admission ( $n=234)$

$\mathrm{T} 1$ ( $\mathrm{n}=204$ )

Improved

Stable

Worsened

T2 ( $=$ 174)

Improved

Stable

Worsened

T3 ( $\mathrm{n}=89$ )

Improved

Stable

Worsened
$11 / 46$ (23.9)

$31 / 46(67.4)$

4/46 (8.7)

21/37 (56.8)

$12 / 37$ (32.4)

4/37 (10.8)

$16 / 25$ (64.0)

$8 / 25$ (32.0)

$1 / 25$ (4.0)

$n=131$

4/117 (3.4)

108/117 (92.3)

5/117 (4.3)

$5 / 96(5.2)$

$88 / 96$ (91.7)

3/96 (3.1)

2/51 (3.9)

47/51 (92.2)

2/51 (3.9)

$\begin{array}{ll}4(3.3) & 0.30 \\ 3(2.4) & 1.0 \\ 1(0.8) & 0.41 \\ 0 & 0.27\end{array}$

$n=20$

Values are given as $N(\%)$. AKI, acute kidney injury; RIFLE classification, $R=$ Risk, I = Injury, F = Failure, $L=$ Loss, $E$ = End stage renal disease; TO, on admission; T1, 1-2 days; T2, 3-7 days; T3, 8-14 days after admission. 
There were no differences in incidence and severity of AKI after admission between the gentamicin and the control group, even when AKI on admission was present (Table 2). Of the 68 patients with AKI on admission, renal function worsened in 4 of the 46 patients $(8.7 \%)$ of the gentamicin group with known creatinine values, and in none of the patients of the control group $(p=0.31)$. At the end of follow up, the majority of patients with AKI on admission returned to their baseline renal function. In the group without AKI on admission $(n=234), 8(6.1 \%)$ in the gentamicin and $4(3.9 \%)$ patients in the control group developed AKI after admission ( $p=0.56)$. Two (3.9\%) patients still had AKI after 8-14 days in the gentamicin compared to none in the control group $(p=0.51)$. There was no difference in the level of renal function at admission and at end of follow-up in most patients.

Comparing the 16 patients with AKI after admission with the 286 patients without $\mathrm{AKI}$ after admission, we found that gentamicin was administered in $75.0 \%$ of the patients with $\mathrm{AKI}$ and in $58.4 \%$ in the group without $\mathrm{AKI}$ ( $p=0.30$, Table 3). We further found that septic shock was more often present in those with AKI (31.2 vs. 9.8\%, respectively, $p=0.02)$ with a relative risk of 3.7 ( $95 \%$ confidence interval $(\mathrm{CI}) 1.4-10.0)$. More patients with AKI were admitted to the ICU (31.2\% vs. 6.6\%, p=0.005) (RR 5.3 (95\% Cl $2.0-14.0)$ ), and 28day mortality was higher than in those without AKI after admission (37.5 vs. $12.2 \%$, respectively, $p=0.001$ ). We found no other differences between these groups. A multivariate analysis was not considered beneficial, since septic shock and ICU admissions were considered to be not independent of each other.

During follow up, some creatinine values were missing. Slightly more values were missing at the end of follow up in the two groups without $A K I$ on admission (61.1\% in the gentamicin vs. $63.1 \%$ in the control group), compared to the two groups with $\mathrm{AKI}$ on admission (47.9\% in the gentamicin vs. $65.0 \%$ in the control group). 
Table 3. Clinical risk factors for AKI after admission.

\begin{tabular}{|c|c|c|c|c|}
\hline & $\begin{array}{l}\text { AKI after } \\
\text { admission } \\
\mathrm{n}=16\end{array}$ & $\begin{array}{l}\text { No AKI after } \\
\text { admission } \\
\mathrm{n}=286\end{array}$ & P-value & $\operatorname{RR}(95 \% \mathrm{Cl})$ \\
\hline Male sex & $8(50.0)$ & $147(51.4)$ & 1.0 & $0.9(0.4-2.5)$ \\
\hline Age (years), mean \pm SD & $68 \pm 10$ & $68 \pm 17$ & 0.98 & \\
\hline \multicolumn{5}{|l|}{ Gentamicin } \\
\hline Administration of gentamicin & $12(75.0)$ & $167(58.4)$ & 0.30 & $2.0(0.7-6.2)$ \\
\hline Dose of gentamicin (mg/kg), mean \pm SD & $4.4 \pm 0.7$ & $4.7 \pm 0.7$ & 0.16 & \\
\hline \multicolumn{5}{|l|}{ Disease severity } \\
\hline Severe sepsis & $5(31.2)$ & $133(46.5)$ & 0.31 & $1.9(0.7-5.2)$ \\
\hline Septic shock & $5(31.2)$ & $28(9.8)$ & 0.02 & $3.7(1.4-10.0)$ \\
\hline Shock index (HR/SBP) & $1.34 \pm 0.40$ & $1.02 \pm 0.31$ & 0.08 & \\
\hline ICU admission & $5(31.2)$ & $19(6.6)$ & 0.005 & $5.3(2.0-14.0)$ \\
\hline \multicolumn{5}{|l|}{ Comorbidities } \\
\hline CKD & $3(18.8)$ & $45(15.7)$ & 0.73 & $1.2(0.4-4.1)$ \\
\hline CVD & $10(62.5)$ & $142(49.7)$ & 0.44 & $1.6(0.6-4.4)$ \\
\hline Diabetes mellitus & $1(6.2)$ & $61(21.3)$ & 0.21 & $0.3(0.1-1.9)$ \\
\hline Liver cirrhosis & $2(12.5)$ & $11(3.8)$ & 0.15 & $3.1(0.8-12.5)$ \\
\hline Dehydration & $6(37.5)$ & $100(35.0)$ & 0.80 & $1.1(0.4-3.0)$ \\
\hline \multicolumn{5}{|l|}{ Renal function influencing medication } \\
\hline ACEI/ARB & $5(31.2)$ & $79(27.6)$ & 0.78 & $1.2(0.4-3.3)$ \\
\hline NSAID & $2(12.5)$ & $21(7.4)$ & 0.35 & $1.7(0.4-7.1)$ \\
\hline Diuretics & $5(31.2)$ & $85(29.7)$ & 1.0 & $1.0(0.4-3.0)$ \\
\hline Intravenous contrast & $2(12.5)$ & $18(6.3)$ & 0.29 & $2.0(0.5-8.2)$ \\
\hline \multicolumn{5}{|l|}{ Kidney function } \\
\hline Baseline creatinine ( $\mu \mathrm{mol} / \mathrm{I})$, median (IRQ) & $73(65-88)$ & $83(65-106)$ & 0.23 & \\
\hline Baseline eGFR (MDRD) (ml/min/1.73m²), mean \pm SD & $85 \pm 30$ & $78 \pm 50$ & 0.64 & \\
\hline Creatinine on admission ( $\mu \mathrm{mol} / \mathrm{I})$, median (IRQ) & $76(68-155)$ & $102(77-146)$ & 0.38 & \\
\hline AKI on admission, by RIFLE class & $4(25.0)$ & $49(17.1)$ & 0.50 & $1.2(0.4-3.7)$ \\
\hline Risk & $1(6.2)$ & $25(8.7)$ & 1.0 & $0.5(0.1-4.1)$ \\
\hline Injury & $1(6.2)$ & $12(4.2)$ & 1.0 & $1.0(0.1-7.9)$ \\
\hline Failure & $2((12.5)$ & $12(4.2)$ & 0.17 & $2.8(0.6-13.4)$ \\
\hline Urea on admission (mmol/L), mean $\pm \mathrm{SD}$ & $12.2 \pm 21.7$ & $10.5 \pm 9.8$ & 0.55 & \\
\hline \multicolumn{5}{|l|}{ Mortality } \\
\hline 28-day mortality & $6(37.5)$ & $35(12.2)$ & 0.001 & \\
\hline
\end{tabular}

Data are presented in absolute numbers (percentage) unless otherwise indicated. AKI, acute kidney injury; RR, relative risk with (95\% confidence intervals); HR, heart rate; SB, systolic blood pressure; ICU, intensive care unit; CKD, chronic kidney disease; CVD, chronic vascular disease; ACEI, ACE inhibitor; ARB, angiotensin receptor blocker; NSAID, non-steroidal anti-inflammatory drug; IQR, interquartile range; eGFR, estimated glomerular filtration rate; MDRD, modification of diet in renal disease; RIFLE classification, $R=$ Risk, I = Injury, $F=$ Failure, $\mathrm{L}=$ Loss, $\mathrm{E}=$ End stage renal disease. 


\section{Discussion}

To our knowledge, this is the first study investigating the incidence of AKI after administration of a single dose of gentamicin in patients with sepsis in the ED. We found no increased risk of AKI after a single dose of gentamicin. The incidence of AKI after admission was low in both the gentamicin and the control group (6.7 vs. $3.3 \%, p=0.30$ ) and $A K I$ often occurred within 48 hours (in $75.0 \%$ of the patients). Only septic shock was found to be a clinical risk factor for developing AKI after admission. At the end of follow up, renal function recovered in about two thirds of the patients with AKI on admission, and was stable in $90 \%$ of those without AKI on admission. This recovery was seen irrespective of treatment with gentamicin, and irrespective of the presence of $\mathrm{AKI}$ at presentation.

Although AKI was often present at admission in patients with sepsis (22.5\%), like in other studies [25-28], the outcome was favourable in most patients. However, 28-day mortality was higher in patients with, than in those without $\mathrm{AKI}$ after admission (37.5 vs. $12.2 \%$, respectively, $\mathrm{p}=0.001$ ).

We found no association between the administration of gentamicin and the development of AKI. The development of AKI is most likely multifactorial, which is illustrated by our analysis of clinical risk factors. Septic shock was more often present in patients with $\mathrm{AKI}$ after admission, compared to patients without AKI after admission (31.2 vs. 9.8\%, $\mathrm{p}=0.02$ ). The same applied to ICU admissions (31.2 vs. 6.6\%, p=0.005). Because these two variables, as well as the shock index, are so closely related to each other, it was not meaningful to test these variables in a multivariate analysis. This multifactorial development of AKI was observed in other studies as well, where AKI occurred frequently in patients with sepsis due to a variety of factors, including hypotension, shock, and hypovolemia [4, 6, 29].

Patients in the gentamicin group were probably in a worse condition than the controls. This is illustrated by the fact that septic shock was more prevalent in patients in the gentamicin group (15.1 vs. 4.9\%, $p=0.005$ ) and that their renal function at admission was worse (higher serum creatinine and urea). Also, they more frequently received intravenous iodinated contrast within 5 days of hospitalization ( 9.5 vs. $2.5 \%, p=0.02$ ). This finding could explain the higher 28-day mortality in the gentamicin group. It is probable that patients received gentamicin because their clinical condition at presentation 
was worse. However, when comparing these patients who are even more susceptible to nephrotoxic stimuli with the patients in the control group, we found no difference in the incidence of AKI after administration of a single dose of gentamicin. We hoped to avoid this selection by choosing patients with pneumosepsis as a control group, because the decision not to administer gentamicin to these patients is taken irrespective of the severity of sepsis. Despite our local guidelines, $23.5 \%$ of patients receiving gentamicin had a respiratory tract infection as focus of sepsis. Most probably, the choice to administer gentamicin is a consequence of the Surviving Sepsis Campaign, which recommends administration of broad spectrum antibiotics in combination with gentamicin within one hour after arrival at the ED [30]. At that time the focus of infection will not always be clear immediately, and before the focus has been found gentamicin is administered.

The follow up of renal function was not complete. The number of missing values was slightly higher in the two groups without AKI on admission, compared to the two groups with AKI on admission, without large differences between the gentamicin and the control group. These missing values are probably the result of discharge of patients who recover from AKI or the fact that patients with a favourable course are not followed up as rigorously as patients who are in a worse condition. This may lead to an overestimation of the incidence of AKI.

There are some other limitations to our study. First, although conducted in an average sized hospital during one year and although more than 300 patients were included, the number of cases with AKI was small, and smaller than we expected. To confirm our findings, combination of our data with those of others might solve this problem. In case of an RCT, assuming we would find the same incidence of $A K I$ in both the control group, as well as in the group with gentamicin patients, an estimated 1280 patients would be needed (power 0.8, $\alpha$ 0.05). This is true, if we would find a doubling of the incidence of AKI after the administration of a single dose of gentamicin relevant, which is open for debate. However, an RCT on the renal safety of unpatented aminoglycosides will not easily be executed because of the costs. 
Furthermore, we had to rely on the accuracy of the charts, and therefore, some information was missing. However, this problem applied to both the gentamicin and the control group. Considering the limitations, this study should be seen as a first exploration of the safety of a single dose of gentamicin with regard to renal function.

We did not measure trough/peak concentrations of gentamicin, for we only administer a single dose of gentamicin. In a future study, measuring these concentrations would be interesting to assess a possible dose dependency.

In conclusion, despite the frequent use of gentamicin in the ED and the known risk of nephrotoxicity, evidence was lacking about the renal safety of a single dose of gentamicin in patients with sepsis. We found that the occurrence of AKI was not associated with the administration of a single dose of gentamicin but with the presence of septic shock. When AKI occurred, it was reversible in most cases, even when patients already had $\mathrm{AKI}$ at presentation.

\section{Acknowledgement}

We want to thank Paul Heuvelmans for his contributions to the data collection. 


\section{References}

1. Kumar A, Safdar N, Kethireddy S, Chateau D. A survival benefit of combination antibiotic therapy for serious infections associated with sepsis and septic shock is contingent only on the risk of death: a meta-analytic/meta-regression study. Critical care medicine. 2010;38(8):1651-64.

2. Tangden T. Combination antibiotic therapy for multidrug-resistant Gram-negative bacteria. Upsala journal of medical sciences. 2014;119(2):149-53.

3. Lacy MK, Nicolau DP, Nightingale CH, Quintiliani R. The pharmacodynamics of aminoglycosides. Clinical infectious diseases : an official publication of the Infectious Diseases Society of America. 1998;27(1):23-7.

4. Lopez-Novoa JM, Quiros Y, Vicente L, Morales AI, Lopez-Hernandez FJ. New insights into the mechanism of aminoglycoside nephrotoxicity: an integrative point of view. Kidney international. 2011;79(1):33-45.

5. Meyer RD. Risk factors and comparisons of clinical nephrotoxicity of aminoglycosides. The American journal of medicine. 1986;80(6b):119-25.

6. Moore RD, Smith CR, Lipsky JJ, Mellits ED, Lietman PS. Risk factors for nephrotoxicity in patients treated with aminoglycosides. Annals of internal medicine. 1984;100(3):352-7.

7. Leehey DJ, Braun BI, Tholl DA, Chung LS, Gross CA, Roback JA, et al. Can pharmacokinetic dosing decrease nephrotoxicity associated with aminoglycoside therapy. Journal of the American Society of Nephrology : JASN. 1993;4(1):81-90.

8. Martinez-Salgado C, Lopez-Hernandez FJ, Lopez-Novoa JM. Glomerular nephrotoxicity of aminoglycosides. Toxicology and applied pharmacology. 2007;223(1):86-98.

9. Nagai J, Takano M. Molecular aspects of renal handling of aminoglycosides and strategies for preventing the nephrotoxicity. Drug metabolism and pharmacokinetics. 2004;19(3):159-70.

10. Rodriguez-Barbero A, Lopez-Novoa JM, Arevalo M. Involvement of platelet-activating factor in gentamicin nephrotoxicity in rats. Experimental nephrology. 1997;5(1):47-54.

11. Ferriols-LisartR, Alos-Alminana M.Effectiveness and safety of once-daily aminoglycosides: a meta-analysis. American journal of health-system pharmacy : AJHP : official journal of the American Society of Health-System Pharmacists. 1996;53(10):1141-50.

12. Barza M, loannidis JP, Cappelleri JC, Lau J. Single or multiple daily doses of aminoglycosides: a meta-analysis. BMJ. 1996;312(7027):338-45.

13. Nicolau DP, Freeman CD, Belliveau PP, Nightingale CH, Ross JW, Quintiliani R. Experience with a once-daily aminoglycoside program administered to 2,184 adult patients. Antimicrobial agents and chemotherapy. 1995;39(3):650-5.

14. Turnidge J. Pharmacodynamics and dosing of aminoglycosides. Infectious disease clinics of North America. 2003;17(3):503-28, v.

15. Cosgrove SE, Vigliani GA, Fowler VG, Jr., Abrutyn E, Corey GR, Levine DP, et al. Initial lowdose gentamicin for Staphylococcus aureus bacteremia and endocarditis is nephrotoxic. Clinical infectious diseases : an official publication of the Infectious Diseases Society of America. 2009;48(6):713-21.

16. Buijk SE, Mouton JW, Gyssens IC, Verbrugh HA, Bruining HA. Experience with a oncedaily dosing program of aminoglycosides in critically ill patients. Intensive care medicine. 2002;28(7):936-42. 
17. Bell S, Davey P, Nathwani D, Marwick C, Vadiveloo T, Sneddon J, et al. Risk of AKI with gentamicin as surgical prophylaxis. Journal of the American Society of Nephrology: JASN. 2014;25(11):2625-32.

18. Thijssen WA, Giesen PH, Wensing M. Emergency departments in The Netherlands. Emergency medicine journal : EMJ. 2012;29(1):6-9.

19. Levy MM, Fink MP, Marshall JC, Abraham E, Angus D, Cook D, et al. 2001 SCCM/ESICM/ ACCP/ATS/SIS International Sepsis Definitions Conference. Critical care medicine. 2003;31(4):1250-6.

20. Pickering JW, Endre ZH. Back-calculating baseline creatinine with MDRD misclassifies acute kidney injury in the intensive care unit. Clinical journal of the American Society of Nephrology : CJASN. 2010;5(7):1165-73.

21. Hoste EA, Clermont G, Kersten A, Venkataraman R, Angus DC, De Bacquer D, et al. RIFLE criteria for acute kidney injury are associated with hospital mortality in critically ill patients: a cohort analysis. Critical care (London, England). 2006;10(3):R73.

22. M A, C B. Shockindex. Dtsch Med Wochenschr. 1967;46:1-10.

23. Bellomo R, Ronco C, Kellum JA, Mehta RL, Palevsky P. Acute renal failure - definition, outcome measures, animal models, fluid therapy and information technology needs: the Second International Consensus Conference of the Acute Dialysis Quality Initiative (ADQI) Group. Critical care (London, England). 2004;8(4):R204-12.

24. Hoste EA, Schurgers M. Epidemiology of acute kidney injury: how big is the problem? Critical care medicine. 2008;36(4 Suppl):S146-51.

25. Lopes JA, Jorge S, Resina C, Santos C, Pereira A, Neves J, et al. Acute renal failure in patients with sepsis. Critical care (London, England). 2007;11(2):411.

26. Rangel-Frausto MS, Pittet D, Costigan M, Hwang T, Davis CS, Wenzel RP. The natural history of the systemic inflammatory response syndrome (SIRS). A prospective study. JAMA. 1995;273(2):117-23.

27. Wang X, Jiang L, Wen Y, Wang MP, Li W, Li ZQ, et al. Risk factors for mortality in patients with septic acute kidney injury in intensive care units in Beijing, China: a multicenter prospective observational study. BioMed research international. 2014;2014:172620.

28. Neveu H, Kleinknecht D, Brivet F, Loirat P, Landais P. Prognostic factors in acute renal failure due to sepsis. Results of a prospective multicentre study. The French Study Group on Acute Renal Failure. Nephrology, dialysis, transplantation : official publication of the European Dialysis and Transplant Association - European Renal Association. 1996;11(2):293-9.

29. Annane D, Bellissant E, Cavaillon JM. Septic shock. Lancet. 2005;365(9453):63-78.

30. Levy MM, Dellinger RP, Townsend SR, Linde-Zwirble WT, Marshall JC, Bion J, et al. The Surviving Sepsis Campaign: results of an international guideline-based performance improvement program targeting severe sepsis. Critical care medicine. 2010;38(2):367-74. 




\section{Chapter 4}

\section{Renal safety of a single dose of gentamicin in patients with sepsis in the emergency department}

M. Cobussen ${ }^{1,2,3}$, M.B. Haeseker ${ }^{1,4}$, J. Stoffers ${ }^{5,6}$, V.H.M. Wanrooij ${ }^{5,6}$, P.H.M. Savelkoul ${ }^{1,2}$, P.M. Stassen ${ }^{2,5}$

${ }^{1}$ Department of Medical Microbiology, Maastricht University Medical Center, Maastricht, the Netherlands.

${ }^{2}$ CAPHRI School for Public Health and Primary Care, Faculty of Health, Medicine and Life Sciences, Maastricht University, Maastricht, the Netherlands.

${ }^{3}$ Department of Internal Medicine, Rijnstate Hospital, Arnhem, the Netherlands

${ }^{4}$ Department of Medical Microbiology, ReinierHaga Medical Diagnostic Center, Delft, the Netherlands.

${ }^{5}$ Department of Internal Medicine, Division of General Medicine, Section Acute Medicine, Maastricht University Medical Center, Maastricht, the Netherlands.

${ }^{6}$ Department of Internal Medicine, Zuyderland Medical Center, Heerlen, the Netherlands 


\section{Abstract}

\section{Objectives}

To determine the effect of a single dose of gentamicin on the incidence and persistence of acute kidney injury (AKI) in patients with sepsis in the emergency department (ED).

\section{Methods}

We retrospectively enrolled patients with sepsis in the ED in three hospitals. Local antibiotic guidelines recommended a single dose of gentamicin as part of empirical therapy in selected patients in one hospital, whereas the other two hospitals did not. Multivariate analysis was used to evaluate the effect of gentamicin and other potential risk factors on the incidence and persistence of AKI after admission. AKI was defined according to the KDIGO criteria.

\section{Results}

Of 1573 patients, $571 / 1573$ (36.3\%) received a single dose of gentamicin. At admission, $181 / 571(31.7 \%)$ of the gentamicin and 228/1002 $(22.8 \%)$ of the non-gentamicin patients had AKI ( $p<0.001)$. After admission, AKI occurred in $64 / 571$ (11.2\%) of the gentamicin and in 82/1002 (8.2\%) of the control group $(p=0.06)$. Multivariate analysis showed that shock (OR $2.72(95 \% \mathrm{Cl}, 1.31-$ 5.67)), diabetes mellitus (OR $1.49(95 \% \mathrm{Cl}, 1.001-2.23))$, and higher baseline (i.e. pre-admission) serum creatinine (OR $1.007(95 \% \mathrm{Cl}, 1.005-1.009))$ were associated with the development of AKI after admission, but not gentamicin (OR $1.29(95 \% \mathrm{Cl}, 0.89-1.86))$. Persistent AKI was rare in both the gentamicin $(16 / 260(6.2 \%))$ and the non-gentamicin group (15/454 (3.3\%), $p=0.09)$.

\section{Conclusions}

Our study shows that a single dose of gentamicin in patients with sepsis in the ED is safe with regard to renal function. The development of AKI after admission was associated with shock, diabetes mellitus, and a higher baseline creatinine. 


\section{Introduction}

Combination therapy of beta-lactam antibiotics and aminoglycosides is widely used in the empirical therapy of sepsis to broaden the Gram negative spectrum [1, 2]. However, the use of aminoglycosides in sepsis is debated, mostly because of nephrotoxic side effects [3-5].

These nephrotoxic side effects result from accumulation of aminoglycosides in the kidney and can lead to acute kidney injury (AKI). This effect is dose and frequency dependent and increases with accumulated doses [6]. When AKI occurs in patients with sepsis treated with aminoglycosides, the origin of AKI is usually multifactorial and in most patients persistent renal impairment is rare $[5,7]$.

Previous research showed ambivalent results regarding the development of aminoglycosides-associated AKI. Some studies report a high risk of AKI, whereas others found no association [4, 7, 8]. Most of these studies were performed in ICU patients, which are the most severely ill and are more often in shock. Possibly, the results of the ICU studies cannot be extrapolated to ED patients, because the spectrum of sepsis as seen in the ED may differ.

It is important to establish the safety of aminoglycosides with respect to $\mathrm{AKI}$, as with increasing antibiotic resistance, the options for appropriate empirical antibiotic therapy with a beta-lactam antibiotic alone are becoming fewer $[9,10]$. Especially the low resistance levels will possibly increase the role of aminoglycosides in sepsis in the future era with increasing antibiotic resistance.

The aim of our study was to determine the effect of a single dose of gentamicin on the incidence and persistence of $\mathrm{AKI}$ in patients with sepsis in the ED. 


\section{Methods}

\section{Study design}

We performed a retrospective cohort study in three large teaching hospitals (Maastricht University Medical Center (MUMC) (Hospital A), Rijnstate Hospital (Hospital B), and Zuyderland Medical Center (Hospital C)). Patients were enrolled between January 2015 and December 2016 (Hospital A) and between July and December 2015 (Hospitals B and C).

Local antibiotic policies differed between the three hospitals with respect to the administration of gentamicin; in Hospital A, patients with sepsis of unknown origin (or those with suspected urinary tract or hepato-biliary tract infection) received amoxicillin/clavulanic acid plus gentamicin $(5 \mathrm{mg} / \mathrm{kg})$ as empirical therapy. Dosing of gentamicin was based on body weight. For obese patients $\left(\mathrm{BMI}>30 \mathrm{~kg} / \mathrm{m}^{2}\right)$, adjusted body weight was used [11]. In Hospitals B and $C$, patients received a cephalosporin (plus metronidazole in suspected digestive tract infections). In all hospitals, subsequent antibiotic therapy was guided on culture results.

\section{Study population}

Patients $\geq 18$ years of age with sepsis, according to either SIRS, qSOFA, or SOFA, who were admitted through the ED to the internal medicine department or ICU were included. Patients were excluded if they had a postrenal cause of $\mathrm{AKI}$ at presentation or during follow up, received concomitant renal replacement therapy (RRT) before the onset of the sepsis episode, received gentamicin later on during their admission, or if no creatinine values were available at the time of admission.

\section{Renal function}

To assess pre-existing baseline renal function, creatinine values up to 3 months prior to ED presentation were retrieved. When these were not available, we used the lowest creatinine value during three months follow up as baseline creatinine $[12,13]$.

The primary outcome of our study was the incidence of AKI within the first week of admission. AKI was classified according to the KDIGO (Kidney Disease Improving Global Outcomes) criteria [14]. These define three stages of AKI (stage 1-3). When serum creatinine increased 1.5 times relative to baseline creatinine, or rose by $\geq 26 \mu \mathrm{mol} / \mathrm{l}$, patients were assigned to stage 1 . 
They were assigned to stage 2 when creatinine doubled and to stage 3 when either serum creatinine tripled, creatinine was $\geq 353 \mu \mathrm{mol} / \mathrm{l}$, or when RRT was initiated. When more than one creatinine value was available, the highest value was used for the analysis. When creatinine values were not available in the first week, these patients were classified as having no AKI [15]. Persistent AKI was defined as at least KDIGO stage 1 during the second week after admission.

\section{Data collection}

All data were retrieved from the electronic hospital charts. Standardised scoring forms were used to extract baseline characteristics, vital parameters, SIRS, qSOFA, and SOFA criteria [16, 17]. According to the SOFA criteria, sepsis was defined when a patient met $\geq 2$ criteria for organ failure. Shock was defined as sepsis accompanied by a lactate $>2 \mathrm{mmol} / \mathrm{l}$ and the need of vasopressors to maintain a MAP $\geq 65 \mathrm{mmHg}$. At presentation at the $E D$, the pre-existing SOFA score was assumed to be zero [18]. Furthermore, risk factors for development of $\mathrm{AKI}$, such as diseases potentially influencing renal function and the use of renal function influencing drugs were retrieved. In addition, 30-day all-cause mortality was retrieved.

\section{Sample size}

A sample size calculation was performed using the findings of our previous study [7]. A sample size of 1383 patients would allow us to detect a significant difference of AKI between the two groups, with $80 \%$ power and $5 \%$ significance.

\section{Statistical analysis}

Statistical analysis was done using IBM SPSS version 22 (SPSS Inc., USA) and GraphPad Prism 6.0 (GraphPad Software Inc., USA). Continuous variables were reported as median (interquartile range (IQR)) and categorical variables as proportions. Comparisons between two groups were made using the MannWhitney test for continuous and Pearson's chi-squared test for categorical data. The log-rank test was used to test for differences in survival.

We made three comparisons to evaluate differences in baseline characteristics and to assess the development of AKI. First, baseline characteristics and renal function were compared between Hospital A and Hospitals B and C. Second, the incidence of AKI was compared between patients with gentamicin (Hospital 
A) and without gentamicin (all Hospitals). Third, we compared patients treated with gentamicin (Hospital A), with patients treated without gentamicin (Hospitals B and C), to explore potential confounding by indication.

Then, we focused on the development of AKI after admission and used a univariate regression analysis to test for risk factors for AKI. Subsequently, multiple regression analysis was performed using variables with an entry criterion of $p<0.05$. When risk factors showed collinearity, we included only one variable. The performance of the model was evaluated with explained variances (Nagelkerke $\mathrm{R}^{2}$ ), calibration (Hosmer-Lemeshow test), and discrimination (area under the receiver operating characteristic (AUROC) curve) measures. Linear regression analysis was performed to test for differences in serum creatinine concentrations over time between the two groups with $\mathrm{AKI}$ on admission (gentamicin vs. no gentamicin). P-values $<0.05$ were considered statistically significant.

\section{Ethical approval}

The Ethics Committees of all hospitals approved this study and waived informed consent (METC 13-4-103.12).

\section{Results}

In total, 1573 patients were included; 1090 in Hospital A, 359 in Hospital B, and 124 in Hospital C (Supplementary Figure 1). In Hospital A, 571/1090 (52.4\%) patients received a single dose of gentamicin with a median dose of $5.1 \mathrm{mg} / \mathrm{kg}$ (4.6-6.0) (Table 1).

The proportion of patients with a qSOFA score $\geq 2$, sepsis and shock were equally prevalent in all hospitals (Table 1 ) as were the number of ICU admissions. Baseline creatinine and creatinine on admission were highest in Hospital A. 
Table 1. Clinical characteristics of sepsis patients per hospital

\begin{tabular}{|c|c|c|c|}
\hline & $\begin{array}{l}\text { Hospital A } \\
\mathrm{n}=1090\end{array}$ & $\begin{array}{l}\text { Hospitals B and C } \\
n=483\end{array}$ & P-value \\
\hline Male sex & $599(55.0)$ & $237(49.1)$ & 0.03 \\
\hline Age (years) & $69(57-79)$ & $71(58-81)$ & 0.049 \\
\hline $\mathrm{BMI}\left(\mathrm{kg} / \mathrm{m}^{2}\right)$ & $25.0(21.8-29.1)$ & $25.9(22.7-29.8)$ & 0.01 \\
\hline \multicolumn{4}{|l|}{ Comorbidities } \\
\hline Myocardial infarction & $107(9.9)$ & $49(10.1)$ & 0.93 \\
\hline Heart failure & $85(7.8)$ & $61(12.6)$ & 0.003 \\
\hline Peripheral arterial disease & $142(13.2)$ & $70(14.5)$ & 0.52 \\
\hline CVA & $151(13.9)$ & $83(17.2)$ & 0.13 \\
\hline Diabetes mellitus & $240(22.0)$ & $116(24.0)$ & 0.40 \\
\hline Liver cirrhosis & $25(2.3)$ & $8(1.7)$ & 0.45 \\
\hline Age adjusted Charlson Comorbidity Index & $5(4-7)$ & $5(4-7)$ & 0.69 \\
\hline \multicolumn{4}{|l|}{ Renal function influencing medication } \\
\hline ACEI/ARB & $350(32.1)$ & $162(33.5)$ & 0.60 \\
\hline NSAID & $54(5.0)$ & $19(3.9)$ & 0.44 \\
\hline Diuretics & $317(29.1)$ & $151(31.3)$ & 0.40 \\
\hline Intravenous contrast $<5$ days of admission & $1(0.1)$ & $1(0.2)$ & 0.52 \\
\hline Vancomycin & $1(0.1)$ & 0 & 1.0 \\
\hline \multicolumn{4}{|l|}{ Sepsis severity } \\
\hline$q S O F A \geq 2$ & $169(15.5)$ & $94(19.5)$ & 0.06 \\
\hline SOFA $\geq 2$ & $649(59.5)$ & $274(56.7)$ & 0.32 \\
\hline Shock & $30(2.8)$ & $22(4.6)$ & 0.07 \\
\hline ICU admission & $64(5.9)$ & $46(9.5)$ & 0.10 \\
\hline \multicolumn{4}{|l|}{ Focus of infection on admission } \\
\hline Lower respiratory tract & $389(35.7)$ & $160(33.1)$ & 0.33 \\
\hline Urinary tract & $261(23.9)$ & $120(24.8)$ & 0.70 \\
\hline Digestive and hepato-biliary tract & $130(11.9)$ & $36(7.5)$ & 0.008 \\
\hline Skin and soft tissue & $74(6.8)$ & $50(10.4)$ & 0.03 \\
\hline Neutropenic fever & $46(4.2)$ & $36(7.5)$ & 0.10 \\
\hline Other & $48(4.4)$ & $13(2.7)$ & 0.12 \\
\hline Unknown & $142(13.0)$ & $65(13.5)$ & 0.81 \\
\hline \multicolumn{4}{|l|}{ Blood cultures } \\
\hline Yielding bacterial growth & $114 / 975(11.7)$ & $89 / 450$ (19.8) & $<0.001$ \\
\hline Yielding Gram negative bacteria & $71 / 975(7.3)$ & $53 / 450(11.8)$ & 0.006 \\
\hline \multicolumn{4}{|l|}{ Gentamicin } \\
\hline Gentamicin & $571(52.4)$ & n.a. & \\
\hline Dose of gentamicin (mg/kg) & $5.1(4.6-6.0)$ & n.a. & \\
\hline
\end{tabular}


Table 1. Continued

\section{Renal function}

\section{Pre-admission}

\begin{tabular}{|c|c|c|c|}
\hline Baseline creatinine ( $\mu \mathrm{mol} / \mathrm{l})$ & $85(68-111)$ & $75(62-96)$ & $<0.001$ \\
\hline Baseline urea $(\mathrm{mmol} / \mathrm{l})$ & $7.2(4.9-10.6)$ & $7.3(5.2-10.5)$ & 0.79 \\
\hline $\begin{array}{l}\text { Baseline eGFR (CKD-EPI) (ml/ } \\
\left.\mathrm{min} / 1.73 \mathrm{~m}^{2}\right)\end{array}$ & $72(50-91)$ & $80(58-96)$ & $<0.001$ \\
\hline Baseline eGFR $<30 \mathrm{ml} / \mathrm{min} / 1.73 \mathrm{~m}^{2}$ & $83(7.6)$ & $32(6.6)$ & 0.53 \\
\hline \multicolumn{4}{|l|}{ On admission } \\
\hline Creatinine on admission $(\mu \mathrm{mol} / \mathrm{l})$ & $96(74-140)$ & $89(68-121)$ & $<0.001$ \\
\hline Urea on admission (mmol/l) & $7.3(5.0-10.9)$ & $7.3(5.1-10.5)$ & 0.97 \\
\hline \multicolumn{4}{|l|}{$\mathrm{AKI}$ on admission, by KDIGO stage } \\
\hline 1 & $201(18.4)$ & $92(19.0)$ & 0.83 \\
\hline 2 & $54(5.0)$ & $19(3.9)$ & 0.44 \\
\hline 3 & $33(3.0)$ & $10(2.1)$ & 0.32 \\
\hline Total & $288(27.1)$ & $121(25.6)$ & 0.53 \\
\hline
\end{tabular}

\section{Post-admission}

AKI in week 1 , by KDIGO stage

\begin{tabular}{|c|c|c|c|}
\hline 1 & $85(7.8)$ & $34(7.1)$ & 0.47 \\
\hline 2 & $10(1.0)$ & $6(1.3)$ & 0.60 \\
\hline 3 & $9(0.9)$ & $2(0.4)$ & 0.52 \\
\hline Total & $104(9.5)$ & 42 (8.7) & 0.64 \\
\hline
\end{tabular}

\section{Mortality}

30-day mortality $137(12.6)$ $48(9.9)$ 0.81

Data are presented in median (interquartile ranges) or in absolute numbers (percentages).

Hospital A: MUMC with empirical gentamicin for specific foci; Hospital B: Rijnstate Hospital, and Hospital C: Zuyderland Medical Centre.

Abbreviations: BMI: body mass index; CVA: cerebrovascular accident; ACEI/ARB: angiotensin converting enzyme inhibitors/angiotensin receptor blocker; NSAID: non-steroidal antiinflammatory drugs; qSOFA: quick sequential organ failure assessment; SOFA: sequential organ failure assessment; ICU: intensive care unit; eGFR: estimated glomerular filtration rate; CKDEPI: Chronic Kidney Disease Epidemiology Collaboration; AKI: acute kidney injury; KDIGO: Kidney Disease Improving Global Outcomes. 
Table 2. Clinical characteristics of sepsis patients categorized by gentamicin use.

\begin{tabular}{|c|c|c|c|}
\hline & $\begin{array}{l}\text { Gentamicin } \\
\mathrm{n}=571\end{array}$ & $\begin{array}{l}\text { No gentamicin } \\
\mathrm{n}=1002\end{array}$ & P-value \\
\hline Male sex & $310(54.3)$ & $526(52.5)$ & 0.50 \\
\hline Age (years) & $70(58-80)$ & $70(57-80)$ & 0.86 \\
\hline BMI $\left(\mathrm{kg} / \mathrm{m}^{2}\right)$ & $25.1(21.7-29.2)$ & $25.4(22.3-29.4)$ & 0.01 \\
\hline \multicolumn{4}{|l|}{ Comorbidities } \\
\hline Myocardial infarction & $54(9.6)$ & $102(10.2)$ & 0.73 \\
\hline Heart failure & $47(8.2)$ & $99(9.9)$ & 0.32 \\
\hline Peripheral arterial disease & $81(14.4)$ & $131(13.2)$ & 0.54 \\
\hline CVA & $82(14.6)$ & $152(15.3)$ & 0.77 \\
\hline Diabetes mellitus & $134(23.5)$ & $222(22.2)$ & 0.57 \\
\hline Liver cirrhosis & $16(2.8)$ & $17(1.7)$ & 0.15 \\
\hline Age adjusted Charlson Comorbidity Index & $5(4-7)$ & $5(4-7)$ & 0.55 \\
\hline \multicolumn{4}{|l|}{ Renal function influencing medication } \\
\hline ACEI/ARB & $198(34.7)$ & $314(31.3)$ & 0.18 \\
\hline NSAID & $30(5.3)$ & $43(4.3)$ & 0.39 \\
\hline Diuretics & $168(29.4)$ & $300(29.9)$ & 0.86 \\
\hline Intravenous contrast $<5$ days of admission & $1(0.2)$ & $1(0.1)$ & 1.0 \\
\hline Vancomycin & 0 & $1(0.1)$ & 1.0 \\
\hline \multicolumn{4}{|l|}{ Sepsis severity } \\
\hline $\mathrm{qSOFA} \geq 2$ & $118(20.7)$ & $145(14.5)$ & 0.002 \\
\hline SOFA $\geq 2$ & $360(63.0)$ & $563(56.2)$ & 0.009 \\
\hline Shock & $26(4.6)$ & $26(2.6)$ & 0.04 \\
\hline ICU admission & $52(9.1)$ & $58(5.8)$ & 0.02 \\
\hline \multicolumn{4}{|l|}{ Focus of infection on admission } \\
\hline Lower respiratory tract & $178(31.2)$ & $371(37.0)$ & 0.02 \\
\hline Urinary tract & $165(28.9)$ & $216(21.6)$ & 0.001 \\
\hline Digestive and hepato-biliary tract & $73(12.8)$ & $93(9.3)$ & 0.03 \\
\hline Skin and soft tissue & $30(5.3)$ & $94(9.4)$ & 0.003 \\
\hline Neutropenic fever & $8(1.4)$ & $74(7.4)$ & $<0.001$ \\
\hline Other & $26(4.5)$ & $35(3.5)$ & 0.34 \\
\hline Unknown & $91(15.9)$ & $116(11.6)$ & 0.02 \\
\hline
\end{tabular}

\section{Blood cultures}

\begin{tabular}{llll} 
Yielding bacterial growth & $77 / 526(14.6)$ & $126 / 899(14.0)$ & 0.75 \\
Yielding Gram negative bacteria & $51 / 526(9.7)$ & $73 / 899(8.1)$ & 0.33 \\
Renal function & & & \\
Pre-admission & & & \\
\hline Baseline creatinine $(\mu \mathrm{mol} / \mathrm{l})$ & $84(67-110)$ & $75(62-96)$ & $<0.001$ \\
\hline & & Continued
\end{tabular}


Table 2. Continued

\begin{tabular}{|c|c|c|c|}
\hline Baseline urea (mmol/l) & $7.3(5.0-10.8)$ & $7.3(5.2-10.5)$ & 0.93 \\
\hline Baseline eGFR (CKD-EPI) (ml/min/1.73m²) & $73(50-91)$ & $80(58-96)$ & 0.001 \\
\hline Baseline eGFR < $30 \mathrm{ml} / \mathrm{min} / 1.73 \mathrm{~m}^{2}$ & $65(11.4)$ & $43(8.9)$ & 0.22 \\
\hline \multicolumn{4}{|l|}{ On admission } \\
\hline Creatinine on admission ( $\mu \mathrm{mol} / \mathrm{l})$ & $98(76-147)$ & $89(68-121)$ & $<0.001$ \\
\hline Urea on admission (mmol/l) & $7.5(5.2-11.5)$ & $7.3(5.1-10.5)$ & 0.25 \\
\hline \multicolumn{4}{|l|}{ AKI on admission, by KDIGO stage } \\
\hline 1 & $124(21.7)$ & $169(16.9)$ & 0.02 \\
\hline 2 & $36(6.3)$ & $37(3.7)$ & 0.02 \\
\hline 3 & $21(3.7)$ & $22(2.2)$ & 0.11 \\
\hline Total & $181(31.7)$ & $228(22.8)$ & $<0.001$ \\
\hline \multicolumn{4}{|l|}{ Post-admission } \\
\hline \multicolumn{4}{|l|}{ AKI in week 1 , by KDIGO stage } \\
\hline 1 & $52(9.1)$ & $67(6.7)$ & 0.09 \\
\hline 2 & $6(1.1)$ & $10(1.0)$ & 1.0 \\
\hline 3 & $6(1.1)$ & $5(0.5)$ & 0.22 \\
\hline Total & $64(11.2)$ & $82(8.2)$ & 0.06 \\
\hline Renal replacement therapy & $3(0.5)$ & $3(0.3)$ & 0.67 \\
\hline Persistent $\mathrm{AKI}$ in week 2 , relative to baseline & $16 / 260(6.2)$ & 15/454 (3.3) & 0.09 \\
\hline $\begin{array}{l}\text { Persistent AKI in week } 2 \text {, relative to } \\
\text { admission }\end{array}$ & $5 / 265(1.9)$ & $5 / 458(1.1)$ & 0.51 \\
\hline \multicolumn{4}{|l|}{ Mortality } \\
\hline 30-day mortality & $77(13.5)$ & $108(10.8)$ & 0.02 \\
\hline
\end{tabular}

Data are presented in medians (interquartile ranges) or in absolute numbers (percentages).

Abbreviations: BMI: body mass index; CVA: cerebrovascular accident; ACEI/ARB: angiotensin converting enzyme inhibitors/angiotensin receptor blocker; NSAID: non-steroidal antiinflammatory drugs; qSOFA: quick sequential organ failure assessment; SOFA: sequential organ failure assessment; ICU: intensive care unit; eGFR: estimated glomerular filtration rate; CKDEPI: Chronic Kidney Disease Epidemiology Collaboration; AKI: acute kidney injury; KDIGO: Kidney Disease Improving Global Outcomes.

\section{Differences between patients treated with and without gentamicin}

Patients who received gentamicin more often had a qSOFA score $\geq 2$ and shock, and they were more often admitted to the ICU, compared with those not treated with gentamicin (Table 2). We found comparable results excluding patients of Hospital A from this analysis, who were not treated with gentamicin (Supplementary Table 1). 


\section{Renal function}

On admission, the incidence of AKI was not different between Hospital $A$ and Hospitals B and C ( $p=0.53$ ) (Table 1). During the first week after admission, no differences were found in the different stages of AKI after admission.

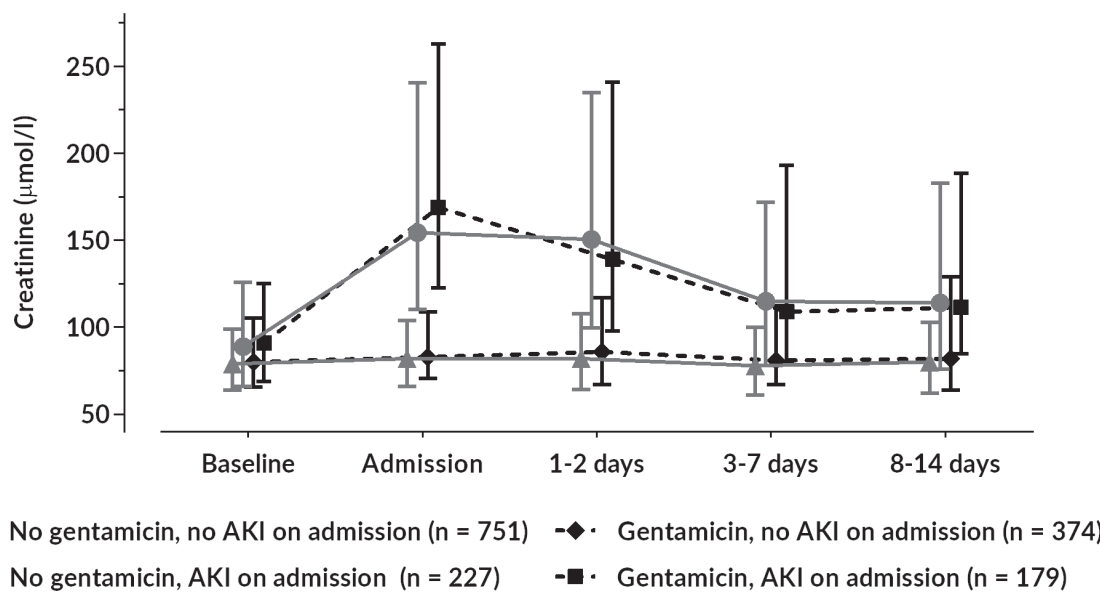

Figure 1. Median serum creatinine levels with IQR during 14 days of follow up.

Baseline: most recent creatinine value prior to admission; Admission: creatinine value on admission; 1-2 days: 1-2 days after admission; 3-7 days: 3-7 days after admission; 8-14 days: 8-14 days after admission; gentamicin: gentamicin treatment group; no gentamicin: control group without gentamicin.

Abbreviation: AKI: acute kidney injury.

Both pre-existing baseline creatinine and serum creatinine on admission at the ED were higher in the gentamicin group, compared to the non-gentamicin group (Table 2). AKI on admission was more prevalent in the gentamicin group (181/571,31.7\%), compared to non-gentamicin group (228/1002, 22.8\%, $\mathrm{p}<0.001$ ), as were KDIGO stage 1 and 2, but not stage 3. However, after admission, and thus after the administration of gentamicin, no difference in the occurrence of AKI (64/571, $11.2 \%$ vs. $82 / 1002,8.2 \%, p=0.06)$, nor in the individual KDIGO stages of $\mathrm{AKI}$ was seen.

Comparing patients with gentamicin (Hospital A) with patients without gentamicin (Hospitals B and C, but not Hospital A), we found similar results (Supplementary Table 1). 
Chapter 4 - Renal safety of a single dose of gentamicin in patients with sepsis

Table 3. Univariate analysis for clinical characteristics of AKI after admission

\begin{tabular}{llll}
\hline & $\begin{array}{l}\text { AKI after } \\
\text { admission } \\
\mathbf{n = 1 4 6}\end{array}$ & $\begin{array}{l}\text { No AKI after } \\
\text { admission } \\
\mathbf{n = 1 4 2 7}\end{array}$ & P-value \\
\hline Male sex & $88(60.3)$ & $748(52.4)$ & 0.08 \\
Age (years) & $71(63-82)$ & $69(57-80)$ & 0.01
\end{tabular}

\section{Comorbidities}

\begin{tabular}{llll} 
Myocardial infarction & $16(11.0)$ & $140(9.8)$ & 0.66 \\
\hline Heart failure & $20(13.7)$ & $126(8.8)$ & 0.07 \\
\hline Peripheral arterial disease & $31(21.2)$ & $181(12.7)$ & 0.007 \\
\hline Diabetes mellitus & $49(33.6)$ & $307(21.5)$ & 0.002 \\
\hline Age adjusted Charlson Comorbidity Index & $6(5-8)$ & $5(4-7)$ & $<0.001$ \\
\hline
\end{tabular}

\section{Renal function influencing medication}

\begin{tabular}{llll} 
ACEI/ARB & $63(43.2)$ & $449(31.5)$ & 0.005 \\
\hline NSAID & $10(6.8)$ & $63(4.4)$ & 0.21 \\
\hline Diuretics & $60(41.1)$ & $408(28.6)$ & 0.002 \\
\hline Intravenous contrast <5 days of admission & 0 & $3(0.2)$ & 1.0 \\
Vancomycin & 0 & $1(0.1)$ & 1.0
\end{tabular}

\section{Sepsis severity}

$\begin{array}{llll}\text { qSOFA } \geq 2 & 30(20.5) & 233(16.3) & 0.20 \\ \text { Shock } & 12(8.2) & 40(2.8) & 0.002 \\ \text { ICU admission } & 28(19.2) & 82(5.7) & <0.001\end{array}$

\section{Focus of infection on admission}

\begin{tabular}{llll} 
Lower respiratory tract & $53(36.3)$ & $496(34.8)$ & 0.72 \\
\hline Urinary tract & $28(19.2)$ & $353(24.7)$ & 0.16 \\
\hline Digestive and hepato-biliary tract & $15(10.3)$ & $151(10.6)$ & 1.0 \\
\hline Skin and soft tissue & $15(10.3)$ & $109(7.6)$ & 0.26 \\
\hline Neutropenic fever & $6(4.1)$ & $76(5.3)$ & 0.70 \\
Other & $7(4.8)$ & $54(3.8)$ & 0.50 \\
Unknown & $22(15.1)$ & $185(13.0)$ & 0.44
\end{tabular}

\section{Blood cultures}

\begin{tabular}{|c|c|c|c|}
\hline Yielding bacterial growth & $35 / 138(25.4)$ & $168 / 1287(13.1)$ & $<0.001$ \\
\hline Yielding Gram negative bacteria & 16/138 (11.8) & $108 / 1287(8.4)$ & 0.20 \\
\hline \multicolumn{4}{|l|}{ Gentamicin } \\
\hline Gentamicin & $64(43.8)$ & $507(35.5)$ & 0.06 \\
\hline Dose of gentamicin (mg/kg) & $5.0(4.7-5.8)$ & $5.0(4.7-5.9)$ & 0.90 \\
\hline \multicolumn{4}{|l|}{ Renal function } \\
\hline Baseline creatinine ( $\mu \mathrm{mol} / \mathrm{l})$ & $109(78-177)$ & $79(64-103)$ & $<0.001$ \\
\hline
\end{tabular}


Table 3. Continued

\begin{tabular}{llll} 
Baseline eGFR (CKD-EPI) $\left(\mathrm{ml} / \mathrm{min} / 1.73 \mathrm{~m}^{2}\right)$ & $51(29-76)$ & $76(57-93)$ & $<0.001$ \\
Baseline eGFR $<30 \mathrm{ml} / \mathrm{min} / 1.73 \mathrm{~m}^{2}$ & $38(26.0)$ & $119(8.3)$ & $<0.001$ \\
\hline Creatinine on admission $(\mu \mathrm{mol} / \mathrm{l})$ & $148(99-223)$ & $91(71-126)$ & $<0.001$ \\
$\begin{array}{l}\text { AKI on admission } \\
\text { Mortality }\end{array}$ & $48(32.9)$ & $361(25.3)$ & 0.06 \\
\hline 30-day mortality & $37(25.3)$ & $148(10.4)$ & 0.32 \\
\hline
\end{tabular}

Data are presented in medians (interquartile ranges) or in absolute numbers (percentages). Abbreviations: AKI: acute kidney injury; qSOFA: quick sequential organ failure assessment; SOFA: sequential organ failure assessment; ICU: intensive care unit; ACEI/ARB: angiotensin converting enzyme inhibitors/angiotensin receptor blocker; NSAID: non-steroidal anti-inflammatory drugs; eGFR: estimated glomerular filtration rate; CKD-EPI: Chronic Kidney Disease Epidemiology Collaboration; Kidney Disease Improving Global Outcomes.

Table 4. Multivariate logistic regression analysis for risk factors of AKI after admission

\begin{tabular}{lll}
\hline Variables & OR $(\mathbf{9 5 \%} \mathrm{Cl})$ & $P$-value \\
\hline Age & $1.007(0.995-1,02)$ & 0.24 \\
Male sex & $0.91(0.63-1.31)$ & 0.59 \\
Gentamicin & $1.29(0.89-1.86)$ & 0.18 \\
Shock & $2.71(1.31-5.67)$ & 0.008 \\
Diabetes Mellitus & $1.49(1.001-2.23)$ & $<0.05$ \\
ACEl/ARB & $1.18(0.80-1.75)$ & 0.40 \\
Diuretics & $1.11(0.76-1.71)$ & 0.52 \\
Baseline creatinine & $1.007(1.005-1.009)$ & $<0.001$ \\
AKI on admission & $1.03(0.69-1.53)$ & 0.90 \\
\hline Abbreviations: & &
\end{tabular}

Abbreviations: ACEI/ARB: angiotensin converting enzyme inhibitors/angiotensin receptor blocker; AKI: acute kidney injury.

Due to missing cases, 1531/1573 patients were included in the analysis.

Performance with Nagelkerke $R^{2}=0.123$. Calibration with Hosmer-Lemeshow test $p=0.52$.

* Per point increase 
When $\mathrm{AKI}$ after admission developed, persistent $\mathrm{AKI}$ in the second week of admission was rare in both the gentamicin and non-gentamicin group (Table 2). Six patients received RRT $(3 / 571(0.5 \%)$ in the gentamicin vs. $3 / 1002$ $(0.3 \%)$ in the non-gentamicin group, $p=0.67)$, of whom three had a pre-existent eGFR $<10 \mathrm{ml} / \mathrm{min} / 1.73 \mathrm{~m}^{2}$. In two of the other three patients, renal function recovered and RRT could be stopped within two months.

Linear regression analysis showed no differences in the course of median serum creatinine concentrations over a 14-day period between those with gentamicin and $\mathrm{AKI}$, and those without gentamicin with $\mathrm{AKI}$ on admission $(p=0.85)$ (Figure 1).

\section{Risk factors for AKI after admission}

In total, AKI after admission was seen in 146/1573 (9.3\%) patients. Table 3 shows the univariate analysis for clinical characteristics of $\mathrm{AKI}$ after admission. The multivariate analysis showed that the development of $\mathrm{AKI}$ after admission was multifactorial, whereby shock (OR 2.72 (95\% CI, 1.31-5.67)), diabetes mellitus (OR 1.49 (95\% Cl, 1.001-2.23)), and baseline serum creatinine (OR 1.007 per point increase $(95 \% \mathrm{Cl}, 1.005-1.009))$ were independently associated with the development of AKI after admission (AUROC=0.73) (Table 4). Gentamicin (OR 1.29 (95\% Cl, 0.89-1.86)) was not found to be a risk factor for AKI. Risk factors showing collinearity were excluded from the multivariate analysis.

\section{Discussion}

Our multi-centre study shows that the development of AKI after admission in patients presenting with sepsis at the ED is not associated with the administration of a single dose of gentamicin. The development of AKI after admission is multifactorial, with shock, diabetes mellitus and a higher baseline creatinine as contributing factors. When AKI after admission occurred, it was reversible in most cases, as persistent $A K I$ was rare.

Patients in the gentamicin group tended to be more severely ill, compared to those in the non-gentamicin group, as illustrated by the higher incidence of AKI on admission, qSOFA criteria $\geq 2$, shock, ICU admissions and 30day mortality. Despite this difference in disease severity at admission, no significant differences were seen in the incidence of $A K I$ during the first week of admission between the gentamicin and the non-gentamicin group. 
The observed non-significant differences could be explained by the worse baseline renal function in patients treated with gentamicin, as shown in our multivariate analysis.

Our findings are in line with findings of other studies [7, 8, 19]. In contrast, a recent ICU study concluded that exposure to gentamicin was associated with the development of AKI [4]. In that ICU study, only patients with shock were included and the RIFLE criteria from stage Failure or worse were used to define AKI. Furthermore, it was unclear to which prior creatinine value the described value was compared to. These differences in population and used definitions possibly explain why gentamicin was a risk factor for the development of AKI in the ICU study, but not in our study.

Our study consists of a large population of patients with all severities of sepsis and is therefore a good reflection of common daily practice in the ED. The differences in the use of gentamicin as part of the empirical antibiotic therapy between the three hospitals created a natural experiment for evaluating the influence of gentamicin on the development of AKI in patients with sepsis at the ED. For such an experiment, it is a prerequisite that the patient cohorts are as equal as possible regarding severity of sepsis and renal function. We found that both groups (gentamicin vs. non-gentamicin in all hospitals) were comparable. In addition, we also compared the gentamicin group, with patients without gentamicin from Hospitals B and C, to explore potential confounding by indication. This yielded similar results, which indicates that the risk of confounding by indication is low. Therefore, we believe that the effect of gentamicin in patients with sepsis in the ED on the development of $\mathrm{AKI}$ could be evaluated properly.

Our study has several limitations. First, we included patients with SIRS criteria, while SOFA criteria are better in selecting the most severely ill patients [20]. We have decided to include patients with SIRS criteria as well, because the sensitivity of the SOFA criteria is probably not high enough for early detection of organ dysfunction, and for predicting ICU admission and in-hospital mortality in patients with infections in the ED [21, 22]. Secondly, despite local guidelines, some patients should not have been treated with gentamicin, as they had a respiratory tract infection. This non-adherence to local antibiotic policies may have led to confounding by indication. However, this non-adherence is possibly explained by the fact that the focus of infection is not always known at the time of administering antibiotics. Furthermore, 
survivorship bias may have occurred, because study participants had to survive long enough to develop AKI. However, since we used a one week time period for developing AKI, the risk of missing the development of $A K I$ after admission is low. Lastly, although renal function was followed for 14 days strictly, follow up was not always complete. Missing values may lead to both under- and overestimation of AKI. However, we think that overestimation of $A K I$ is more likely, because missing values probably result from discharge of patients who recover or from a favourable course. Therefore, we chose to classify patients as having no AKI when creatinine values were not available [15]. A prospective study with strict follow up protocols could solve this issue.

In a world with increasing antibiotic resistance, the options for appropriate empirical antibiotic therapy with a beta-lactam antibiotic alone are becoming fewer. Aminoglycosides can reduce the use of 3rd and 4th generation cephalosporins and carbapenems. In a country with a low prevalence of multidrug resistant micro-organisms, such as the Netherlands, the resistance rates of Enterobacteriaceae in clinical blood isolates for amoxicillin/clavulanic acid and 2nd generation cephalosporins range from 7-24\%, compared to $1-3 \%$ for the combination of gentamicin and amoxicillin/clavulanic acid or a 2nd generation cephalosporin [10]. In the ICU [10] and in countries with a higher prevalence of multidrug resistant micro-organisms, these numbers are even higher [23]. This reflects the usefulness of aminoglycosides in patients with sepsis, which may even increase in the future.

The dosing of gentamicin in this study was $5 \mathrm{mg} / \mathrm{kg}$, although some studies suggest that higher doses are needed in case of sepsis [24]. It is questionable whether higher doses of gentamicin would lead to more AKI, as the risk of nephrotoxicity is determined by trough and not peak concentrations. Since gentamicin has a half-life of 2-3h in patients with normal renal function, one would expect normal trough concentrations and therefore equal rates of $\mathrm{AKI}$, even with higher doses [11].

In conclusion, our multicentre study in a large population of ED patients with sepsis shows that it is safe to administer a single dose of gentamicin in patients with sepsis in the ED with regard to renal function. The development of $\mathrm{AKI}$ after admission was independently associated with shock, diabetes mellitus, and a higher baseline creatinine. When AKI after admission developed, it was reversible in most cases and persistent renal failure was rare. 
Supplementary Table 1. Clinical characteristics of sepsis patients by gentamicin use excluding patients without gentamicin from Hospital A.

\begin{tabular}{llll}
\hline & $\begin{array}{l}\text { Gentamicin } \\
\mathbf{n = 5 7 1}\end{array}$ & $\begin{array}{l}\text { No gentamicin } \\
\mathbf{n = 4 8 3}\end{array}$ & P-value \\
\hline Male sex & $310(54.3)$ & $237(49.1)$ & 0.10 \\
Age (years) & $70(58-80)$ & $71(58-81)$ & 0.19 \\
BMl $\left(\mathrm{kg} / \mathrm{m}^{2}\right)$ & $25.1(21.7-29.2)$ & $25.9(22.7-29.8)$ & 0.05
\end{tabular}

\section{Comorbidities}

Age adjusted Charlson Comorbidity Index $5(4-7)$

$5(4-7) \quad 0.58$

\section{Sepsis severity}

qSOFA $\geq 2$

$118(20.7)$

$94(19.5)$

0.64

SOFA $\geq 2$

360 (63.0)

$274(56.7)$

0.04

Shock

26 (4.6)

22 (4.6)

1.0

ICU admission

52 (9.1)

$46(9.5)$

0.83

\section{Focus of infection on admission}

\begin{tabular}{llll} 
Lower respiratory tract & $178(31.2)$ & $160(33.1)$ & 0.51 \\
Urinary tract & $165(28.9)$ & $120(24.8)$ & 0.14 \\
\hline Digestive and hepato-biliary tract & $73(12.8)$ & $36(7.5)$ & 0.005 \\
Skin and soft tissue & $30(5.3)$ & $50(10.4)$ & 0.002 \\
Neutropenic fever & $8(1.4)$ & $36(7.5)$ & $<0.001$ \\
Other & $26(4.6)$ & $13(2.7)$ & 0.14 \\
Unknown & $91(15.9)$ & $65(13.5)$ & 0.30 \\
Blood cultures & & & \\
Yielding bacterial growth & $77 / 526(14.6)$ & $89 / 450(19.8)$ & 0.04 \\
Yielding Gram negative bacteria & $51 / 526(9.7)$ & $53 / 450(11.8)$ & 0.30
\end{tabular}

\section{Renal function}

\section{Pre-admission}

\begin{tabular}{|c|c|c|c|}
\hline Baseline creatinine ( $\mu \mathrm{mol} / \mathrm{l})$ & $84(67-110)$ & $75(62-96)$ & $<0.001$ \\
\hline Baseline urea (mmol/l) & $7.3(5.0-10.8)$ & $7.3(5.2-10.5)$ & 0.93 \\
\hline $\begin{array}{l}\text { Baseline eGFR (CKD-EPI) (ml/ } \\
\left.\mathrm{min} / 1.73 \mathrm{~m}^{2}\right)\end{array}$ & $73(50-91)$ & $80(58-96)$ & 0.001 \\
\hline Baseline eGFR < $30 \mathrm{ml} / \mathrm{min} / 1.73 \mathrm{~m}^{2}$ & $65(11.4)$ & $43(8.9)$ & 0.22 \\
\hline \multicolumn{4}{|l|}{ On admission } \\
\hline Creatinine on admission $(\mu \mathrm{mol} / \mathrm{l})$ & $98(76-147)$ & $89(68-121)$ & $<0.001$ \\
\hline Urea on admission (mmol/l) & $7.5(5.2-11.5)$ & $7.3(5.1-10.5)$ & 0.25 \\
\hline \multicolumn{4}{|l|}{ AKI on admission, by KDIGO stage } \\
\hline 1 & $124(21.7)$ & $92(19.0)$ & 0.32 \\
\hline 2 & $36(6.3)$ & $19(3.9)$ & 0.10 \\
\hline 3 & $21(3.6)$ & $10(2.1)$ & 0.14 \\
\hline Total & $181(31.7)$ & $121(25.1)$ & 0.02 \\
\hline
\end{tabular}




\section{Supplementary Table 1. Continued}

\begin{tabular}{|c|c|c|c|}
\hline \multicolumn{4}{|l|}{ Post-admission } \\
\hline \multicolumn{4}{|l|}{ AKI in week 1 , by KDIGO stage } \\
\hline 1 & $52 / 535(9.7)$ & $34 / 463(7.3)$ & 0.21 \\
\hline 2 & $6 / 535(1.1)$ & $6 / 463(1.3)$ & 1.0 \\
\hline 3 & $6 / 535(1.1)$ & $2 / 463(0.4)$ & 0.30 \\
\hline Total & $64 / 535(12.0)$ & $42 / 463(9.1)$ & 0.18 \\
\hline Renal replacement therapy & $3(0.5)$ & 0 & 0.26 \\
\hline $\begin{array}{l}\text { Persistent AKI in week } 2 \text {, relative to } \\
\text { baseline }\end{array}$ & $16 / 260(6.2)$ & $6 / 206(2.9)$ & 0.13 \\
\hline $\begin{array}{l}\text { Persistent AKI in week } 2 \text {, relative to } \\
\text { admission }\end{array}$ & $5 / 265(1.5)$ & $1 / 207(0.5)$ & 0.24 \\
\hline \multicolumn{4}{|l|}{ Mortality } \\
\hline 30-day mortality & $77(13.5)$ & $48(9.9)$ & 0.34 \\
\hline
\end{tabular}

Data are presented in medians (interquartile ranges) or in absolute numbers (percentages).

Abbreviations: BMI: body mass index; qSOFA: quick sequential organ failure assessment; SOFA: sequential organ failure assessment; ICU: intensive care unit; eGFR: estimated glomerular filtration rate; CKD-EPI: Chronic Kidney Disease Epidemiology Collaboration; AKI: acute kidney injury; Kidney Disease Improving Global Outcomes.. 


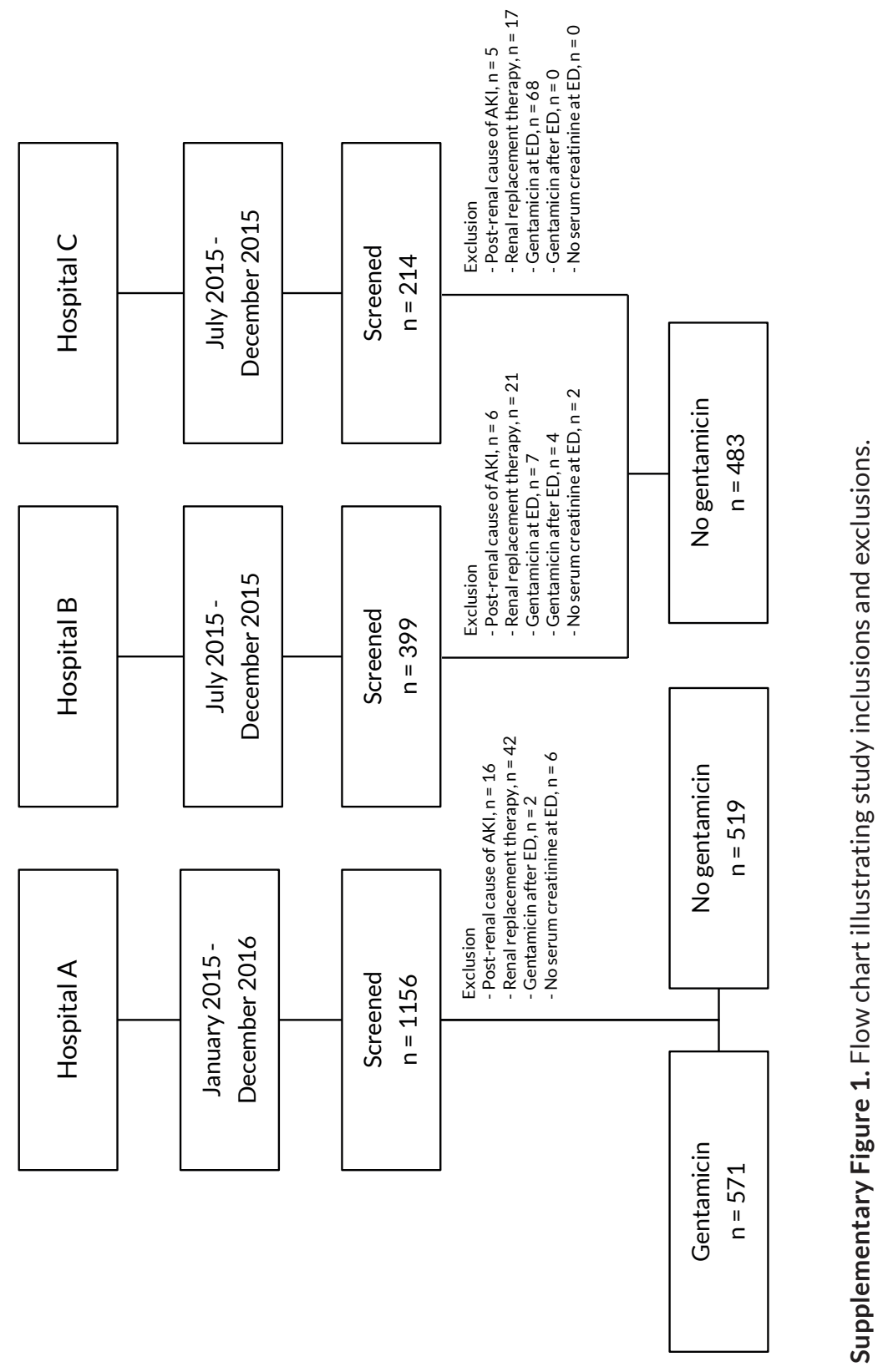




\section{References}

1. Kumar A, Safdar N, Kethireddy S, Chateau D. A survival benefit of combination antibiotic therapy for serious infections associated with sepsis and septic shock is contingent only on the risk of death: a meta-analytic/meta-regression study. Critical care medicine. 2010;38(8):1651-64.

2. Martinez JA, Cobos-Trigueros N, Soriano A, Almela M, Ortega M, Marco F, et al. Influence of empiric therapy with a beta-lactam alone or combined with an aminoglycoside on prognosis of bacteremia due to gram-negative microorganisms. Antimicrobial agents and chemotherapy. 2010;54(9):3590-6.

3. Paul M, Lador A, Grozinsky-Glasberg S, Leibovici L. Beta lactam antibiotic monotherapy versus beta lactam-aminoglycoside antibiotic combination therapy for sepsis. The Cochrane database of systematic reviews. 2014(1):Cd003344.

4. Ong DSY, Frencken JF, Klein Klouwenberg PMC, Juffermans N, van der Poll T, Bonten MJM, et al. Short-Course Adjunctive Gentamicin as Empirical Therapy in Patients With Severe Sepsis and Septic Shock: A Prospective Observational Cohort Study. Clinical infectious diseases : an official publication of the Infectious Diseases Society of America. 2017;64(12):1731-36.

5. Hayward RS, Harding J, Molloy R, Land L, Longcroft-Neal K, Moore D, et al. Adverse effects of a single dose of gentamicin in adults: a systematic review. British journal of clinical pharmacology. 2018;84(2):223-38.

6. Martinez-Salgado C, Lopez-Hernandez FJ, Lopez-Novoa JM. Glomerular nephrotoxicity of aminoglycosides. Toxicology and applied pharmacology. 2007;223(1):86-98.

7. Cobussen M, de Kort JM, Dennert RM, Lowe SH, Stassen PM. No increased risk of acute kidney injury after a single dose of gentamicin in patients with sepsis. Infectious diseases (London, England). 2016;48(4):274-80.

8. Picard W, Bazin F, Clouzeau B, Bui HN, Soulat M, Guilhon E, et al. Propensity-based study of aminoglycoside nephrotoxicity in patients with severe sepsis or septic shock. Antimicrobial agents and chemotherapy. 2014;58(12):7468-74.

9. World Health Organization (WHO). Antimicrobial Resistance: Global Report on Surveillance. Geneva: World Health Organization (WHO); 2014.

10. de Greeff SC, Mouton JW, Schoffelen AF, Verduin CM. NethMap 2019 - Consumption of antimicrobial agents and antimicrobial resistance among medically important bacteria in the Netherlands in 2018.; 2019 Jun-2019.

11. Nicolau DP, Freeman CD, Belliveau PP, Nightingale CH, Ross JW, Quintiliani R. Experience with a once-daily aminoglycoside program administered to 2,184 adult patients. Antimicrobial agents and chemotherapy. 1995;39(3):650-5.

12. Pickering JW, Endre ZH. Back-calculating baseline creatinine with MDRD misclassifies acute kidney injury in the intensive care unit. Clinical journal of the American Society of Nephrology : CJASN. 2010;5(7):1165-73.

13. Hoste EA, Clermont G, Kersten A, Venkataraman R, Angus DC, De Bacquer D, et al. RIFLE criteria for acute kidney injury are associated with hospital mortality in critically ill patients: a cohort analysis. Critical care (London, England). 2006;10(3):R73. 
14. Kellum JA, Lameire N, Aspelin P, Barsoum RS, Burdmann EA, Goldstein SL, et al. Kidney disease: improving global outcomes (KDIGO) acute kidney injury work group. KDIGO clinical practice guideline for acute kidney injury. Kidney international supplements. 2012;2(1):1-138.

15. Zeng X, McMahon GM, Brunelli SM, Bates DW, Waikar SS. Incidence, outcomes, and comparisons across definitions of $\mathrm{AKI}$ in hospitalized individuals. Clinical journal of the American Society of Nephrology : CJASN. 2014;9(1):12-20.

16. Levy MM, Fink MP, Marshall JC, Abraham E, Angus D, Cook D, et al. 2001 SCCM/ESICM/ ACCP/ATS/SIS International Sepsis Definitions Conference. Critical care medicine. 2003;31(4):1250-6.

17. Singer M, Deutschman CS, Seymour CW, Shankar-Hari M, Annane D, Bauer M, et al. The Third International Consensus Definitions for Sepsis and Septic Shock (Sepsis-3). JAMA. 2016;315(8):801-10.

18. Raith EP, Udy AA, Bailey M, McGloughlin S, Maclsaac C, Bellomo R, et al. Prognostic Accuracy of the SOFA Score, SIRS Criteria, and qSOFA Score for In-Hospital Mortality Among Adults With Suspected Infection Admitted to the Intensive Care Unit. JAMA. 2017;317(3):290-300.

19. Ong L-Z, Tambyah PA, Lum LH, Low Z-J, Cheng I, Murali TM, et al. Aminoglycosideassociated acute kidney injury in elderly patients with and without shock. Journal of Antimicrobial Chemotherapy. 2016;71(11):3250-7.

20. Seymour CW, Liu VX, Iwashyna TJ, Brunkhorst FM, Rea TD, Scherag A, et al. Assessment of Clinical Criteria for Sepsis: For the Third International Consensus Definitions for Sepsis and Septic Shock (Sepsis-3). JAMA. 2016;315(8):762-74.

21. Song JU, Sin CK, Park HK, Shim SR, Lee J. Performance of the quick Sequential (sepsisrelated) Organ Failure Assessment score as a prognostic tool in infected patients outside the intensive care unit: a systematic review and meta-analysis. Critical care (London, England). 2018;22(1):28.

22. Liu YC, Luo YY, Zhang X, Shou ST, Gao YL, Lu B, et al. Quick Sequential Organ Failure Assessment as a prognostic factor for infected patients outside the intensive care unit: a systematic review and meta-analysis. Internal and emergency medicine. 2019;14(4):60315.

23. European Centre for Disease Prevention and Control. Antimicrobial resistance surveillance in Europe 2015. Annual Report of the European Antimicrobial Resistance Surveillance Network (EARS-Net). Stockholm; 2017.

24. Rea RS, Capitano B, Bies R, Bigos KL, Smith R, Lee H. Suboptimal aminoglycoside dosing in critically ill patients. Therapeutic drug monitoring. 2008;30(6):674-81. 




\section{Chapter 5}

\section{Gentamicin is frequently underdosed in patients with sepsis in the emergency department}

M. Cobussen ${ }^{1}$, V. Hira ${ }^{1}$, J.M.L. de Kort ${ }^{2}$, D. Posthouwer ${ }^{1,3}$, P.M. Stassen ${ }^{3}$, M.B. Haeseker ${ }^{1}$

${ }^{1}$ Maastricht University Medical Center, Department of Medical Microbiology, Maastricht, the Netherlands,

${ }^{2}$ Dr. Horacio E. Oduber Hospitaal, Department of Internal Medicine, Oranjestad, Aruba.

${ }^{3}$ Maastricht University Medical Center, Department of Internal Medicine, Maastricht, the Netherlands.

Neth J Med. 2015 Nov;73(9):443-4. 
Dosing of antibiotics can be challenging. Therefore, we would like to warn colleagues for potential underdosing of gentamicin in patients with sepsis, as we recently found in our emergency department (ED).

Aminoglycosides are frequently used in the empirical treatment of sepsis in the emergency department (ED). In our hospital, we aim to prescribe gentamicin $5 \mathrm{mg} / \mathrm{kg}$ once daily, to broaden the antibiotic spectrum of amoxicillin/clavulanic acid [1]. Gentamicin is a concentration dependent bactericidal antibiotic. Underdosing will lead to a lower gentamicin peak concentration and consequently to potential treatment failure and increased morbidity and mortality [2, 3]. Therefore, we investigated actual gentamicin dosing in patients with sepsis in our ED.

All patients who received gentamicin at our ED (Maastricht University Medical Center, the Netherlands) from April 2011 to April 2012 were included. We retrospectively retrieved body weight, length, gentamicin dose and clinical characteristics from electronic patient files and the electronic prescribing system. To calculate the correct dose of gentamicin $(5 \mathrm{mg} / \mathrm{kg})$, actual body weight was used for patients with a BMI $<30 \mathrm{~kg} / \mathrm{m} 2$, and adjusted body weight for patients with $\mathrm{BMI}>30 \mathrm{~kg} / \mathrm{m}^{2}$ [4]. Underdosing of gentamicin was defined as at least $10 \%$ under the advised dose, i.e. $<4.5 \mathrm{mg} / \mathrm{kg}$.

We included 173 patients, of whom thirty four (19.7\%) were underdosed. The mean gentamicin dose was $3.8 \pm 0.5 \mathrm{mg} / \mathrm{kg}$ in the underdosed group, and $5.1 \pm 0.5 \mathrm{mg} / \mathrm{kg}$ in the adequately dosed group (Table 1). There was no difference in severity of sepsis according to the SIRS criteria (i.e. sepsis, severe sepsis, or septic shock) in both groups [5]. Mean serum creatinine was higher in underdosed patients $(203 \pm 171$ vs. $132 \pm 91 \mu \mathrm{mol} / \mathrm{l}, \mathrm{p}=0.001)$ and underdosed patients were more often directly admitted to the ICU $(21 \%$ vs. $7 \%$ of patients, $p<0.05$ ), which may indicate a worse condition of these patients.

In conclusion, gentamicin is frequently underdosed in septic patients in our ED. This leads to lower peak concentrations, which may negatively influence clinical outcome. The higher serum creatinine in gentamicin underdosed patients might suggest that fear of nephrotoxic side effects is an important reason for underdosing. Other reasons might be a wrong estimation of 
body weight, which was also seen in patients receiving thrombolysis [6], or downwards rounding of the gentamicin dose, based on whole ampules (i.e. $80 \mathrm{mg} / \mathrm{ampule})$.

Table 1. Patient characteristics comparing underdosed patients with adequately dosed patients

\begin{tabular}{llll}
\hline & $\begin{array}{l}\text { Underdosed } \\
\mathbf{n}=\mathbf{3 4}\end{array}$ & $\begin{array}{l}\text { Adequately dosed } \\
\mathbf{n}=139\end{array}$ & p-value \\
\hline Age & $70.0 \pm 15.6$ & $66.7 \pm 17.1$ & 0.31 \\
(Calculated) Weight & $74.6 \pm 14.5$ & $68.9 \pm 10.6$ & 0.01 \\
\hline BMI & $26.7 \pm 5.1$ & $25.0 \pm 5.8$ & 0.12 \\
\hline Dose $(\mathrm{mg} / \mathrm{kg})$ & $3.8 \pm 0.5$ & $5.1 \pm 0.5$ & $<0.001$ \\
Sepsis & $10(29.4)$ & $62(44.6)$ & 0.12 \\
Severe sepsis & $17(50.0)$ & $57(41.0)$ & 0.44 \\
Septic shock & $7(20.6)$ & $20(14.4)$ & 0.43 \\
ICU admission & $7(20.6)$ & $10(7.2)$ & $<0.05$ \\
Creatinine at ED $(\mu \mathrm{mol} / \mathrm{I})$ & $203 \pm 171$ & $132 \pm 91$ & 0.001 \\
28-day mortality & $7(20.6)$ & $16(11.5)$ & 0.17 \\
\hline
\end{tabular}

Data are presented in mean \pm SD or in absolute numbers (percentages).

Given the frequent occurrence of underdosing of gentamicin in our hospital, this could be a concern in other hospitals as well. We suggest that other EDs check the actually given doses of aminoglycosides. To improve adequate dosing, standardized weighing before administering gentamicin might be considered. Alternatively, plasma peak concentrations could be useful in the adequate dosing of gentamicin. 


\section{References}

1. Dutch Working Party on Antibiotic Policy (SWAB). SWAB guidelines for antibacterial therapy of adult patients with sepsis. Amsterdam; 2010.

2. Moore RD, Lietman PS, Smith CR. Clinical response to aminoglycoside therapy: importance of the ratio of peak concentration to minimal inhibitory concentration. The Journal of infectious diseases. 1987;155(1):93-9.

3. Kashuba AD, Nafziger AN, Drusano GL, Bertino JS, Jr. Optimizing aminoglycoside therapy for nosocomial pneumonia caused by gram-negative bacteria. Antimicrobial agents and chemotherapy. 1999;43(3):623-9.

4. Nicolau DP, Freeman CD, Belliveau PP, Nightingale CH, Ross JW, Quintiliani R. Experience with a once-daily aminoglycoside program administered to 2,184 adult patients. Antimicrobial agents and chemotherapy. 1995;39(3):650-5.

5. Levy MM, Fink MP, Marshall JC, Abraham E, Angus D, Cook D, et al. 2001 SCCM/ESICM/ ACCP/ATS/SIS International Sepsis Definitions Conference. Critical care medicine. 2003;31(4):1250-6.

6. Breuer L, Nowe T, Huttner HB, Blinzler C, Kollmar R, Schellinger PD, et al. Weight approximationinstrokebeforethrombolysis:theWAIST-Study:aprospectiveobservational "dose-finding" study. Stroke; a journal of cerebral circulation. 2010;41(12):2867-71. 




\section{Chapter 6}

\section{Evaluation of gentamicin peak concentrations in patients with sepsis at the emergency department}

M. Cobussen ${ }^{1}$, P.M. Stassen ${ }^{2}$, D. Posthouwer ${ }^{2}$, F.H. van Tiel ${ }^{1}$, P.H.M. Savelkoul', T. Havenith ${ }^{3}$, M.B. Haeseker ${ }^{1}$

${ }^{1}$ Department of Medical Microbiology, Maastricht University Medical Centre, Maastricht, the Netherlands.

${ }^{2}$ Department of Internal Medicine, Maastricht University Medical Centre, Maastricht, the Netherlands.

${ }^{3}$ Department of Clinical Pharmacy, Maastricht University Medical Centre, Maastricht, the Netherlands.

PLoS One. 2019 Jan 22;14(1):e0210012. 


\section{Abstract}

\section{Objective}

To achieve an optimal effect in patients with sepsis at the emergency department (ED), the gentamicin peak concentration should be sufficiently high (i.e. peak concentration/MIC $\geq 8-10$ ). ICU patients with sepsis often need higher gentamicin doses to achieve sufficiently high peak concentrations. The aim of this study is to investigate which dose is needed to reach adequate peak concentrations in patients presenting with sepsis at the ED.

\section{Methods}

Patients with sepsis at the ED were included from August 2015 until February 2017. Peak concentrations were measured in blood 30 minutes after the first gentamicin dose. The study consisted of three phases. In the first phase, peak concentrations were measured after a standard dose of $5 \mathrm{mg} / \mathrm{kg}$. In the second phase, a simulation ((peak concentration/actual dose) $\times$ simulated dose) was performed to determine which dose was needed to reach adequate gentamicin peak concentrations of $\geq 16 \mathrm{mg} / \mathrm{L}$. In the third phase, peak concentrations were measured for the best simulated dose.

\section{Results}

In phase one, of 86 patients who received a dose of $5 \mathrm{mg} / \mathrm{kg}, 34$ (39.5\%) patients did not reach the target peak concentration of $\geq 16 \mathrm{mg} / \mathrm{L}$, and 73 (84.9\%) did not reach $\geq 20 \mathrm{mg} / \mathrm{L}$. In phase two, the simulation showed that with a dose of $7 \mathrm{mg} / \mathrm{kg} 83$ (96.5\%) patients would reach peak concentrations $\geq 16 \mathrm{mg} / \mathrm{L}$, and $67(77.9 \%)$ of $\geq 20 \mathrm{mg} / \mathrm{L}$. In phase three, 53 patients received a dose of $7 \mathrm{mg} / \mathrm{kg}$, of whom 45 (84.9\%) reached peak concentrations of $\geq 16$ $\mathrm{mg} / \mathrm{L}$, and $31(58.5 \%)$ of $\geq 20 \mathrm{mg} / \mathrm{L}$.

\section{Conclusion}

Patients with sepsis at the ED need higher doses of gentamicin. A dose of 7 $\mathrm{mg} / \mathrm{kg}$ is needed to achieve adequate peak concentrations in the majority of patients. 


\section{Introduction}

Sepsis is associated with high morbidity and mortality [1]. Aminoglycosides, such as gentamicin, are frequently used as empirical treatment of sepsis at the emergency department (ED). Generally, aminoglycosides are combined with broad spectrum $\beta$-lactam antibiotics to broaden the Gram negative spectrum. Early administration of empirical antibiotic therapy within one hour of presentation in patients with sepsis is essential to improve outcome [2].

Gentamicin is a bactericidal antibiotic with concentration dependent pharmacodynamic properties. In order to achieve a maximal bactericidal effect of gentamicin, it is recommended that the ratio between the peak concentration and the minimal inhibitory concentration (MIC) must be $8-10 \times$ MIC $[3,4]$. The height of the peak concentration corresponds with the clinical response rate and is approximately $85 \%$ with a ratio of $8: 1$, and $90 \%$ with a ratio of 10:1 [5, 6]. According to the European Committee on Antimicrobial Susceptibility Testing (EUCAST), gentamicin MIC breakpoints for Enterobacteriaceae are $\leq 2 \mathrm{mg} / \mathrm{L}$, which leads to a target peak concentration of $16-20 \mathrm{mg} / \mathrm{L}$ for gentamicin susceptible isolates [7].

Critically ill patients at the intensive care unit (ICU) do not reach an adequate peak concentration of $\geq 16 \mathrm{mg} / \mathrm{L}$ after a gentamicin dose of $5 \mathrm{mg} / \mathrm{kg}[8,9]$, which is most probably due to a larger volume of distribution ( $\mathrm{Vd}$ ) of these patients compared to healthy subjects [8, 10-13]. This larger $\mathrm{Vd}$ leads to lower gentamicin peak concentrations, and therefore a higher dose of $\geq 7 \mathrm{mg} /$ $\mathrm{kg}$ has been advised in these patients [9]. To our knowledge, all studies have been performed in ICU patients and so far, no studies have been performed in patients with sepsis at the ED. However, it is likely that patients with sepsis at the ED also have a larger $\mathrm{Vd}$ and also need a higher dose of gentamicin (e.g. $>5$ $\mathrm{mg} / \mathrm{kg}$ ).

To investigate the gentamicin dose that leads to an adequate peak concentration in patients with sepsis at the ED, we measured gentamicin peak concentrations in patients with sepsis at the ED after the first dose of $5 \mathrm{mg} / \mathrm{kg}$ gentamicin to determine whether target peak concentrations were reached in these patients. We further determined which dose was necessary to achieve target peak concentrations in a simulated model and subsequently tested this simulated dose to validate the simulated dose. 


\section{Material and Methods}

\section{Study population}

We performed a prospective study in the Maastricht University Medical Center (MUMC). Patients $\geq 18$ years of age presenting with sepsis, according to the SIRS criteria for sepsis [14], at the ED from August 2015 to February 2017 , that were treated with broad spectrum $\beta$-lactam antibiotics (usually amoxicillin/clavulanic acid 1000/200mg q6h) and gentamicin intravenously (5 or $7 \mathrm{mg} / \mathrm{kg}$ once daily) [15], with a peak serum concentration available after the first dose, were included. For patients with a BMI $>30 \mathrm{~kg} / \mathrm{m}^{2}$, the adjusted body weight was used to calculate the dose of gentamicin [16]. Patients were excluded when serum peak concentrations were not obtained according to protocol.

In our hospital, a practical approach is to give a single dose of an aminoglycoside in combination with broad spectrum $\beta$-lactam antibiotics to patients presenting with severe sepsis or septic shock in the ED, to reevaluate after 24 hours and then decide whether or not to repeat the aminoglycoside dosing, based on the clinical condition of the patient and the follow-up laboratory results. A substantial number of hospitals in the Netherlands, including ours, use this strategy.

During the study period the sepsis criteria were renewed from the SIRS criteria to the SOFA criteria and we retrieved data for both criteria [17]. For inclusion, patients would have to meet the SIRS criteria for sepsis.

\section{Data collection}

All data were retrieved from the electronic hospital charts and the hospital's microbiological database. Standardised scoring forms were used to extract the data from the charts. We recorded age, sex, weight, length, vital parameters, gentamicin dose, date and time of gentamicin peak concentration, and microbiological data. In addition to the SIRS criteria for sepsis [14], the new Sepsis-3 criteria, the SOFA criteria, were retrieved [17].

\section{Pharmacokinetic/pharmacodynamic analysis}

Our study was performed in three consecutive phases. In phase one, gentamicin peak concentrations were measured in patients with sepsis at the ED who had received the standard gentamicin dose of $5 \mathrm{mg} / \mathrm{kg}$. Gentamicin was infused over 30 minutes. The gentamicin blood concentrations were 
drawn 30 minutes after the gentamicin infusion was stopped. According to the EUCAST the gentamicin clinical breakpoint for Enterobacteriaceae is 2 $\mathrm{mg} / \mathrm{L}$. This means that micro-organisms with an $\mathrm{MIC} \leq 2 \mathrm{mg} / \mathrm{L}$ are susceptible for gentamicin. The PD target peak concentration should be at $8 \times 2 \mathrm{mg} / \mathrm{L}$ $=16 \mathrm{mg} / \mathrm{L}$, or even better $10 \times 2 \mathrm{mg} / \mathrm{L}=20 \mathrm{mg} / \mathrm{L}$. Therefore, a gentamicin peak concentration of $\geq 16 \mathrm{mg} / \mathrm{L}$ was defined as adequate [3, 4]. The $\mathrm{Vd}$ was calculated with the formula: ' $\mathrm{Vd}(\mathrm{L} / \mathrm{kg})=$ gentamicin peak concentration $(\mathrm{mg} / \mathrm{L}) /$ gentamicin dose $(\mathrm{mg} / \mathrm{kg})$ '.

A validated fluorescence polarization immunoassay (Roche Cobas Integra 800) was used to measure the gentamicin peak concentrations. The lower threshold of detection was $0.2 \mathrm{mg} / \mathrm{L}$, the upper threshold of detection was $9.0 \mathrm{mg} / \mathrm{L}$, and at $0.3 \mathrm{mg} / \mathrm{L}$, the coefficient of variation was $8.5 \%$. At 1,4 , and $8 \mathrm{mg} / \mathrm{L}$, the coefficient of variation was $0.9 \%, 1.7 \%$ and $2.9 \%$, respectively. Samples of peak concentrations were manually diluted before analysis.

In phase two, peak concentrations were simulated for different dosage regimens using the $\mathrm{Vd}$ and peak concentrations of the patients in phase one. Simulations for doses of 6 to $10 \mathrm{mg} / \mathrm{kg}$ ('simulated dose') were performed to calculate the 'peak concentration simulated dose' with the formula: 'peak concentration simulated dose $=($ peak concentration/actual dose $) \times$ simulated dose'.

In phase three, a new gentamicin dosing regimen with the best simulated dose was implemented in our hospital to confirm the simulations of that dose. The best simulated dose was defined as that dose with which $>95 \%$ would reach a peak concentration of $>16 \mathrm{mg} / \mathrm{L}$. After implementation, gentamicin peak concentrations were measured in a new group of patients with sepsis receiving the best simulated gentamicin dose, to confirm whether the desired target peak concentrations were reached.

\section{Renal function}

Although our study was not designed to assess the risk of nephrotoxicity, we investigated whether increasing the dose of gentamicin from the standard dose to the best simulated dose would lead to an increase in nephrotoxic side effects, and a higher occurrence of acute kidney injury (AKI). Serum creatinine values were retrieved at the moment of presentation at the ED and followed for up to 14 days when available. To assess baseline renal function, creatinine values up to 3 months prior to ED presentation were retrieved. When these 
creatinine values were not available, we used the lowest creatinine value during admission as baseline creatinine [18]. AKI was classified according to the Risk, Injury, Failure, Loss of function and End stage renal disease (RIFLE) criteria using serum creatinine values [19]. The occurrence of AKI was evaluated on three different time periods (T1: 1-2 days after admission, T2: 3-7 days after admission, T3: 8-14 days after admission) during 14 days of follow up. $\mathrm{AKI}$ on admission was defined as a decrease in kidney function at the ED relative to baseline creatinine value. When patients received concomitant renal replacement therapy or had a post-renal cause of AKI they were excluded from analysis of the occurrence of AKI.

\section{Microbiological analysis}

All positive blood cultures from ED patients in 2015 with Gram negative bacteria were retrieved for the analysis of MIC distributions. Identification of bacteria in the blood cultures was performed using Becton Dickinson Phoenix Automated Microbiology System (USA). The MIC was measured with the Phoenix or E-test (bioMerieux, France).

\section{Statistical analysis}

Statistical analysis was made using IBM SPSS version 22 (SPSS Inc., USA). Continuous variables were reported as median (interquartile range (IQR)), and categorical variables as proportions. For AKI, valid percentages were reported, since some creatinine values were missing during follow up. Comparisons between two groups were made using Mann-Whitney test for continuous non-Gaussian data and Pearson's chi-squared test for categorical data. Linear regression analysis was used to test for correlation between simulated and measured values. $P$ values $<0.05$ were considered statistically significant.

\section{Ethical approval}

The Ethics Committee of the Maastricht University Medical Center reviewed and approved the protocol for this study and waived the need for consent. (METC 14-4-099). 


\section{Results}

\section{Study population}

During phase 1, a total of 86 patients with sepsis receiving gentamicin in a dose of $5 \mathrm{mg} / \mathrm{kg}$ was included. The median age was $66(60-77)$ and $59.3 \%$ was male (Table 1). Median body weight was $76 \mathrm{~kg}(64-90)$ and median BMI was $25.3 \mathrm{~kg} / \mathrm{mg}^{2}$ (21.7-29.3). All patients had sepsis according to the SIRS criteria. Severe sepsis was found in $25.6 \%$ of patients, and $10.5 \%$ had septic shock. According to the SOFA criteria, $46.5 \%$ of patients had sepsis, and $7.0 \%$ had septic shock.

Median baseline creatinine prior to admission was $84 \mu \mathrm{mol} / \mathrm{L}$ (71-116). On admission, serum creatinine was $91 \mu \mathrm{mol} / \mathrm{L}$ (77-158) (Table 1$)$.

Table 1. Characteristics of patients with a dosing of $5 \mathrm{mg} / \mathrm{kg}$ and $7 \mathrm{mg} / \mathrm{kg}$

\begin{tabular}{|c|c|c|c|}
\hline & $\begin{array}{l}5 \mathrm{mg} / \mathrm{kg} \\
\mathrm{n}=86\end{array}$ & $\begin{array}{l}7 \mathrm{mg} / \mathrm{kg} \\
\mathrm{n}=53\end{array}$ & $P$ value \\
\hline Male sex & $51(59.3)$ & $35(66.0)$ & 0.48 \\
\hline Age (years) & $66(60-77)$ & $72(60-80)$ & 0.24 \\
\hline Length (m) & $1.70(1.64-1.78)$ & $1.70(1.65-1.79)$ & 0.92 \\
\hline Body weight (kg) & $76(64-90)$ & $78(67-89)$ & 0.39 \\
\hline $\mathrm{BMI}\left(\mathrm{kg} / \mathrm{m}^{2}\right)$ & $25.3(21.7-29.3)$ & $26.5(23.3-30.8)$ & 0.21 \\
\hline Gentamicin dose (mg/kg) & $5.0(4.6-5.1)$ & $6.9(6.3-7.1)$ & \\
\hline Gentamicin peak concentration (mg/L) & $16.6(14.7-18.8)$ & $21.8(18.0-26.0)$ & $<0.001$ \\
\hline Peak concentration < $16 \mathrm{mg} / \mathrm{L}$ & $34(39.5)$ & $8(15.1)$ & 0.002 \\
\hline Peak concentration $<20$ mg/L & $73(84.9)$ & $22(41.5)$ & $<0.001$ \\
\hline Volume of distribution (L/kg) & $0.29(0.26-0.34)$ & $0.31(0.26-0.38)$ & 0.23 \\
\hline \multicolumn{4}{|l|}{ Sepsis (SIRS) } \\
\hline Sepsis & $55(64.0)$ & $42(79.2)$ & 0.06 \\
\hline Severe sepsis & $22(25.6)$ & $9(17.0)$ & 0.30 \\
\hline Septic shock & $9(10.5)$ & $2(3.8)$ & 0.21 \\
\hline \multicolumn{4}{|l|}{ Sepsis (SOFA) } \\
\hline No sepsis & $40(46.5)$ & $25(47.2)$ & 1.0 \\
\hline Sepsis & $40(46.5)$ & $26(49.1)$ & 0.86 \\
\hline Septic shock & $6(7.0)$ & $2(3.8)$ & 0.71 \\
\hline Baseline creatinine ( $\mu \mathrm{mol} / \mathrm{L})$ & $84(71-116)$ & $84(68-108)$ & 0.39 \\
\hline Baseline urea (mmol/L) & $5.7(3.7-10.8)$ & $5.9(3.8-7.8)$ & 0.62 \\
\hline Admission creatinine ( $\mu \mathrm{mol} / \mathrm{L})$ & $90(76-155)$ & $95(67-117)$ & 0.22 \\
\hline Admission urea (mmol/L) & $7.4(4.4-10.8)$ & $5.8(4.9-9.5)$ & 0.63 \\
\hline
\end{tabular}

Data are presented in absolute numbers (percentage) or median (IQR). BMI: body mass index; SIRS: systemic inflammatory response syndrome [14]; SOFA: sequential organ failure assessment [17]. 


\section{Phase 1: Determining adequacy of peak concentrations with standard gentamicin dose $5 \mathrm{mg} / \mathrm{kg}$}

Patients were given a median first dose of $5.0 \mathrm{mg} / \mathrm{kg}$ (4.6-5.1) with a $\mathrm{Vd}$ of $0.29 \mathrm{~L} / \mathrm{kg}(0.26-0.34)$ (Table 1). A median gentamicin peak concentration of $16.6 \mathrm{mg} / \mathrm{L}$ (14.7-18.8) was measured in these patients. With this gentamicin dosing regimen of $5 \mathrm{mg} / \mathrm{kg}, 34$ (39.5\%) patients did not reach the advised peak concentration of at least $16 \mathrm{mg} / \mathrm{L}$, and 73 (84.9\%) patients did not reach a peak concentration of $>20 \mathrm{mg} / \mathrm{L}$ (Table 2 and Figure 1 ).

\section{Phase 2: Simulations}

To determine which dose was needed to reach an adequate gentamicin peak concentration of $\geq 16 \mathrm{mg} / \mathrm{L}$, doses were simulated with a range of $5-10 \mathrm{mg} / \mathrm{kg}$ (Table 2). The simulations showed that with a dose of $7 \mathrm{mg} / \mathrm{kg}$ $96.5 \%$ of patients would reach the target of $\geq 16 \mathrm{mg} / \mathrm{L}$, and $77.9 \%$ would reach a peak concentration of $\geq 20 \mathrm{mg} / \mathrm{L}$ (Table 3 and Figure 1).

\section{Phase 3: Confirmation of new gentamicin dosing regimen of $7 \mathrm{mg} /$ $\mathrm{kg}$ with peak concentrations}

After the simulations, we assumed that a dose of $7 \mathrm{mg} / \mathrm{kg}$ was needed to achieve an adequate gentamicin peak concentration in the majority of patients. A new dosing regimen was implemented in our hospital according to which a dose of $7 \mathrm{mg} / \mathrm{kg}$ was administered to patients with sepsis at the ED. Gentamicin peak concentrations were measured according to protocol for confirmation of the simulated doses.

A total of 53 patients was included in this third phase. Of these patients, $66.0 \%$ was male with an age of 72 years (60-80) (Table 1). Median body weight was 78 $\mathrm{kg}$ (67-89) and BMI was $26.5 \mathrm{~kg} / \mathrm{mg}^{2}$ (23.3-30.8). No differences were found in baseline characteristics between the group receiving $5 \mathrm{mg} / \mathrm{kg}$, and the group receiving $7 \mathrm{mg} / \mathrm{kg}$. Patients were treated with a dose of $6.9 \mathrm{mg} / \mathrm{kg}(6.3-7.1)$ and reached a peak concentration of $21.8 \mathrm{mg} / \mathrm{L}$ (18.0-26.0). With a dose of $7 \mathrm{mg} / \mathrm{kg}$, a total of $15.1 \%$ of patients did not reach a peak concentration of $\geq 16 \mathrm{mg} / \mathrm{L}$, and $41.5 \%$ did not reach a peak concentration of $\geq 20 \mathrm{mg} / \mathrm{L}$, respectively. These findings are shown in Figure 1, with a similar pattern for the simulated dose of $7 \mathrm{mg} / \mathrm{kg}$, and the measured dose of $7 \mathrm{mg} / \mathrm{kg}(R=0.993$, $P<0.001)$. 
Table 2. Actual ( $x-5$ and $x-7)$ and simulated (s5 - s10) gentamicin peak concentrations

\begin{tabular}{|c|c|c|c|c|c|c|c|c|}
\hline & $\begin{array}{l}x-5 \\
m g / k g\end{array}$ & $\begin{array}{l}\mathrm{s}-5 \\
\mathrm{mg} / \mathrm{kg}\end{array}$ & $\begin{array}{l}\mathrm{s}-6 \\
\mathrm{mg} / \mathrm{kg}\end{array}$ & $\begin{array}{l}\mathrm{s}-7 \\
\mathrm{mg} / \mathrm{kg}\end{array}$ & $\begin{array}{l}\mathrm{s}-8 \\
\mathrm{mg} / \mathrm{kg}\end{array}$ & $\begin{array}{l}\mathrm{s}-9 \\
\mathrm{mg} / \mathrm{kg}\end{array}$ & $\begin{array}{l}\mathrm{s}-10 \\
\mathrm{mg} / \mathrm{kg}\end{array}$ & $\begin{array}{l}x-7 \\
m g / k g\end{array}$ \\
\hline$<16 \mathrm{mg} / \mathrm{L}$ & $34(39.5)$ & $33(38.4)$ & $11(12.8)$ & $3(3.5)$ & 0 & 0 & 0 & $8(15.1)$ \\
\hline$<20 \mathrm{mg} / \mathrm{L}$ & 73 (84.9) & $67(77.9)$ & $38(44.2)$ & 19 (22.1) & $3(3.5)$ & $3(3.5)$ & 0 & $22(41.5)$ \\
\hline$\geq 20 \mathrm{mg} / \mathrm{L}$ & $13(15.1)$ & 19 (22.1) & $48(55.8)$ & $67(77.9)$ & $83(96.5)$ & $83(96.5)$ & $86(100)$ & 31 (58.5) \\
\hline
\end{tabular}

Data are presented in absolute numbers (percentage). $x$-5: actual dose given $5 \mathrm{mg} / \mathrm{kg}$; 55 - s10mg/kg: simulated doses using the formula: 'peak concentration simulated dose = (peak concentration/actual dose) $\times$ simulated dose'; $x-7$ : actual dose given $7 \mathrm{mg} / \mathrm{kg}$.

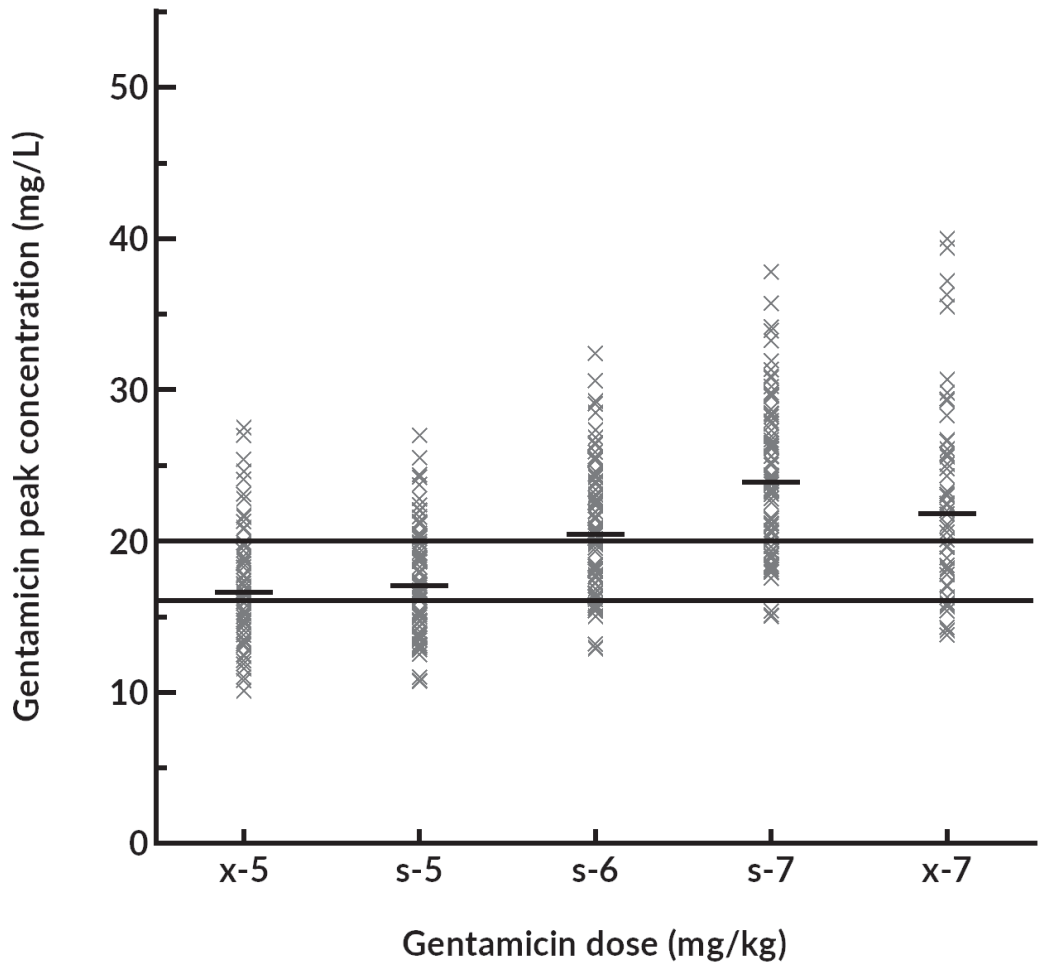

Figure 1. Measured and simulated gentamicin peak concentrations

Gentamicin peak concentrations for actual given doses ( $x-5$ : actual given dose $5 \mathrm{mg} / \mathrm{kg}$ (phase 1), and $x-7$ : actual given dose $7 \mathrm{mg} / \mathrm{kg}$ (phase 3 )), and simulated doses (s5 - s7: simulated doses for $5-7 \mathrm{mg} / \mathrm{kg}$ (phase 2)). The short black line represents the median peak concentration in $\mathrm{mg} / \mathrm{L}$ of every dose. 


\section{Renal function}

All patients received a single dose of gentamicin as part of the empirical antibiotic treatment of sepsis. Creatinine values at baseline and at admission were similar in the group receiving $5 \mathrm{mg} / \mathrm{kg}$, and the group receiving $7 \mathrm{mg} / \mathrm{kg}$ $(84 \mu \mathrm{mol} / \mathrm{L}$ vs. $84 \mu \mathrm{mol} / \mathrm{L}, P=0.39)$ (Table 3). After the administration of gentamicin, there were no differences between both groups regarding creatinine values during follow up of 14 days. The overall incidence of AKI relative to creatinine value at admission was low in both groups, with 1 patient (1.2\%) with Risk in the $5 \mathrm{mg} / \mathrm{kg}$ group, and 1 patient (4.2\%) with Risk, and another one with Injury in the $7 \mathrm{mg} / \mathrm{kg}$ group. No patients needed renal replacement therapy.

\section{Microbiological analysis}

Of the 80 positive blood cultures with Gram negative bacteria taken at the ED in 2015, 67.5\% were E. coli, $17.5 \%$ were Klebsiella spp., $11.2 \%$ were other Enterobacteriaceae, and 3.8\% were P. aeruginosa. Of the Enterobacteriaceae, 58 strains $(75.2 \%)$ had an MIC $<2 \mathrm{mg} / \mathrm{L}$, and seven strains $(9.1 \%)$ had an MIC = $2 \mathrm{mg} / \mathrm{L}$. Twelve (15.6\%) had an MIC $\geq 4 \mathrm{mg} / \mathrm{L}$, and were resistant for gentamicin (Table 4).

\section{Discussion}

Our study shows that in patients presenting with sepsis at the ED a gentamicin dose of $7 \mathrm{mg} / \mathrm{kg}$ is superior to $5 \mathrm{mg} / \mathrm{kg}$ in order to achieve sufficient gentamicin peak concentrations of $\geq 16 \mathrm{mg} / \mathrm{L}$. This is in line with previous studies in ICU patients [8,9].

Since insufficient gentamicin peak concentrations (i.e. $<16 \mathrm{mg} / \mathrm{L}$ ) were measured in $39.5 \%$ of patients with sepsis at the ED after a dose of $5 \mathrm{mg} / \mathrm{kg}$, peak concentrations for higher doses of gentamicin were determined by simulation. According to these simulations, with a dose of $7 \mathrm{mg} / \mathrm{kg}$ almost $95 \%$ of patients would reach a peak concentration of $\geq 16 \mathrm{mg} / \mathrm{L}$, which would be the preferred peak concentration for bacteria with an MIC of $2 \mathrm{mg} / \mathrm{L}$ [7]. Nearly $10 \%$ of positive blood cultures with Enterobacteriaceae in our ED had an MIC of $2 \mathrm{mg} / \mathrm{L}$, which shows the need for adequate dosage of gentamicin during the empirical treatment of sepsis at the ED. This applies especially to countries with a higher prevalence of resistant micro-organisms compared to the Netherlands. 
After the implementation of the new gentamicin dosing regimen, the measured peak concentrations corresponded well with our simulations. A gentamicin dose of $7 \mathrm{mg} / \mathrm{kg}$ turned out to be sufficient in the majority (84.9\%) of patients at the ED for Enterobacteriaceae with an MIC of $2 \mathrm{mg} / \mathrm{L}$.

Table 3. Monitoring of renal function after the administration of a gentamicin dose of 5 and $7 \mathrm{mg} / \mathrm{kg}$.

\begin{tabular}{|c|c|c|c|}
\hline & $\begin{array}{l}5 \mathrm{mg} / \mathrm{kg} \\
\mathrm{n}=86\end{array}$ & $\begin{array}{l}7 \mathrm{mg} / \mathrm{kg} \\
\mathrm{n}=53\end{array}$ & $P$ value \\
\hline Baseline creatinine ( $\mu \mathrm{mol} / \mathrm{L})$ & $84(71-116)$ & $84(68-108)$ & 0.39 \\
\hline Admission creatinine ( $\mu \mathrm{mol} / \mathrm{L})$ & $90(76-155)$ & $95(67-117)$ & 0.22 \\
\hline Creatinine T1 ( $\mu \mathrm{mol} / \mathrm{L})$ & $87(72-136)$ & $95(78-126)$ & 0.71 \\
\hline Creatinine T2 ( $\mu \mathrm{mol} / \mathrm{L})$ & $91(76-155)$ & $93(70-158)$ & 0.96 \\
\hline Creatinine T3 ( $\mu \mathrm{mol} / \mathrm{L})$ & $91(91-169)$ & $74(64-136)$ & 0.10 \\
\hline AKI on admission (relative to baseline) & $16 / 84(19.0)$ & $8 / 52(15.4)$ & \\
\hline Risk & $9 / 84(10.7)$ & $6 / 52(11.5)$ & \\
\hline Injury & $4 / 84(4.8)$ & $2 / 52(3.8)$ & \\
\hline Failure & $3 / 84(3.6)$ & 0 & \\
\hline $\begin{array}{l}\text { AKI on T3 (relative to admission; e.g. after } \\
\text { the administration of gentamicin) }\end{array}$ & $1 / 74(1.4)$ & $2 / 49(4.1)$ & \\
\hline Risk & $1 / 74(1.4)$ & $1 / 49(2.0)$ & \\
\hline Injury & 0 & $1 / 49(2.0)$ & \\
\hline Failure & 0 & 0 & \\
\hline
\end{tabular}

Data are presented in absolute numbers (percentage) or median (IQR). Baseline creatinine: most recent creatinine value prior to admission; Admission creatinine: creatinine value on admission; T1: 1-2 days after admission; T2: 3-7 days after admission; T3: 8-14 days after admission; AKI: acute kidney injury according to the RIFLE criteria [19].

Table 4. MIC distributions of positive blood cultures with Gram negative bacteria

\begin{tabular}{lllll}
\hline Micro-organism & & \multicolumn{3}{c}{ Gentamicin MIC distribution (n \%) } \\
\hline & & MIC $<2$ mg/L & MIC = 2 mg/L & MIC $\geq 4$ mg/L \\
\hline E. coli & $54(67.5)$ & $41(51.3)$ & $6(7.5)$ & $7(8.8)$ \\
Klebsiella spp. & $14(17.5)$ & $11(13.8)$ & 0 & $3(3.8)$ \\
Other Enterobacteriaceae & $9(11.2)$ & $6(7.5)$ & $1(1.3)$ & $2(2.5)$ \\
P. aeruginosa & $3(3.8)$ & $2(2.5)$ & $1(1.3)$ & 0 \\
Total & $80(100)$ & $60(75)$ & $8(10)$ & $12(15)$ \\
\hline
\end{tabular}

Data are presented in absolute numbers (percentage). MIC: minimal inhibitory concentration (mg/L) 
There are concerns whether a short course of gentamicin in a dose of $5 \mathrm{mg} / \mathrm{kg}$ leads to $\mathrm{AKI}$ and some question whether aminoglycosides are needed at all in the empirical treatment of sepsis [20]. These concerns will probably increase with the use of higher doses of gentamicin.

Although our study was not designed and powered to study the incidence of $\mathrm{AKI}$, we did not find differences in the incidence of $\mathrm{AKI}$ after the administration of a single dose of gentamicin between the two groups ( $5 \mathrm{vs} .7 \mathrm{mg} / \mathrm{kg}$ ) and the overall incidence of AKI was very low. This is in line with Nicolau et al., where only a low incidence of nephrotoxicity (1.2\%) was found after a short course of $7 \mathrm{mg} / \mathrm{kg}$ of gentamicin in 2184 clinical patients (non-ICU and non-ED) [4]. In addition, a single dose of gentamicin $5 \mathrm{mg} / \mathrm{kg}$ as part of the empirical treatment in 179 patients with sepsis at the ED, was not associated with an increased incidence of $\mathrm{AKI}$ in another study [21]. Therefore, the empirical use of aminoglycosides in patients with sepsis appears to be safe and in our opinion the advantages of a higher peak concentration outweigh the potential renal side effects, although our study is underpowered and was not designed for this purpose.

Furthermore, aminoglycosides can reduce the use of $3^{\text {rd }}$ and $4^{\text {th }}$ generation cephalosporins and carbapenems. For example, in a country with a low prevalence of multidrug resistant micro-organisms such as the Netherlands, the resistance rates of Enterobacteriaceae in clinical blood isolates for amoxicillin/clavulanic acid and $2^{\text {nd }}$ generation cephalosporins range from 7 - 24\% [22]. In the ICU [22], and in countries with a higher prevalence of multidrug resistant micro-organisms these numbers are higher [23]. However, the resistance rates of Enterobacteriaceae in non-ICU clinical blood isolates in the Netherlands are as low as 1-3\% for the combination of gentamicin and amoxicillin/clavulanic acid or a $2^{\text {nd }}$ generation cephalosporin [22].

Our study has some limitations. First, it is a single-centre study, and second, we had to rely on the correctness of the blood sampling protocol. However, our ED staff is well trained and adhered well to the peak sampling protocol. Second, our study was not powered to assess differences in the incidence of $\mathrm{AKI}$; therefore, conclusions regarding the renal safety of the higher gentamicin dosing regimen cannot be drawn from this study. Furthermore, when using the target peak concentration of $16-20 \mathrm{mg} / \mathrm{L}$ for Enterobacteriaceae, dosage is based on the assumption that all gentamicin susceptible Enterobacteriaceae could have an MIC $=2 \mathrm{mg} / \mathrm{L}$. In our study only $9.1 \%$ of Enterobacteriaceae 
had an MIC = $2 \mathrm{mg} / \mathrm{L}$, resulting in over-treating the majority of patients using this target. However, at the time of administering antibiotics in sepsis at the $E D$, the MIC of the causative pathogen is unknown. Therefore, this overtreatment is inevitable, since we assume the worst case scenario of an MIC = $2 \mathrm{mg} / \mathrm{L}$ when decisions are being made at the ED.

In conclusion, a gentamicin dose of $5 \mathrm{mg} / \mathrm{kg}$ leads to inadequate peak concentrations in a significant proportion of patients with sepsis at the ED. Since it is essential that aminoglycosides are adequately dosed in order to achieve a maximal bactericidal effect in patients with sepsis, we advise that other EDs using gentamicin as part of their empirical treatment of sepsis increase the dose of gentamicin to $7 \mathrm{mg} / \mathrm{kg}$.

\section{Acknowledgement}

We want to thank Rik van den Biggelaar for his excellent contributions to the data acquisition. 


\section{References}

1. Angus DC, Linde-Zwirble WT, Lidicker J, Clermont G, Carcillo J, Pinsky MR. Epidemiology of severe sepsis in the United States: analysis of incidence, outcome, and associated costs of care. Critical care medicine. 2001;29(7):1303-10.

2. Levy MM, Dellinger RP, Townsend SR, Linde-Zwirble WT, Marshall JC, Bion J, et al. The Surviving Sepsis Campaign: results of an international guideline-based performance improvement program targeting severe sepsis. Critical care medicine. 2010;38(2):367-74.

3. Lacy MK, Nicolau DP, Nightingale CH, Quintiliani R. The pharmacodynamics of aminoglycosides. Clinical infectious diseases : an official publication of the Infectious Diseases Society of America. 1998;27(1):23-7.

4. Nicolau DP, Freeman CD, Belliveau PP, Nightingale CH, Ross JW, Quintiliani R. Experience with a once-daily aminoglycoside program administered to 2,184 adult patients. Antimicrobial agents and chemotherapy. 1995;39(3):650-5.

5. Moore RD, Smith CR, Lipsky JJ, Mellits ED, Lietman PS. Risk factors for nephrotoxicity in patients treated with aminoglycosides. Annals of internal medicine. 1984;100(3):352-7.

6. Kashuba AD, Nafziger AN, Drusano GL, Bertino JS, Jr. Optimizing aminoglycoside therapy for nosocomial pneumonia caused by gram-negative bacteria. Antimicrobial agents and chemotherapy. 1999;43(3):623-9.

7. European Committee on Antimicrobial Susceptibility Testing (EUCAST). Gentamicin rationale for the EUCAST clinical breakpoints, version 1.2.; 2009.

8. Buijk SE, Mouton JW, Gyssens IC, Verbrugh HA, Bruining HA. Experience with a oncedaily dosing program of aminoglycosides in critically ill patients. Intensive care medicine. 2002;28(7):936-42.

9. Rea RS, Capitano B, Bies R, Bigos KL, Smith R, Lee H. Suboptimal aminoglycoside dosing in critically ill patients. Therapeutic drug monitoring. 2008;30(6):674-81.

10. Dasta JF, Armstrong DK. Variability in aminoglycoside pharmacokinetics in critically ill surgical patients. Critical care medicine. 1988;16(4):327-30.

11. Tang GJ, Tang JJ, Lin BS, Kong CW, Lee TY. Factors affecting gentamicin pharmacokinetics in septic patients. Acta anaesthesiologica Scandinavica. 1999;43(7):726-30.

12. Goncalves-Pereira J, Martins A, Povoa P. Pharmacokinetics of gentamicin in critically ill patients: pilot study evaluating the first dose. Clinical microbiology and infection : the official publication of the European Society of Clinical Microbiology and Infectious Diseases. 2010;16(8):1258-63.

13. Blot SI, Pea F, Lipman J. The effect of pathophysiology on pharmacokinetics in the critically ill patient--concepts appraised by the example of antimicrobial agents. Advanced drug delivery reviews. 2014;77:3-11.

14. Levy MM, Fink MP, Marshall JC, Abraham E, Angus D, Cook D, et al. 2001 SCCM/ESICM/ ACCP/ATS/SIS International Sepsis Definitions Conference. Critical care medicine. 2003;31(4):1250-6.

15. Dutch Working Party on Antibiotic Policy (SWAB). SWAB guidelines for antibacterial therapy of adult patients with sepsis. Amsterdam; 2010.

16. Traynor AM, Nafziger AN, Bertino JS, Jr. Aminoglycoside dosing weight correction factors for patients of various body sizes. Antimicrobial agents and chemotherapy. 1995;39(2):545-8. 
17. Singer M, Deutschman CS, Seymour CW, Shankar-Hari M, Annane D, Bauer M, et al. The Third International Consensus Definitions for Sepsis and Septic Shock (Sepsis-3). JAMA. 2016;315(8):801-10.

18. Hoste EA, Clermont G, Kersten A, Venkataraman R, Angus DC, De Bacquer D, et al. RIFLE criteria for acute kidney injury are associated with hospital mortality in critically ill patients: a cohort analysis. Critical care (London, England). 2006;10(3):R73.

19. Bellomo R, Ronco C, Kellum JA, Mehta RL, Palevsky P. Acute renal failure - definition, outcome measures, animal models, fluid therapy and information technology needs: the Second International Consensus Conference of the Acute Dialysis Quality Initiative (ADQI) Group. Critical care (London, England). 2004;8(4):R204-12.

20. Ong DSY, Frencken JF, Klein Klouwenberg PMC, Juffermans N, van der Poll T, Bonten MJM, et al. Short-Course Adjunctive Gentamicin as Empirical Therapy in Patients With Severe Sepsis and Septic Shock: A Prospective Observational Cohort Study. Clinical infectious diseases : an official publication of the Infectious Diseases Society of America. 2017;64(12):1731-36.

21. Cobussen M, de Kort JM, Dennert RM, Lowe SH, Stassen PM. No increased risk of acute kidney injury after a single dose of gentamicin in patients with sepsis. Infectious diseases (London, England). 2016;48(4):274-80.

22. de Greeff SC, Mouton JW, Schoffelen AF, Verduin CM. NethMap 2019 - Consumption of antimicrobial agents and antimicrobial resistance among medically important bacteria in the Netherlands in 2018.; 2019 Jun-2019.

23. European Centre for Disease Prevention and Control. Antimicrobial resistance surveillance in Europe 2015. Annual Report of the European Antimicrobial Resistance Surveillance Network (EARS-Net). Stockholm; 2017. 




\section{Chapter 7}

\section{Summarising discussion}




\section{Summarising discussion}

Sepsis is a frequently encountered condition in the emergency department (ED) that is associated with high mortality and morbidity. Aminoglycosides, such as gentamicin, are often used in the treatment of sepsis. Acute kidney injury (AKI) is an important complication of both sepsis and the treatment with aminoglycosides. Since sepsis in itself is already associated with AKI and the development of $A K I$ in sepsis is often multifactorial [1,2], determining the additional effect of aminoglycoside on the risk of AKI in patients with sepsis can be difficult. Aminoglycosides are, and will be, critically important antibiotics for human medicine. Therefore, this thesis investigated the proportion of patients with sepsis already presenting with AKI and established the balance between sepsis, AKI, and the treatment with aminoglycosides. In addition, we evaluated the safety of a single dose of gentamicin and aimed to optimise the treatment of gentamicin in patients with sepsis in the ED.

It is likely that the definitions of both AKI and sepsis will develop and change again in the future when evidence mounts, but in Chapter 2 we evaluated the most used definitions of today, to acquire a baseline of the number of patients with $A K I$ who present themselves with sepsis at the ED. We investigated the incidence of $A K I$ in patients with sepsis in the ED, with an emphasis on the differences between several $\mathrm{AKI}$ and sepsis definitions.

The aim of using criteria for $A K I$ is to recognize $A K I$ in patients with sepsis as early as possible, because sepsis associated AKI is associated with increased mortality and morbidity. In addition, when AKI is recognised early, close monitoring of the complications of renal failure is required to preserve and improve renal function. Next to this, renal preserving measures can be taken, such as dose adjustment of drugs, adequate fluid resuscitation and to withhold harmful drugs to the kidney. Therefore, the criteria to define AKI should select all those patients that have true $\mathrm{AKI}$ and are at risk for persistent kidney injury and increased morbidity and mortality. They should be sensitive enough for the initial evaluation and require greater specificity for the final diagnosis. And over time, the patient's clinical course and response to therapy can be included in the assessment of AKI.

The highest incidence of AKI was found in qSOFA patients applying the AKIN and KDIGO definition (51.1\%). In patients with sepsis according to the SOFA criteria, AKI was already present at presentation at the ED in $37.3 \%$, with 
the KDIGO and AKIN criteria defining the most patients with AKI. Previous studies found similar findings [3,4], however, our study is the first to take into account the SOFA criteria for sepsis.

The fact that the qSOFA criteria define the most patients with AKI, could mean that the qSOFA criteria select the most severely ill patients. However, since the qSOFA criteria are used as a screening instrument, it is questionable whether this should be a characteristic of a screening instrument, since it misses a lot of patients with true sepsis. These findings are in line with a recent meta-analysis in which the qSOFA criteria had poor sensitivity and moderate specificity for short-term mortality. The SIRS criteria had sensitivity superior to that of qSOFA, supporting the use of SIRS for screening of patients with sepsis [5]. This shows that the different sepsis criteria select different patients and thus a different risk of AKI. Following from this, we hypothesize that the qSOFA score at the ED may be interpreted as a reliable predictor for the development of $\mathrm{AKI}$, since half of the patients who met $\geq 2$ qSOFA criteria presented with AKI. However, a lot of patients with AKI are missed using this method, since the qSOFA score selected only 161/465 (34.6\%) patients with $\mathrm{AKI}$ according to the KDIGO criteria.

Applying the five different AKI criteria, the majority of patients had concordant AKI diagnoses. This high concordance between the AKI definitions is not remarkable, as the five definitions already clearly overlap. One can argue whether the newest KDIGO criteria really add an additional advantage compared to the already existing AKIN criteria. Our findings that the incidence of AKI using the AKIN and KDIGO do not differ much are also supported by several other studies [6-8], although other studies found that the KDIGO criteria yielded a higher incidence of AKI [9-11]. In addition, there is evidence to support that patients diagnosed with the same stage of AKI by the KDIGO criteria have significantly different outcomes using the different criteria; patients with AKI according to the combination of serum creatinine criteria and urine output criteria performed worse, compared to patients with AKI according to urine output criteria alone $[12,13]$. This means that within a criteria set itself, there are already differences in the incidence. Next to this, there is no consensus on whether urine output should be measured using consecutive hourly readings or mean output, which makes defining and staging of AKI vulnerable to inconsistency [14]. Furthermore, standardized documentation of urine production is difficult to achieve, especially in the ED. For this reason we chose to use the creatinine criteria of the AKI definitions only. 
The use of aminoglycosides in sepsis is debated, mostly because of the earlier mentioned nephrotoxic side effects. Previous research showed ambivalent results regarding the development of aminoglycosides-associated AKI. Some studies report a high risk of AKI, whereas others found no association [1517]. Most of these studies were performed in ICU patients, which are the most severely ill and are more often in shock. Probably, the results of the ICU studies cannot be extrapolated to ED patients, because the spectrum of sepsis as seen in the ED differs. In addition, little is known about the risk of developing $\mathrm{AKI}$ after the administration of a single dose of gentamicin.

In Chapter 3 and 4 we showed that a single dose of gentamicin does not increase the risk of $\mathrm{AKI}$ in patients with sepsis in the ED, which is in line with findings of several other studies [18-20]. In Chapter 3 we compared patient with sepsis who received gentamicin with a group of patients with pneumosepsis who were treated with antibiotics, but no aminoglycosides, as a control group. The patients with pneumosepsis turned out to be less severely ill and had less shock and less organ failure and thus had less AKI also; however, when comparing these patients who are even more susceptible to nephrotoxic stimuli, with the patients in the control group, we found no difference in the incidence of $\mathrm{AKI}$ after administration of a single dose of gentamicin.

Since our control group in this study, presented in Chapter 3, was less severely ill than the gentamicin group, we chose a different method of selecting the control group in Chapter 4. We selected patients with sepsis from a hospital using gentamicin as part of the empirical antibiotic treatment in selected foci, and compared them with patients with sepsis from two hospitals who did not routinely treat these patients with gentamicin or another aminoglycoside. In this study, we found similar findings; gentamicin was not a risk factor for the development of $\mathrm{AKI}$, and when $\mathrm{AKI}$ developed, this was multifactorial. The development of AKI was associated with shock, diabetes mellitus, and a higher baseline creatinine. These findings indicate that the severity of sepsis and pre-existent renal function are the most important features to develop sepsis associated $\mathrm{AKI}$, and not a single dose of gentamicin.

Although the groups were quite comparable, the control group still tended to be less severely ill and had less risk factors for the development of AKI compared to the gentamicin group. However, since the two groups were more alike than the two groups of our first study, we think this study approaches 
the truth. Only a randomised controlled trial (RCT) would solve the issues mentioned above. However, since the patent of gentamicin has expired, funding such a study will be very difficult.

Although gentamicin was not given routinely in two hospitals, some patients did receive gentamicin. These numbers were small and to avoid confounding by indication, we excluded these patients from the study. In addition, not all patients had an indication for gentamicin, as nearly one-third of the patients had a respiratory tract infection. This could be the result of the retrospective classification of the focus of the infection, because at the time of the administration of antibiotics at the ED, the focus of infection is not always known. Since the aim of our study was to investigate the effect of a single dose of gentamicin on the incidence and persistence of AKI in patients with sepsis in the ED and these patients met the sepsis criteria and were treated with gentamicin, we did not exclude these patients.

Two recent studies support our findings that a short course of gentamicin is not a risk factor for developing AKI $[18,19]$. One study concluded that patients with sepsis are prone to develop AKI, but did not find gentamicin to be a triggering factor for AKI. As we did in our studies in Chapter 3 and 4, they showed that the cause of developing AKI was multifactorial [18]. In addition, a systematic review showed a significant number of patients with a transient rise in creatinine after a single dose of gentamicin in a heterogeneous population, however persistent renal impairment was rare [21].

Due to the possible serious side effects of aminoglycosides, in 2018, the Dutch Health and Youth Care Inspectorate (IGJ) stated that informed consent should be obtained when aminoglycosides are administered [22]. Preferably informed consent should be obtained prior to the administration; however, in an acute setting this could be obtained afterwards. In the same report of this statement, of the 14 inspected hospitals, no hospital met the necessary conditions of informed consent. Informing patients about possible side effects of any therapy and obtaining informed consent we fully support. However, given the fact that we showed that a single dose of gentamicin does not increase the risk of $\mathrm{AKI}$, it is questionable whether such a strict disposition is truly necessary for a single dose of aminoglycoside given in an acute setting like sepsis in the ED. 
In contrast to the findings of our studies, an ICU study published in 2017 concluded that exposure to a short course of gentamicin was associated with the development of AKI [23]. In that ICU study, only patients with shock were included and the RIFLE criteria from stage Failure or worse were used to define AKI. In addition, a combined endpoint of AKI and mortality was used. Given these differences in population and used definitions and endpoint, this may explain why gentamicin was a risk factor for the development of AKI in the ICU study, but not in our studies. In addition, the empirical treatment in the ICU study consisted of a third-generation cephalosporin (plus metronidazole for a digestive tract infection). However, an alternative antimicrobial regimen was often used. In the non-gentamicin group, carbapenems and quinolones were more often used. Since aminoglycosides could be used to diminish the use of these reserve antibiotics, no fair judgment can be made on differences in the incidence of AKI or mortality, with respect to a short course of empirical gentamicin because of this heterogeneity in antibiotic treatment. Next to this, in this study, the median duration of gentamicin exposure was 2 (IQR, 1-3) days, whereas the patients in our studies received a single dose only.

Furthermore, vancomycin use was significantly higher in the gentamicin group ( $41 \%$ vs. $18 \%$ in the non-gentamicin group). It is known that the combination of vancomycin with aminoglycosides is highly nephrotoxic and a high risk of developing AKI [24-26]. In addition, there was a risk of confounding by indication, since $28 \%$ of hospital $A$ did not receive gentamicin and were included in the non-gentamicin arm and $7 \%$ of patients of hospital B were treated with gentamicin and included in the gentamicin arm. Moreover, it is possible that the patients treated with gentamicin were more severely ill than the patients who had not received gentamicin, and had run a higher risk of AKI. Lastly, in our study a risk factor for developing AKI was a higher baseline serum creatinine. In the latter study this was not taken into account in the multivariable analysis [23], nor was this addressed in other studies on this subject $[15,19]$

Another recent ICU study compared the incidence of AKI and the mortality rate between critically ill patients treated with a combined aminoglycoside regimen or a meropenem based regimen [19]. They concluded that the aminoglycoside regimen neither presented a higher AKI incidence nor mortality rate when compared with those on the meropenem regimen. This shows that aminoglycosides may be a safe option for the treatment of critically ill patients on carbapenem-sparing antimicrobial stewardship 
programs. The use of gentamicin as empirical treatment can reduce the use of carbapenems and quinolones (and other reserve antibiotics) and is therefore of benefit to patients with sepsis and, on the long term, society.

In the debate on the renal safety of empiric aminoglycoside therapy, some say a benefit must be shown, instead of showing the absence of clinically significant harm. A double-blind RCT with a broad spectrum beta-lactam antibiotic in one arm, and an adjunctive aminoglycoside to the other treatment arm would solve this controversy. However, such a trial will probably never be executed due to difficulties and costs, since the patent of aminoglycosides has expired, as stated earlier. In addition, to our knowledge no studies are done comparing broad spectrum penicillins, $2^{\text {nd }}, 3^{\text {rd }}$ and $4^{\text {th }}$ generation cephalosporins and carbapenems, or any other group of antibiotics, in the empiric treatment of sepsis.

Controversy remains as several studies have not shown an added survival benefit from a single daily dosing regimen of an aminoglycoside when combined with beta-lactam antibiotics [20, 27, 28], In one study, despite an almost perfect empiric antibiotic coverage with aminoglycosides (98.1\%), compared to $85.3 \%$ without aminoglycosides, no survival benefit on day 30 was seen [28]. However, in the aminoglycoside group more patients had septic shock and a low dose of aminoglycosides was used; mean gentamicin dose $3.9 \mathrm{mg} / \mathrm{kg}$ and mean tobramycin dose $4.7 \mathrm{mg} / \mathrm{kg}$. This combined with a higher volume of distribution in shock, can result in underdosing. In contrast, a meta-analysis did show a survival benefit, especially in those with septic shock [29]. Our studies were not designed to detect differences in mortality. However, the debate with conflicting evidence on the aminoglycosides' effect on mortality or the lack thereof may also be the result of high sensitive MICs in some studies or underdosing of aminoglycosides [28], which is a common finding, as we showed in Chapter 5 and 6 also.

There is growing resistance to commonly used antibiotics. With increasing antibiotic resistance, the options for appropriate empirical antibiotic therapy with a beta-lactam antibiotic alone are becoming fewer [30, 31]. Especially the low resistance levels will possibly increase the role of aminoglycosides in sepsis in the future era with increasing antibiotic resistance. In addition, in 2019 the World Health Organization (WHO) listed, among others, piperacillin/tazobactam, 3rd generation cephalosporins, and carbapenems as 'Watch' antibiotics in the 2019 WHO AWaRe Classification Database [32]. 
This means that these antibiotics have a higher resistance potential and are at relatively high risk of selection of bacterial resistance. Therefore, according to the WHO, these should be prioritized as a key target of stewardship programs to limit their use to ensure that these antibiotic agents can be used in the near future.

The use of aminoglycosides as empiric antibiotic therapy meets the WHO guidelines, because they can reduce the use of reserve antibiotics, such as piperacillin/tazobactam, 3rd and 4th generation cephalosporins and carbapenems, and keep resistance levels for these antibiotics low. This is, in our opinion, an important argument in a world with rising antibiotic resistance, especially since we showed that a single dose of gentamicin is safe with regard to renal function. This opinion is endorsed by the Nethmap also, a Dutch collaboration between the Centre for Infectious Disease Control (Clb), part of the National Institute for Public Health and the Environment (RIVM), and the Dutch Working Party on Antibiotic Policy (SWAB), as they state in the Nethmap 2020: "Combination therapy of a beta-lactam with an aminoglycoside is still the best suitable option for empirical treatment in serious infections with Gram-negative bacteria" [33]. When aminoglycosides are safe to use and the combination therapy with aminoglycosides is clinically non-inferior in patients with sepsis, this, in our opinion, would be sufficient to advocate for the use of aminoglycosides in sepsis.

In Chapter 5 and 6 adequate dosing of gentamicin in patients with sepsis was addressed, since it is essential in order to achieve a maximal bactericidal effect. Underdosing will lead to a lower gentamicin peak concentration and consequently to potential treatment failure and increased morbidity and mortality. However, dosing of drugs per kilogram body weight can be challenging, especially in an environment like the ED since estimating body weight by patients and healthcare workers is prone to error [34]. In addition, gentamicin is hydrophilic, which means that for obese patients (BMI >30 $\mathrm{kg} / \mathrm{m} 2$ ), the adjusted body weight should be used to calculate the dose of gentamicin. In Chapter 5 we found that nearly a fifth of the patients with sepsis were underdosed and underdosing was also found in other studies [35, 36]. Potential reasons for underdosing may be fear of nephrotoxic side effects, incorrect estimation of body weight, or rounding down of the gentamicin dose, based on whole ampules [37]. To improve dosing, standardised weighing 
before administering gentamicin might be considered [36]. Alternatively, plasma peak concentrations could be useful in reducing suboptimal dosing of gentamicin, which we subsequently did in Chapter 6.

With a gentamicin dose of $5 \mathrm{mg} / \mathrm{kg}$, a high number of patients (39.5\%) did not reach adequate gentamicin peak concentrations of $>16 \mathrm{mg} / \mathrm{L}$, as was previously shown by other studies in ICU patients [38, 39]. However, our study was the first to address this issue in patients with sepsis in the ED. After this finding, a simulation was performed to determine which dose was needed to reach adequate gentamicin peak concentrations of $\geq 16 \mathrm{mg} / \mathrm{L}$. After the simulations, we chose a gentamicin dosing of $7 \mathrm{mg} / \mathrm{kg}$ and subsequently implemented this new regimen in the ED of the Maastricht University Medical Center. After implementing this new regimen, the majority (84.9\%) of patients had a sufficient peak concentration of $>16 \mathrm{mg} / \mathrm{L}$.

The ratio of using therapeutic drug monitoring and measuring gentamicin peak concentrations consists of findings of studies that the height of the peak concentration corresponds with the clinical response rate. Approximately $85 \%$ of patients have a good clinical response with a Cmax/MIC-ratio of 8:1 and $90 \%$ with a ratio of $10: 1$ [40,41]. Gentamicin is started empirically, as soon as the indication to start antibiotics has been made and before culture results are received (i.e. before the susceptibility (MIC) of the causative microorganism is known). According to the European Committee on Antimicrobial Susceptibility Testing (EUCAST) the gentamicin MIC clinical breakpoint for Enterobacteriaceae is $2 \mathrm{mg} / \mathrm{L}$ [42]. This means that MICs $\leq 2 \mathrm{mg} / \mathrm{L}$ indicate susceptibility for gentamicin. Therefore, the peak concentration should be aimed at all gentamicin susceptible micro-organisms and should aim at the worst case scenario (i.e. $\mathrm{MIC}=2$ ), which consequently leads to a PD target of at least $8 \times 2 \mathrm{mg} / \mathrm{l}=16 \mathrm{mg} / \mathrm{L}$. However, when a micro-organism has a MIC <2, lower peak concentrations are probably sufficient.

We used the Cmax/MIC-ratio as the pharmacodynamical target. However, some argue that the AUC/MIC ratio might be a better method to predict the bactericidal effect $[43,44]$. The earliest clinical studies often did not take into account the AUC/MIC ratio as a pharmacodynamical target and focussed on the Cmax. Since high collinearity exists between $\mathrm{Cmax}$ and AUC, an increase in Cmax will lead to an increase in AUC also [44]. 
Several other pharmacological studies suggest that higher doses (i.e. 7 or 8 $\mathrm{mg} / \mathrm{kg}$ ) are needed in case of sepsis also [38, 39]. There are concerns whether higher doses of gentamicin lead to AKI, however, the risk of nephrotoxicity is determined by the trough concentration in serum [45, 46]. Higher doses and higher peak concentrations do not necessarily cause a higher risk of nephrotoxicity. In patients with normal renal function, half-life is $2-3$ hours, so one would expect normal trough concentrations and therefore equal rates of AKI, even with higher doses of $7 \mathrm{mg} / \mathrm{kg}$. However, this is a reason for some doctors to withhold aminoglycosides in patients with sepsis and $\mathrm{AKI}$ or chronic kidney disease (CKD). Since patients with AKI (409/1573 (26.0\%) of patients in Chapter 4) and CKD (134/1573 (8.5\%) of patients in Chapter 4) were also represented in our studies, in whom we found no risk of AKI after a single dose of gentamicin, we think there is no good reason to withhold at least a single dose of aminoglycosides in these patients if there is an indication to administer aminoglycosides.

Although our study was not designed and powered to study the incidence of $\mathrm{AKI}$, we did not find differences in the incidence of $A K I$ after the administration of a single dose of gentamicin between patients with $5 \mathrm{mg} /$ $\mathrm{kg}$ and $7 \mathrm{mg} / \mathrm{kg}$. These findings were in line with another study where only a low incidence of nephrotoxicity (1.2\%) was found after a short course of $7 \mathrm{mg} / \mathrm{kg}$ of gentamicin in 2184 clinical patients (non-ICU and non-ED), although a different definition of AKI was used (i.e. a rise in serum creatinine of $\geq 44 \mu \mathrm{mol} / \mathrm{l}$ above the baseline value during aminoglycoside therapy) [47]. Establishing the differences in risk of AKI between a gentamicin dose of $5 \mathrm{mg} /$ $\mathrm{kg}$ and $7 \mathrm{mg} / \mathrm{kg}$ could be a goal for future research. In addition, we did not take vestibulo-ototoxicity into account. However, in a case series of 103 patients during a selected 23 year study period, only 6 patients received a single dose only [48].

Some debate that even higher doses are needed, i.e. a dose $>10 \mathrm{mg} / \mathrm{kg}$ rather than $7 \mathrm{mg} / \mathrm{kg}[49,50]$. However, in our opinion and using our simulations and measured peak concentrations, $7 \mathrm{mg} / \mathrm{kg}$, or maybe $8 \mathrm{mg} / \mathrm{kg}$, is an adequate dose for most patients with sepsis at the ED. Higher daily doses (e.g. $>10$ $\mathrm{mg} / \mathrm{kg}$ ) lead to overshooting the PD target in more patients and the possible advantages of a higher peak concentration would not outweigh the potential side effects and allowing for a second dose as early as possible if necessary. Ideally, in the future we can achieve personalised medicine and determine which patient should receive a higher or lower dose. 
Physicians at the EDs that use gentamicin as part of their empirical treatment could use the findings of our study in order to reach adequate target peak concentrations to cover Enterobacteriaceae with an MIC $\leq 2 \mathrm{mg} / \mathrm{L}$. In our ED, nearly $10 \%$ of positive blood cultures with Enterobacteriaceae had an MIC of $2 \mathrm{mg} / \mathrm{L}$. This shows the need for adequate dosage of gentamicin (and aminoglycosides in general) during the empirical treatment of sepsis at the ED. This applies especially to countries with a higher prevalence of resistant micro-organisms compared to the Netherlands, as long as gentamicin can be used empirically. If however resistance rates for gentamicin rise to a level that empirical use of gentamicin offers no added clinical benefit (i.e. broadening of the Gram negative spectrum of activity of the beta-lactam antibiotic of first choice), the empirical use of gentamicin will not be useful anymore.

We investigated the role of gentamicin in sepsis and $\mathrm{AKI}$. Whether we can extrapolate these results to other aminoglycosides is not known, however, given the similarities of the most commonly used aminoglycosides in terms of mechanism of action and toxicity, we think the results of the renal safety of a single dose of gentamicin can be extrapolated to the other aminoglycosides [51].

In conclusion, sepsis is a leading cause of death with a heterogeneous presentation. Aminoglycosides are fascinating antibiotics that are still widely used to treat sepsis. Not only are aminoglycosides ancient antibiotics (when it comes down to antibiotic history), they are treated with scepticism by some and praised by others. And above all, everyone has an opinion about aminoglycosides.

Balancing between sepsis, AKI, and the treatment with aminoglycosides is a difficult task for all of us doctors. This thesis shows that AKI is already common in patients presenting with sepsis in the ED. AKI is associated with a higher baseline serum creatinine and septic shock, and not with a single dose of gentamicin. Therefore, it is safe to administer a single dose of gentamicin to these patients. When it comes to the dosing of gentamicin in patients with sepsis in the ED, underdosing is common and a dose of $7 \mathrm{mg} / \mathrm{kg}$ tips the balance to an adequate dosing regimen in these patients. The combination of a beta-lactam antibiotic and an aminoglycoside gives a better antibiotic coverage, compared to monotherapy beta-lactam, and it is an effective and safe empirical sepsis treatment. 
We hope this thesis will contribute to a more adequate dosing of gentamicin and a more positive view on the safety profile of gentamicin, so gentamicin can be used for an even longer period of time and can help reduce the use of reserve antibiotics in a world with rising antibiotic resistance. So we can use our antibiotics for future generations to come. 


\section{References}

1. Bagshaw SM, Uchino S, Bellomo R, Morimatsu H, Morgera S, Schetz M, et al. Septic acute kidney injury in critically ill patients: clinical characteristics and outcomes. Clinical journal of the American Society of Nephrology: CJASN. 2007;2(3):431-9.

2. Alobaidi R, Basu RK, Goldstein SL, Bagshaw SM. Sepsis-associated acute kidney injury. Seminars in nephrology. 2015;35(1):2-11.

3. Koeze J, Keus F, Dieperink W, van der Horst IC, Zijlstra JG, van Meurs M. Incidence, timing and outcome of AKI in critically ill patients varies with the definition used and the addition of urine output criteria. BMC nephrology. 2017;18(1):70.

4. Zhou J, Liu Y, Tang Y, Liu F, Zhang L, Zeng X, et al. A comparison of RIFLE, AKIN, KDIGO, and Cys-C criteria for the definition of acute kidney injury in critically ill patients. International urology and nephrology. 2016;48(1):125-32.

5. Fernando SM, Tran A, Taljaard M, Cheng W, Rochwerg B, Seely AJE, et al. Prognostic Accuracy of the Quick Sequential Organ Failure Assessment for Mortality in Patients With Suspected Infection: A Systematic Review and Meta-analysis. Annals of internal medicine. 2018;168(4):266-75.

6. Nisula S, Kaukonen KM, Vaara ST, Korhonen AM, Poukkanen M, Karlsson S, et al. Incidence, risk factors and 90-day mortality of patients with acute kidney injury in Finnish intensive care units: the FINNAKI study. Intensive care medicine. 2013;39(3):420-8.

7. Levi TM, de Souza SP, de Magalhães JG, de Carvalho MS, Cunha AL, Dantas JG, et al. Comparison of the RIFLE, AKIN and KDIGO criteria to predict mortality in critically ill patients. Revista Brasileira de terapia intensiva. 2013;25(4):290-6.

8. Rodrigo E, Suberviola B, Albines Z, Castellanos Á, Heras M, Rodriguez-Borregán JC, et al. A comparison of acute kidney injury classification systems in sepsis. Nefrologia : publicacion oficial de la Sociedad Espanola Nefrologia. 2016;36(5):530-4.

9. Roy AK, Mc Gorrian C, Treacy C, Kavanaugh E, Brennan A, Mahon NG, et al. A Comparison of Traditional and Novel Definitions (RIFLE, AKIN, and KDIGO) of Acute Kidney Injury for the Prediction of Outcomes in Acute Decompensated Heart Failure. Cardiorenal medicine. 2013;3(1):26-37.

10. Luo X, Jiang L, Du B, Wen Y, Wang M, Xi X. A comparison of different diagnostic criteria of acute kidney injury in critically ill patients. Critical care (London, England). 2014;18(4):R144.

11. Pereira M, Rodrigues N, Godinho I, Gameiro J, Neves M, Gouveia J, et al. Acute kidney injury in patients with severe sepsis or septic shock: a comparison between the 'Risk, Injury, Failure, Loss of kidney function, End-stage kidney disease' (RIFLE), Acute Kidney Injury Network (AKIN) and Kidney Disease: Improving Global Outcomes (KDIGO) classifications. Clinical kidney journal. 2017;10(3):332-40.

12. Kellum JA, Sileanu FE, Murugan R, Lucko N, Shaw AD, Clermont G. Classifying AKI by Urine Output versus Serum Creatinine Level. Journal of the American Society of Nephrology : JASN. 2015;26(9):2231-8.

13. Howitt SH, Grant SW, Caiado C, Carlson E, Kwon D, Dimarakis I, et al. The KDIGO acute kidney injury guidelines for cardiac surgery patients in critical care: a validation study. BMC nephrology. 2018;19(1):149. 
14. Allen JC, Gardner DS, Skinner H, Harvey D, Sharman A, Devonald MAJ. Definition of hourly urine output influences reported incidence and staging of acute kidney injury. BMC nephrology. 2020;21(1):19.

15. Picard W, Bazin F, Clouzeau B, Bui HN, Soulat M, Guilhon E, et al. Propensity-based study of aminoglycoside nephrotoxicity in patients with severe sepsis or septic shock. Antimicrobial agents and chemotherapy. 2014;58(12):7468-74.

16. Ong L-Z, Tambyah PA, Lum LH, Low Z-J, Cheng I, Murali TM, et al. Aminoglycosideassociated acute kidney injury in elderly patients with and without shock. Journal of Antimicrobial Chemotherapy. 2016;71(11):3250-7.

17. Cobussen M, de Kort JM, Dennert RM, Lowe SH, Stassen PM. No increased risk of acute kidney injury after a single dose of gentamicin in patients with sepsis. Infectious diseases (London, England). 2016;48(4):274-80.

18. Carlsen S, Boel J, Jarlov JO, Gjorup I, Soborg C, Arpi M. The effect of short-course gentamicin therapy on kidney function in patients with bacteraemia-a retrospective cohort study. European journal of clinical microbiology \& infectious diseases : official publication of the European Society of Clinical Microbiology. 2018;37(12):2307-12.

19. Pitta RD, Gasparetto J, De Moraes TP, Telles JP, Tuon FF. Antimicrobial therapy with aminoglycoside or meropenem in the intensive care unit for hospital associated infections and risk factors for acute kidney injury. European journal of clinical microbiology \& infectious diseases : official publication of the European Society of Clinical Microbiology. 2020;39(4):723-8.

20. Heffernan AJ, Sime FB, Sun J, Lipman J, Kumar A, Andrews K, et al. ?-lactam antibiotic versus combined $\beta$-lactam antibiotics and single daily dosing regimens of aminoglycosides for treating serious infections: A meta-analysis. International journal of antimicrobial agents. 2020;55(3):105839.

21. Hayward RS, Harding J, Molloy R, Land L, Longcroft-Neal K, Moore D, et al. Adverse effects of a single dose of gentamicin in adults: a systematic review. British journal of clinical pharmacology. 2018;84(2):223-38.

22. Health and Youth Care Inspectorate (IGJ). Toezichtresultaten ziekenhuisbezoeken Therapeutic Drug Monitoring Aminoglycosiden. Utrecht: Health and Youth Care Inspectorate (IGJ); 2018.

23. Ong DSY, Frencken JF, Klein Klouwenberg PMC, Juffermans N, van der Poll T, Bonten MJM, et al. Short-Course Adjunctive Gentamicin as Empirical Therapy in Patients With Severe Sepsis and Septic Shock: A Prospective Observational Cohort Study. Clinical infectious diseases : an official publication of the Infectious Diseases Society of America. 2017;64(12):1731-36.

24. Rybak MJ, Abate BJ, Kang SL, Ruffing MJ, Lerner SA, Drusano GL. Prospective evaluation of the effect of an aminoglycoside dosing regimen on rates of observed nephrotoxicity and ototoxicity. Antimicrobial agents and chemotherapy. 1999;43(7):1549-55.

25. Rybak MJ, Albrecht LM, Boike SC, Chandrasekar PH. Nephrotoxicity of vancomycin, alone and with an aminoglycoside. The Journal of antimicrobial chemotherapy. 1990;25(4):679-87.

26. Goetz MB, Sayers J. Nephrotoxicity of vancomycin and aminoglycoside therapy separately and in combination. The Journal of antimicrobial chemotherapy. 1993;32(2):325-34.

27. Paul M, Lador A, Grozinsky-Glasberg S, Leibovici L. Beta lactam antibiotic monotherapy versus beta lactam-aminoglycoside antibiotic combination therapy for sepsis. The Cochrane database of systematic reviews. 2014(1):Cd003344. 
28. Deelen JWT, Rottier WC, Buiting AGM, Dorigo-Zetsma JW, Kluytmans J, van der Linden PD, et al. Short-course aminoglycosides as adjunctive empirical therapy in patients with Gram-negative bloodstream infection, a cohort study. Clinical microbiology and infection : the official publication of the European Society of Clinical Microbiology and Infectious Diseases. 2020.

29. Kumar A, Safdar N, Kethireddy S, Chateau D. A survival benefit of combination antibiotic therapy for serious infections associated with sepsis and septic shock is contingent only on the risk of death: a meta-analytic/meta-regression study. Critical care medicine. 2010;38(8):1651-64.

30. World Health Organization (WHO). Antimicrobial Resistance: Global Report on Surveillance. Geneva: World Health Organization (WHO); 2014.

31. de Greeff SC, Mouton JW, Schoffelen AF, Verduin CM. NethMap 2019 - Consumption of antimicrobial agents and antimicrobial resistance among medically important bacteria in the Netherlands in 2018.; 2019 Jun-2019.

32. World Health Organization (WHO). World Health Organization model list of essential medicines: 21st list 2019. Geneva: World Health Organization; 2019.

33. de Greeff SC, Schoffelen AF, Verduin CM. NethMap 2020 - Consumption of antimicrobial agents and antimicrobial resistance among medically important bacteria in the Netherlands in 2019. 2020.

34. Menon S, Kelly AM. How accurate is weight estimation in the emergency department? Emergency medicine Australasia : EMA. 2005;17(2):113-6.

35. Egan S, Murphy PG, Fennell JP, Kelly S, Hickey M, McLean C, et al. Using Six Sigma to improve once daily gentamicin dosing and therapeutic drug monitoring performance. BMJ quality \& safety. 2012;21(12):1042-51.

36. de Montmollin E, Bouadma L, Gault N, Mourvillier B, Mariotte E, Chemam S, et al. Predictors of insufficient amikacin peak concentration in critically ill patients receiving a $25 \mathrm{mg} / \mathrm{kg}$ total body weight regimen. Intensive care medicine. 2014;40(7):998-1005.

37. Leong CL, Buising K, Richards $M$, Robertson M, Street A. Providing guidelines and education is not enough: an audit of gentamicin use at The Royal Melbourne Hospital. Internal medicine journal. 2006;36(1):37-42.

38. Buijk SE, Mouton JW, Gyssens IC, Verbrugh HA, Bruining HA. Experience with a oncedaily dosing program of aminoglycosides in critically ill patients. Intensive care medicine. 2002;28(7):936-42.

39. Rea RS, Capitano B, Bies R, Bigos KL, Smith R, Lee H. Suboptimal aminoglycoside dosing in critically ill patients. Therapeutic drug monitoring. 2008;30(6):674-81.

40. Moore RD, Lietman PS, Smith CR. Clinical response to aminoglycoside therapy: importance of the ratio of peak concentration to minimal inhibitory concentration. The Journal of infectious diseases. 1987;155(1):93-9.

41. Kashuba AD, Nafziger AN, Drusano GL, Bertino JS, Jr. Optimizing aminoglycoside therapy for nosocomial pneumonia caused by gram-negative bacteria. Antimicrobial agents and chemotherapy. 1999;43(3):623-9.

42. European Committee on Antimicrobial Susceptibility Testing (EUCAST). Gentamicin rationale for the EUCAST clinical breakpoints, version 1.2.; 2009. 
43. Mouton JW, Jacobs N, Tiddens H, Horrevorts AM. Pharmacodynamics of tobramycin in patients with cystic fibrosis. Diagnostic microbiology and infectious disease. 2005;52(2):123-7.

44. Abdul-Aziz MH, Alffenaar JC, Bassetti M, Bracht H, Dimopoulos G, Marriott D, et al. Antimicrobial therapeutic drug monitoring in critically ill adult patients: a Position Paper. Intensive care medicine. 2020;46(6):1127-53.

45. Dahlgren JG, Anderson ET, Hewitt WL. Gentamicin blood levels: a guide to nephrotoxicity. Antimicrobial agents and chemotherapy. 1975;8(1):58-62.

46. Streetman DS, Nafziger AN, Destache CJ, Bertino AS, Jr. Individualized pharmacokinetic monitoring results in less aminoglycoside-associated nephrotoxicity and fewer associated costs. Pharmacotherapy. 2001;21(4):443-51.

47. Nicolau DP, Freeman CD, Belliveau PP, Nightingale CH, Ross JW, Quintiliani R. Experience with a once-daily aminoglycoside program administered to 2,184 adult patients. Antimicrobial agents and chemotherapy. 1995;39(3):650-5.

48. Ahmed RM, Hannigan IP, MacDougall HG, Chan RC, Halmagyi GM. Gentamicin ototoxicity: a 23-year selected case series of 103 patients. The Medical journal of Australia. 2012;196(11):701-4.

49. Allou N, Charifou Y, Augustin P, Galas T, Valance D, Corradi L, et al. A study to evaluate the first dose of gentamicin needed to achieve a peak plasma concentration of $30 \mathrm{mg} / \mathrm{l}$ in patients hospitalized for severe sepsis. European journal of clinical microbiology \&amp; infectious diseases : official publication of the European Society of Clinical Microbiology. 2016;35(7):1187-93.

50. Pernod C, Lamblin A, Cividjian A, Gerome P, Pierre-François W. Use of Gentamicin for Sepsis and Septic Shock in Anaesthesia-Intensive Care Unit: A Clinical Practice Evaluation. 2019.

51. Craig WA. Optimizing aminoglycoside use. Critical care clinics. 2011;27(1):107-21. 


Chapter 8

Impact for society 


\section{Impact for society}

Aminoglycosides, such as gentamicin, are antibiotic drugs that are considered harmful to the kidneys when not used properly. Therefore, there is frequent hesitation in administering these drugs in severely ill patients with sepsis despite there being an indication. However, in a world with increasing antibiotic resistance it is important to keep all antibiotic options open since the options for appropriate empirical antibiotic therapy with the commonly used broad spectrum antibiotics are becoming fewer. Since aminoglycosides kill bacteria rapidly and there is a low resistance rate, it is important to establish the safety and to optimise the use of these agents as the role of aminoglycosides in the treatment of sepsis will possibly increase in the future era with increasing antibiotic resistance.

Previously, the toxicity of aminoglycosides on the kidneys was mostly studied in ICU patients. However, patients often present themselves with sepsis in the emergency department (ED) and the patients in the ED are often less severely ill.

It is likely that the results of ICU studies cannot be extrapolated to ED patients, because the spectrum of sepsis as seen in these patients in the ED differs.

Our studies were the first to evaluate the effect of a single dose of gentamicin in patients with sepsis in the ED. In two different studies, we established that it is safe to administer a single dose of gentamicin to patients with sepsis in the ED with regard to renal function.

Subsequently, we showed that underdosing of gentamicin is a common finding in the ED. In addition, even when the aimed dose of gentamicin is administered, we measured insufficient gentamicin blood levels in a large number of patients, which consequently could lead to potential treatment failure and eventually to worse outcome. After these findings, simulations were executed to determine which dose would be needed to reach adequate gentamicin blood levels. Using the results of these simulations, a new dosing regimen for gentamicin was introduced by the Antibiotic Committee of the Maastricht University Medical Center+. The dose of gentamicin was increased from $5 \mathrm{mg} / \mathrm{kg}$ to $7 \mathrm{mg} / \mathrm{kg}$ body weight. After the implementation of this new 
dosing regimen, gentamicin blood levels were measured again and we found that a gentamicin dose of $7 \mathrm{mg} / \mathrm{kg}$ turned out to be sufficient in the majority of patients.

We established that a single dose of gentamicin is safe with regard to renal function. In addition, we showed ways to optimise the use of gentamicin in the ED, which other hospitals and physicians can use to optimise their own antibiotic treatment protocols. Since sepsis is a life-threatening condition and the incidence of sepsis is increasing over the years, adequate antibiotic treatment is of the utmost importance. The findings of our studies are useful for all physicians of all specialties treating patients with sepsis and can help to make a well-informed choice on appropriate and adequate antibiotic therapy in patients with sepsis.

Due to the possible serious side effects of aminoglycosides, since 2018 the Dutch Health and Youth Care Inspectorate (IGJ) demands that informed consent should be obtained when aminoglycosides are administered. However, we showed that a single dose of gentamicin is safe with regard to renal function. Therefore, maybe such a strict disposition is not necessary for only one dose.

The findings of our studies were published in peer-reviewed journals and if possible as an open access manuscript to make them freely accessible via the internet for a broad public, including developing countries. The general public can benefit from the results of our studies due to more appropriate and adequate antibiotic therapy in terms of antibiotic coverage, in a time with worldwide increasing antibiotic resistance. 


Appendices 


Nederlandse samenvatting 


\section{Nederlandse samenvatting}

Sepsis is een ernstige en levensbedreigende ziekte. Het wordt veroorzaakt door een infectie, waarbij het lichaam heel heftig reageert op deze infectie. Patiënten zijn vaak erg ziek, hebben hoge koorts, een hoge hartslag en snelle ademfrequentie en ze kunnen erg bleek of zweterig zien. Ook kan de bloeddruk erg laag zijn. Uiteindelijk leidt sepsis tot orgaan falen, waarbij vaak verschillende organen van het lichaam tegelijkertijd niet meer functioneren. Zo kan er afzonderlijk nier-, long-, hart- of leverfalen optreden, maar ook gelijktijdig met elkaar. Uiteindelijk resulteert multi-orgaan falen vaak in overlijden. In 2018 werden in Nederland meer dan 5000 patiënten met sepsis opgenomen op de Intensive Care (IC). Het aantal patiënten met sepsis dat de spoedeisende hulp bezoekt is nog vele malen hoger.

Vaak wordt sepsis veroorzaakt door een bacteriële infectie. Gezien de ernst van de ziekte, is het essentieel dat sepsis vroegtijdig wordt herkend en er ook vroegtijdig behandeling wordt gestart in de vorm van vochtinfusie, antibiotica en zo nodig bloeddruk verhogende medicijnen. Dit omdat vroegtijdige behandeling bij kan dragen aan minder ernstige ziekte en een lager risico op overlijden.

Om sepsis vroegtijdig te kunnen herkennen zijn er verschillende sepsis scores ontwikkeld. En omdat we in het begin nog niet weten welke ziekteverwekker de oorzaak van de infectie is, wordt er breedspectrum antibiotica gegeven. Dit zijn antibiotica die tegen veel verschillende soorten bacteriën werken. In veel ziekenhuizen worden aminoglycosiden, zoals gentamicine, gegeven als onderdeel van de behandeling met breedspectrum antibiotica. Met name als spectrumverbreding voor de behandeling van Gram-negatieve bacteriën (dit zijn vooral bacteriën die normaal gesproken in de darmen van mensen voorkomen). De reden om gentamicine toe te voegen aan de antibiotische behandeling is dat vooral Gram-negatieve bacteriën in toenemende mate resistent zijn voor de eerstelijns antibiotica die worden gegeven aan patiënten. De resistentie voor aminoglycosiden, zoals gentamicine, ligt over het algemeen een stuk lager waardoor je met gentamicine bacteriën, die resistent zijn voor de eerstelijns middelen, wel kunt behandelen. Daarnaast steriliseren aminoglycosiden snel de bloedbaan, zijn ze goedkoop en zijn ze gemakkelijk verkrijgbaar. 
Daarnaast kunnen aminoglycosiden het gebruik van reserve-antibiotica verminderen. Reserve-antibiotica zijn antibiotica die niet binnen het normale antibioticabeleid opgenomen zijn en waarbij gebruik alleen geïndiceerd is bij speciale resistente micro-organismen of voor specifieke ziektegevallen. Omdat deze middelen soms een laatste redmiddel zijn heeft de Wereldgezondheidsorganisatie (WHO) geadviseerd om het gebruik van deze reserve-antibiotica zoveel mogelijk te beperken. Aminoglycosiden kunnen hier dus bij helpen.

Het gebruik van aminoglycosiden voor de behandeling van sepsis is echter niet onomstreden. Dit komt doordat acute nierschade een belangrijke bijwerking van aminoglycoside is. Aangezien patiënten met sepsis op zichzelf al risico hebben op acute nierschade, onder andere door een lage bloeddruk en daardoor verminderde bloedaanvoer naar de nieren, is het niet altijd duidelijk wat nu de oorzaak van de acute nierschade is bij patiënten met sepsis wanneer ook aminoglycosiden zijn toegediend. Aangezien acute nierschade een belangrijk teken is van ernstige ziekte en een risicofactor voor overlijden, zijn sommige artsen terughoudend met het geven van aminoglycosiden aan patiënten met sepsis. Vanwege de belangrijke consequenties van acute nierschade zijn ook hiervoor verschillende scores ontwikkeld, zodat men bij vroegtijdige herkenning maatregelen kan nemen om te proberen de nierschade te herstellen of verdere schade te voorkomen.

Hoofdstuk 1, de introductie, geeft een overzicht over sepsis, het gebruik van aminoglycosiden en acute nierschade, dat zowel geassocieerd is met sepsis, als met het gebruik van aminoglycosiden. Daarnaast geeft het een overzicht van de wetenschappelijke literatuur die reeds bestaat. Deze introductie is de opmaat voor de overige onderdelen van het proefschrift en zet het doel en de achterliggende vragen uiteen.

In hoofdstuk 2 onderzoeken we de invloed van verschillende definitie scores voor sepsis en acute nierschade op het vóórkomen van acute nierschade. In 2016 werd er na 15 jaar een nieuwe sepsis score geïntroduceerd. De SIRS (systemic inflammatory response syndrome) score werd verlaten en de SOFA (sequential organ failure assessment) score werd in gebruik genomen. Daarnaast is er een afgeleide score van de SOFA score, de qSOFA (quick sequential organ failure assessment) score, ontwikkeld. Deze scores 
zijn vooral handig om snel patiënten met sepsis te herkennen, zodat deze patiënten snel behandeld kunnen worden. Om acute nierschade te definiëren zijn er ook verschillende definities ontwikkeld.

Eerder is er veel onderzoek gedaan naar het aantal patiënten met sepsis volgens de oude SIRS criteria dat ook acute nierschade heeft. Er was nog geen onderzoek gedaan naar het aantal patiënten met sepsis volgens de SOFA score, dat zich presenteert op de eerste hulp met ook acute nierschade. Deze studie richt zich hier op, zodat dokters zich hiervan bewust kunnen zijn en de juiste maatregelen kunnen nemen om zowel de sepsis, als de acute nierschade, goed te kunnen behandelen.

In dit hoofdstuk toonden we aan dat het vóórkomen van acute nierschade bij patiënten met sepsis sterk afhankelijk is van de gebruikte definitie van zowel sepsis, als acute nierschade. Afhankelijk van de gebruikte definities had tussen de 17.7 en $51.1 \%$ van de patiënten acute nierschade. Wanneer acute nierschade optrad, ging dit gepaard met een langere opnameduur en een hogere kans op chronische nierschade en overlijden.

Hoofdstuk 3 toont de resultaten van een onderzoek naar het optreden van acute nierschade na een eenmalige gift gentamicine aan patiënten met sepsis op de spoedeisende hulp. Patiënten met sepsis veroorzaakt door verschillende soorten infecties, die behandeld werden met gentamicine, werden vergeleken met patiënten met sepsis veroorzaakt door een longontsteking. Deze patiënten met een sepsis door longontsteking werden gekozen als controle groep, omdat deze patiënten nooit met gentamicine worden behandeld aangezien gentamicine niet werkt tegen de bacteriën die meestal een longontsteking veroorzaken.

We vonden dat een groot deel van de patiënten al acute nierschade had bij presentatie op de spoedeisende hulp. Van de patiënten die gentamicine kregen op de spoedeisende hulp had $26.8 \%$ al acute nierschade bij presentatie op de spoedeisende hulp, dus nog voordat ze behandeld waren. Bij patiënten in de controle groep was dit percentage $16.3 \%$. Gedurende de opname, na een eenmalige gift gentamicine, had $6.7 \%$ acute nierschade. Bij de controle groep zonder gentamicine was dit percentage 3.3\%. Statistisch gezien was dit echter niet verschillend. Bij aanvullende analyses vonden we dat acute nierschade niet geassocieerd was met een eenmalige gift gentamicine, maar met de ernst van de sepsis. Dit zou een verklaring kunnen zijn waarom we een klein, niet 
statistisch significant, verschil zagen in het optreden van acute nierschade ten nadele van de gentamicine groep; deze patiënten hadden vaker een ernstigere sepsis en bij presentatie al vaker acute nierschade.

Concluderend zagen wij geen verhoogd risico op acute nierschade na een eenmalige gift gentamicine aan patiënten met sepsis op de spoedeisende hulp.

In hoofdstuk 4 borduurden wij voort op het vorige hoofdstuk. Teneinde meer solide bewijs te vergaren hadden wij een grotere patiëntengroep nodig en daarnaast een meer gelijke controle groep. Daarom zetten we een nieuwe studie op in meerdere ziekenhuizen. In één ziekenhuis werd gentamicine, als onderdeel van de antibiotische behandeling, gegeven aan patiënten met sepsis met geselecteerde infecties. In twee andere ziekenhuizen werd ongeacht de oorzaak van de sepsis geen gentamicine gegeven als onderdeel van de antibiotische behandeling. Dit zorgde voor een natuurlijk experiment, waarbij we de invloed van een eenmalige gift gentamicine op het optreden van acute nierschade bij patiënten met sepsis konden onderzoeken. Daarnaast konden we evalueren wat eventuele andere risicofactoren voor het optreden van acute nierschade zijn.

Hoewel de groepen meer gelijk waren, zagen we opnieuw kleine verschillen. Van de patiënten die gentamicine kregen, had $31.7 \%$ acute nierschade bij presentatie op de spoedeisende hulp. Bij de controle groep was dit aantal $22.8 \%$. Gedurende de opname en na één gift gentamicine, trad bij $11.2 \%$ van de patiënten acute nierschade op, in vergelijking met $8.2 \%$ bij de patiënten zonder gentamicine (statistisch gezien geen significant verschil). Middels aanvullende analyses toonden we opnieuw aan dat niet gentamicine geassocieerd was met de toediening van gentamicine, maar een meer ernstige vorm van sepsis. Daarnaast bleken ook een slechtere uitgangsnierfunctie en diabetes mellitus risicofactoren voor het optreden van acute nierschade bij sepsis.

Concluderend zagen we ook in deze studie dat een eenmalige gift gentamicine niet geassocieerd is met een verhoogde kans op acute nierschade. Een ernstigere vorm van sepsis, diabetes mellitus en een al verminderde nierfunctie zijn dat wel. 
Om gentamicine goed zijn werk te laten doen moet het middel voldoende hoog gedoseerd worden. Al langer zijn er berichten dat ernstig zieke patiënten opgenomen op de IC een hogere dosis gentamicine zouden moeten krijgen om een voldoende hoge concentratie in het bloed te bereiken. Dit komt voort uit het feit dat bij ernstig zieke patiënten allerlei veranderingen in het lichaam kunnen zorgen voor lagere concentraties in het bloed, waardoor de effectiviteit van het middel af kan nemen. Juist voor gentamicine is het van belang om een voldoende hoge concentratie in het bloed te bereiken, omdat de hoogte van de piekconcentratie (de hoogste concentratie die in het bloed wordt bereikt, bij gentamicine meestal 1 uur na het begin van de infusie) een belangrijke maat is voor de effectiviteit van gentamicine.

Gentamicine wordt, zoals alle aminoglycosiden, gedoseerd op basis van het lichaamsgewicht van de patiënt. Eerder was al aangetoond dat het gewicht van de patiënt op de spoedeisende hulp niet altijd goed bekend is. Vaak is wegen in de hectiek van een spoedeisende hulp niet mogelijk en regelmatig wordt er een verkeerde schatting gemaakt door zowel de patiënt als de zorgverleners. Vanwege het belang van een juiste dosering gentamicine gingen we in hoofdstuk 5 na wat nu de exacte dosering van gentamicine (in milligram per kilogram $(\mathrm{mg} / \mathrm{kg})$ ) was bij patiënten met sepsis op de spoedeisende hulp. Daarnaast wilden we weten hoeveel patiënten ondergedoseerd werden (gedefinieerd als een meer dan 10\% lagere dosis).

Uiteindelijk bleek $19.7 \%$ van de patiënten ondergedoseerd. Mogelijke oorzaken hiervoor zouden een verkeerde schatting van het lichaamsgewicht kunnen zijn of angst voor acute nierschade, aangezien de patiënten die ondergedoseerd waren vaker een verminderde nierfunctie hadden.

Omdat ook patiënten op de spoedeisende hulp erg ziek kunnen zijn, was onze hypothese dat ook patiënten met sepsis op de spoedeisende hulp baat kunnen hebben bij een hogere gentamicine dosis, net als patiënten op de IC. Daarom hebben we in hoofdstuk 6 direct gemeten of de dosis (gentamicine $5 \mathrm{mg} / \mathrm{kg}$ ) adequate concentraties in het bloed gaf door piekconcentraties te meten in patiënten met sepsis op de spoedeisende hulp. 
Bij 86 patiënten werden piekconcentraties gemeten na een dosis van $5 \mathrm{mg} / \mathrm{kg}$. $\mathrm{Bij}$ 39.5\% bleek een inadequate piekconcentratie. Na deze bevinding hebben we simulaties verricht om te bepalen welke dosis nodig zou zijn om adequate piekconcentraties te bereiken in de meerderheid van de patiënten; dat wil zeggen meer dan 95\% van de patiënten met een adequate piekconcentratie.

Simulaties werden verricht voor doses van 6 tot $10 \mathrm{mg} / \mathrm{kg}$ met behulp van de gegevens verzameld tijdens de metingen. De simulaties lieten zien dat met een dosis van $7 \mathrm{mg} / \mathrm{kg} 96.5 \%$ van de patiënten een adequate piekconcentratie zou bereiken. Om de uitkomsten van deze simulaties te verifiëren werd het antibioticabeleid aangepast naar deze nieuwe dosis van $7 \mathrm{mg} / \mathrm{kg}$. Na de invoering van dit nieuwe antibioticabeleid hebben we in een nieuwe patiëntengroep opnieuw piekconcentraties gemeten. Hieruit bleek dat na de dosisverhoging de gesimuleerde en ware dosis van $7 \mathrm{mg} / \mathrm{kg}$ goed met elkaar overeen kwamen; $84.9 \%$ van de patiënten had een adequate piekconcentratie. $\mathrm{Na}$ deze verificatie is dit beleid blijvend ingevoerd in het Maastricht Universitair Medisch Centrum.

Hoofdstuk 7 van dit proefschrift is een samenvatting van alle bevindingen en een algemene discussie met betrekking tot de gevonden resultaten in relatie tot het al bekende bewijs in de medische literatuur. De algemene conclusie van dit proefschrift is dat acute nierschade een veel voorkomende aandoening is bij patiënten met sepsis op de spoedeisende hulp. Een eenmalige toediening van gentamicine bij deze patiënten geeft geen groter risico op acute nierschade en is dus veilig is met betrekking tot de nierfunctie. Verder hebben we aangetoond dat onderdosering van gentamicine veel voorkomt én hebben we laten zien dat een dosis van $5 \mathrm{mg} / \mathrm{kg}$ in het merendeel van de patiënten tot te lage piekconcentraties leidt. Een dosis van $7 \mathrm{mg} / \mathrm{kg}$ is voor deze patiënten een dosis waarmee het merendeel van de patiënten wel een adequate piekconcentratie bereikt.

We hopen dat dit proefschrift zal bijdragen aan een betere dosering van gentamicine en een positievere kijk op het veiligheidsprofiel van gentamicine, zodat gentamicine voor een nog langere periode kan worden gebruikt en gentamicine het gebruik van reserve-antibiotica kan helpen verminderen. Opdat we in een wereld met stijgende antibioticaresistentie onze antibiotica kunnen blijven gebruiken voor toekomstige generaties. 




\section{List of publications}




\section{Research articles}

1. Cobussen M, Verhave JC, J. Buijs J, Stassen PM. The incidence and outcome of $A K I$ in patients with sepsis in the emergency department applying different definitions of $A K I$ and sepsis. Submitted.

2. Cobussen M, Haeseker MB, Stoffers J, Wanrooij VHM, Savelkoul PHM, Stassen PM. Renal safety of a single dose of gentamicin in patients with sepsis in the emergency department. Clin Microbiol Infect. 2020 Jul $1 ;$ S1198-743X(20)30376-1.

3. Cobussen M, Havenith T, Posthouwer D, van Tiel FH, Savelkoul PHM, Stassen PM, Haeseker MB. Improving peak concentrations of a single dose regime of gentamicin in patients with sepsis in the emergency department. PLoS One. 2019 Jan 22;14(1):e0210012.

4. Cobussen M, van Tiel FH, Oude Lashof AML. Management of S. aureus bacteraemia in the Netherlands; infectious diseases consultation improves outcome. Neth J Med. 2018 Sep;76(7):322-329.

5. Machiels JD, Cobussen M, Bosboom RW, van Os NJH, Hageman ATM, Hassing R. Myelitis transversa door schistosomiasis. Ned Tijdschr Geneeskd. 2018 May 3;162:D2382.

6. Cobussen $\mathrm{M}^{*}$, de Kort $\mathrm{JM}^{*}$, Dennert RM, Lowe SH, Stassen PM. No increased risk of acute kidney injury after a single dose of gentamicin in patients with sepsis. Infect Dis (Lond). 2016 Apr;48(4):274-280.

* Contributed equally

7. Cobussen M, Hira V, de Kort JM, Posthouwer D, Stassen PM, Haeseker MB. Gentamicin is frequently underdosed in patients with sepsis in the emergency department. Neth J Med. 2015 Nov;73(9):443-4. 


\section{Correspondence}

1. Cobussen M, Haeseker MB, Savelkoul PHM, Stassen PM. Re: 'The renal safety of a single dose of gentamicin in patients with sepsis in the emergency department' - Author's reply. Clin Microbiol Infect. 2020 Aug 19:S1198743X(20)30498-5.

2. Cobussen M, Havenith T, Posthouwer D, van Tiel FH, Stassen PM, Haeseker MB. Short-course of empirical gentamicin in patients with severe sepsis and septic shock in the ICU: a benefit or a burden? Clin Infect Dis. 2017 Sep 1;65(5):873-874.

\section{Congresses and symposia}

1. Accepted abstract for a paper poster presentation at the European Congress of Clinical Microbiology and Infectious Diseases (ECCMID) 2020, Paris. The ECCMID 2020 was cancelled due to the COVID-19 pandemic. ECCMID Abstract book 2020, abstract 2363, p 1128. Cobussen M, Haeseker MB, Savelkoul PHM, Stassen PM. A single dose of gentamicin in patients with sepsis in the emergency department is safe with regard to renal function.

2. Oral presentation at the Internistendagen, 19-04-2017, Maastricht. Cobussen M, Havenith T, Posthouwer D, van Tiel FH, Savelkoul PHM, Stassen PM, Haeseker MB. Improving peak concentrations of a single dose regime of gentamicin in patients with sepsis in the emergency department.

3. Poster presentation at the Scientific Spring Meeting KNVM \& NVMM, 14-04- 2015, Arnhem. Cobussen M, Hira V, de Kort JM, Posthouwer D, Stassen PM, Haeseker MB. Gentamicin is frequently underdosed in patients with sepsis in the emergency department. 


Dankwoord 


\section{Dankwoord}

Dit proefschrift is mede mogelijk gemaakt door velen. Eenieder die heeft bijgedragen aan de totstandkoming hiervan, wil ik dan ook van harte bedanken! Een aantal van hen wil ik graag expliciet benoemen.

Prof. dr. Savelkoul, beste Paul, het moet niet gemakkelijk zijn geweest om iemand die, ver weg in Arnhem/Nijmegen en bezig met zijn opleiding tot internist, de kans te geven om 'buiten te promoveren'. Dank voor deze kans en voor je oprechte en intelligente begeleiding. Dank ook voor het faciliteren van het promoveren op afstand. Wij waren onze tijd al ver vooruit met onze telefonische/beeldbel overleggen en altijd kon ik na onze gesprekken de puntjes weer op de i zetten en mijn to-do-lijst verder afstrepen.

Dr. Stassen, beste Patricia, tijdens mijn co-schappen liet je mij kennis maken met je uitgebreide enthousiasme voor het vak en het onderzoek. Jij was degene die me op het spoor zette van dit promotietraject en vanwege je enthousiasme ben ik die uitdaging met je aangegaan als buitenpromovendus. Je enthousiasme werkt aanstekelijk en altijd zie je kansen, waarbij het regelmatig voorkwam dat ik die op dat moment nog niet altijd zag. Maar na ieder overleg kreeg ik weer nieuwe energie en zag ik nieuwe mogelijkheden. Uiteindelijk is uit al deze kansen een mooi promotietraject tot stand gekomen waarvoor ik je heel hartelijk wil bedanken!

Dr. Haeseker, beste Michiel, tijdens mijn keuze co-schap bij de infectieziekten maakten we voor het eerst kennis. Samen met de andere AIOS medische microbiologie legde je me het vuur aan de schenen tijdens mijn eerste coschap; de vuurdoop. Toen al was je met je kritische blik en je uitgebreide ervaring een goede mentor. En dat ben je gebleven! Altijd kritisch en meedenkend en daarbij de rust zelve. Leuk was ook ons overleg bij je thuis in Delft en ons plan om gezamenlijk naar de ECCMID in Parijs te gaan. Reis en verblijf waren al geboekt en de poster was al bijna gedrukt. Helaas gooide ook hierbij COVID-19 roet in het eten.

Dank voor jullie begeleiding. Ik heb veel van jullie geleerd!

Verder wil ik de leden van de manuscriptcommissie, prof. Kooman, prof. Bonten, prof. Touw en dr. Oudhuis, bedanken voor de kritische beoordeling van dit proefschrift. 
Dank ook aan de internist-infectiologen in Maastricht, Astrid, Dirk en Selwyn, dankzij jullie enthousiaste begeleiding werd ik alleen maar gesterkt in mijn gedachte om internist-infectioloog te willen worden. Ook de fellows infectieziekten en overige AIOS medische microbiologie, met Jaclyn de Kort, Maarten Visschers en Vishal Hira in het bijzonder, wil ik bedanken voor de goede leerschool.

Dr. Reichert en dr. van Bon, beste Louis en Arianne en alle andere internisten uit het Rijnstate ziekenhuis, dank voor jullie vertrouwen in mij en het prettige opleidingsklimaat dat jullie geschapen hebben in het Rijnstate ziekenhuis. Dr. Verhave, beste Jacobien, in alle assistenten ben jij oprecht geïnteresseerd. Altijd vriendelijk, altijd tijd, altijd meedenkend en altijd onderwijsgericht. Ik heb veel van je geleerd. Bedankt ook dat je me wegwijs hielp maken binnen het Rijnstate. Speciale dank ook aan de internist-infectiologen, Jet, Mark en Robert-Jan, bedankt voor het laten meezuigen in jullie ongebreidelde enthousiasme voor de infectieziekten. Ik heb veel van jullie geleerd en voelde me erg thuis.

Alle andere medeauteurs: Jacqueline, Robert, Judith, Vera, Frank en Thomas, allen bedankt voor jullie hulp en kritische bijdrages. Zonder jullie zou dit proefschrift niet zijn waar het nu is.

Alle internist-infectiologen, fellows infectieziekten en medisch microbiologen van het Radboudumc, dank voor de inspirerende, uitdagende opleiding en omgeving die jullie gecreëerd hebben, waarin je continue wordt uitgedaagd om een betere dokter te worden. Ik heb erg veel zin in de komende opleidingstijd!

Arjan, Dennis, Dieneke, Megan, Roel, Sean en Titus, dank voor de gezelligheid op het werk, eerst in Arnhem, vervolgens in Nijmegen (en vervolgens weer in Arnhem tijdens de hepatitis poli). En naast het werk de gezellige etentjes en borrels en andere activiteiten. Met en zonder de kinderen erbij. Sean, mijn paranimf, gelukkig kunnen we ons favoriete medicijn in ons beider specialisme blijven gebruiken.

Dion, Luuk, Pim, Remco, Sjoerd en Wouter, we kennen elkaar vanaf het eerste jaar van de studie Geneeskunde. We hebben veel meegemaakt samen en ik hoop dat we nog lang veel mee zullen maken samen. Na onze studies is ieder zijn eigen weg gegaan, maar ten minste $1 \mathrm{x} / \mathrm{jaar}$ komen we weer met zijn allen 
samen. Hopelijk is COVID-19 snel voorbij, zodat we de draad weer op kunnen pakken en er vele mooie momenten en herinneringen bij zullen komen! Sjoerd, mijn paranimf, ik ben benieuwd of we elkaar professioneel gezien ooit nog eens tegen komen binnen de infectieziekten/immunologie.

Pap en mam, dankzij jullie solide basis ben ik geworden wie ik ben en heb ik de kansen gehad om mezelf te ontwikkelen. Zonder jullie zou dit proefschrift er niet zijn geweest. Bedankt dat jullie altijd voor me klaarstaan!

Lieve Nienke, we kennen elkaar al ontzettend lang en hebben geen geheimen meer voor elkaar. Wat er achter dit traject is schuil gegaan is dan ook geen geheim voor jou. Bedankt dat je me steunde en je interesse toonde, maar vooral ook voor de momenten dat het over andere dingen ging. Zonder jou was dit proefschrift er niet gekomen! En zoals je weet was het ooit mijn idee om dit traject af te ronden voor er kinderen zouden komen. Met de geboorte van Sepp net voor de COVID-19 uitbraak in februari 2020 is dat niet helemaal gelukt, maar hij is wat mij betreft het allermooiste wat ons is overkomen. Nu dit traject in de afrondende fase zit zullen we nog meer tijd hebben voor elkaar en onze mooie vrolijke zoon! 
A 




\section{Curriculum Vitae}




\section{Curriculum Vitae}

Maarten Cobussen was born on the $21^{\text {st }}$ of June in 1990 in Bergharen, where he grew up with his parents and his older brother. After primary school, he attended the Gymnasium at the Pax Christi College in Druten. In 2009 he started Medical School at Maastricht University in Maastricht. During his internships, he developed a special interest in internal medicine, and infectious diseases in particular. His internship of choice was at the Infectious Diseases department of the Maastricht University Medical Centre, under the supervision of Dr Selwyn Lowe. It was during that internship that he first came into contact with research in the field of infectious diseases and medical microbiology. After his internship he participated in a study on the renal toxicity of gentamicin, led by Dr Patricia Stassen. He performed a scientific internship on Staphylococcus aureus bacteraemia within the Infectious Diseases department, supervised by Dr Astrid Oude Lashof. His final clinical internship was at the department of Internal Medicine at the Orbis Medical Centre (currently Zuyderland hospital) in Sittard-Geleen. After his graduation in 2015, he started his clinical career as an intern at the department of Internal Medicine in the Rijnstate hospital in Arnhem, supervised by Dr Louis Reichert. After 10 months as an intern, he started as a resident in internal medicine in the same hospital in 2016. Simultaneously he started his PhD-project in the Maastricht University Medical Centre. This project was mentored by Prof Paul Savelkoul, Dr Michiel Haeseker and Dr Patricia Stassen. In 2019 he continued his training as a resident in the Radboudumc in Nijmegen under the supervision of Dr Gerald Vervoort, followed by his specialisation to become an internist - infectious diseases specialist under the supervision of Dr Jaap ten Oever in 2020. Maarten is married with his beloved Nienke and together they have a beautiful son, Sepp. 
A 
